\title{
ABC Transporters at the Blood-Brain Interfaces, Their Study Models, and Drug Delivery Implications in Gliomas
}

\author{
David Gomez-Zepeda ${ }^{1,2,3, *,+}$ (D) Méryam Taghi ${ }^{1,2,3}$, Jean-Michel Scherrmann ${ }^{1,2,3}$, \\ Xavier Decleves ${ }^{1,2,3,4, \ddagger}$ and Marie-Claude Menet ${ }^{1,2,3,5, *, \ddagger(\mathbb{D})}$ \\ 1 Inserm, UMR-S 1144, Optimisation Thérapeutique en Neuropsychopharmacologie, 75006 Paris, France; \\ meryam.taghi@parisdescartes.fr (M.T.); jean-michel.scherrmann@parisdescartes.fr (J.-M.S.); \\ xavier.decleves@parisdescartes.fr (X.D.) \\ 2 Sorbonne Paris Cité, Université Paris Descartes, 75006 Paris, France \\ 3 Sorbonne Paris Cité, Université Paris Diderot, 75013 Paris, France \\ 4 UF Biologie du médicament et toxicologie, Hôpital Cochin, AP HP, 75006 Paris, France \\ 5 UF Hormonologie adulte, Hôpital Cochin, AP HP, 75006 Paris, France \\ * Correspondence: davidgz.science@gmail.com (D.G.-Z.); marie-claude.menet@parisdescartes.fr (M.-C.M.) \\ + Current affiliation: Laboratorio Nacional de Genómica para la Biodiversidad (Langebio)—Unidad de \\ Genómica Avanzada, Cinvestav, Irapuato 36824, Guanajuato, Mexico. \\ $\ddagger$ These authors are co-last authors.
}

Received: 14 November 2019; Accepted: 20 December 2019; Published: 23 December 2019

\begin{abstract}
Drug delivery into the brain is regulated by the blood-brain interfaces. The blood-brain barrier (BBB), the blood-cerebrospinal fluid barrier (BCSFB), and the blood-arachnoid barrier (BAB) regulate the exchange of substances between the blood and brain parenchyma. These selective barriers present a high impermeability to most substances, with the selective transport of nutrients and transporters preventing the entry and accumulation of possibly toxic molecules, comprising many therapeutic drugs. Transporters of the ATP-binding cassette (ABC) superfamily have an important role in drug delivery, because they extrude a broad molecular diversity of xenobiotics, including several anticancer drugs, preventing their entry into the brain. Gliomas are the most common primary tumors diagnosed in adults, which are often characterized by a poor prognosis, notably in the case of high-grade gliomas. Therapeutic treatments frequently fail due to the difficulty of delivering drugs through the brain barriers, adding to diverse mechanisms developed by the cancer, including the overexpression or expression de novo of $A B C$ transporters in tumoral cells and/or in the endothelial cells forming the blood-brain tumor barrier (BBTB). Many models have been developed to study the phenotype, molecular characteristics, and function of the blood-brain interfaces as well as to evaluate drug permeability into the brain. These include in vitro, in vivo, and in silico models, which together can help us to better understand their implication in drug resistance and to develop new therapeutics or delivery strategies to improve the treatment of pathologies of the central nervous system (CNS). In this review, we present the principal characteristics of the blood-brain interfaces; then, we focus on the $\mathrm{ABC}$ transporters present on them and their implication in drug delivery; next, we present some of the most important models used for the study of drug transport; finally, we summarize the implication of $\mathrm{ABC}$ transporters in glioma and the BBTB in drug resistance and the strategies to improve the delivery of CNS anticancer drugs.
\end{abstract}

Keywords: $\mathrm{ABC}$ transporters; blood-brain barrier (BBB); blood-cerebrospinal fluid barrier (BCSFB); arachnoid barrier (BAB); blood-brain tumor barrier (BBTB); glioma; drug delivery 


\section{Introduction}

Drug delivery and clearance in the central nervous system (CNS) are restricted and regulated by the blood-brain barrier (BBB), the blood-cerebrospinal fluid barrier (BCSFB), and the blood-arachnoid barrier (BAB). These barriers present several mechanisms that are used to regulate the exchange of substances between the blood and the brain, including a high impermeability to most substances and the selective transport of nutrients and transporters, preventing the entry of toxic molecules, comprising many xenobiotics and also therapeutic drugs [1-3]. This last function is performed mainly by transporters from the ATP-binding cassette (ABC) superfamily [3], and to a lesser extent, the solute carrier (SLC) superfamily exchangers [1], both of which have a key role in the absorption, distribution, metabolism, and excretion (ADME) of drugs. The $\mathrm{ABC}$ transporters are particularly important because they extrude many xenobiotics of a broad molecular variety, including several anticancer drugs, preventing thus their entry to the brain and to the tumors in patients. Therefore, many models of the brain barriers have been developed to study drug transport and delivery into the CNS [4-8].

Cancers of the CNS, and particularly gliomas, represent a worldwide problem for healthcare because patients become highly disabled by the disease, treatments are expensive, and prognosis is poor, due to the tumor's aggressiveness and resistance to multiple chemotherapeutic drugs [9-11]. As in other cancers, brain tumors can present modifications in the DNA repair system and the cell cycle, an enhanced metabolism of xenobiotics, and anti-apoptosis phenotypes [12,13]. In addition, drug delivery and accumulation into brain tumors is restricted by the blood-brain interfaces [14]. Importantly, the overexpression of ABC transporters at the BBB or the blood-brain tumor barrier (BBTB), as well as in the tumor cells, is often observed [15], which can lead to an improved multidrug resistance [16]. Thus, it is important to understand the function of these transporters and their changes in the pathology.

In this review, we present the principal characteristics of the blood-brain interfaces implicated in drug delivery. Then, we focus on the $\mathrm{ABC}$ transporters present on these barriers and their implication in drug delivery. Next, we present some of the most important models used for the study of drug transport. Finally, we summarize the implication of ABC transporters in glioma and the BBTB in drug resistance and the strategies to improve the delivery of CNS anticancer drugs.

\section{Brain Barriers and Their Implication in Drug Delivery}

Three different barriers formed by endothelial or epithelial cells with tight junctions regulate the substance exchange between brain and blood (Figure 1): (1) The blood-brain barrier (BBB) is comprised by the specialized brain microvascular endothelial cells (BMVEC) separating the blood and brain parenchyma and interstitial fluid. (2) The blood-cerebrospinal fluid barrier (BCSFB) is formed by the epithelium of the choroid plexus (CP), which secretes the cerebrospinal fluid (CSF) into the ventricular system and the meninges. (3) The arachnoid barrier (BAB) surrounding the CNS is an avascular multilayered epithelium separating the blood from the subarachnoid CSF. These interfaces act as selective barriers, regulating the entry and distribution of diverse molecules into the brain and their excretion, including medicinal drugs $[1,17,18]$. Therefore, it is important to study the implication of these barriers in drug delivery to the CNS and pharmacokinetics. The physiology and function of the blood-brain interfaces, as well as their implication in drug delivery, have been extensively reviewed in previous publications $[1,2,14,17-19]$; thus, they will be briefly explained in this section.

\subsection{The Blood-Brain Barrier and the Neurovascular Unit}

The BBB is formed mainly by the brain microvascular endothelial cells (BMVEC), which constitute a physical, transport selective and metabolic barrier. They form a tight monolayer lacking fenestration due to especially tight junctions (TJs) between the cells, restricting the paracellular movement of small polar substances and macromolecules [1,18]. The BMVEC express several transporters with polarized localization at the luminal and/or basolateral membranes to specifically regulate the 
influx and efflux of molecules, such as nutrients, waste metabolites, toxins, xenobiotics, and small peptides. The main transporter proteins expressed at the BBB are SLC transporters and active efflux pumps from the ABC superfamily $[3,20]$. The exchange of macromolecules (i.e., larger peptides and proteins) is regulated by limited transendothelial vesicular trafficking. In addition, BMVEC express specialized enzymes for the degradation of multiple substrates including cytochromes P450 (CYPs450), monooxygenases (phase I enzymes), monoamine oxidase, glutathione-S-transferases (GST), methyltransferases, UDP-glucuronosyltransferases (UGT), and methyltransferases (phase II enzymes) as the catechol-O-methyltransferase (COMT) [21-23]. Therefore, the capability of a molecule to cross the endothelium depends on its physicochemical properties (such as charge state, hydrophobicity, molecular size, spatial conformation), the concentration gradient, its binding to plasma proteins, transporter affinity, and metabolic processing [6].

A)

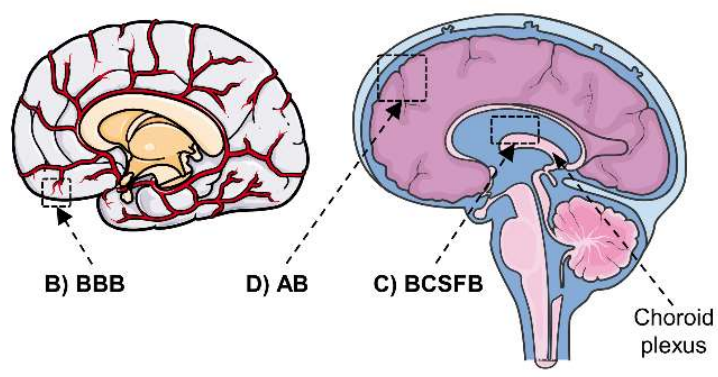

C)

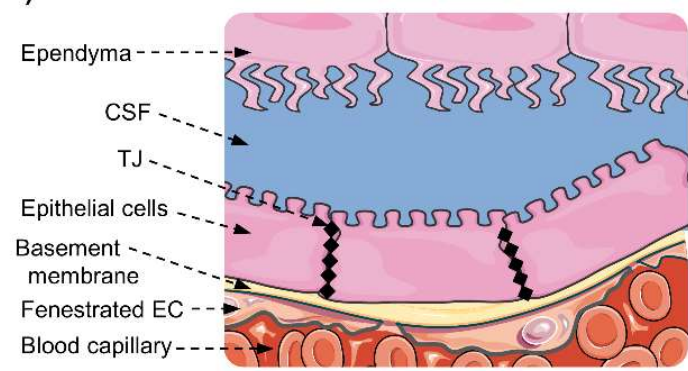

B)

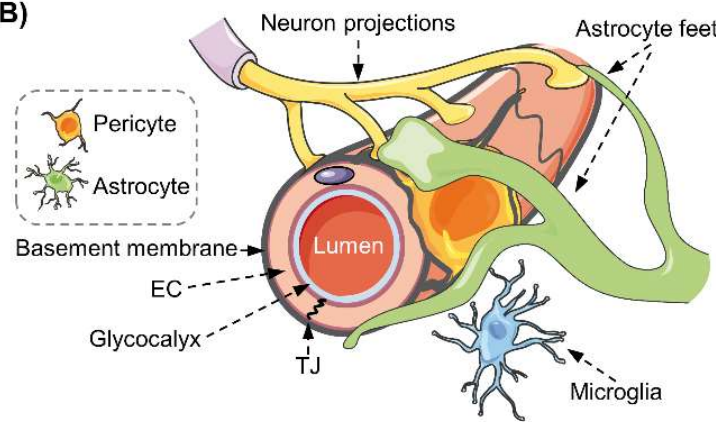

D)

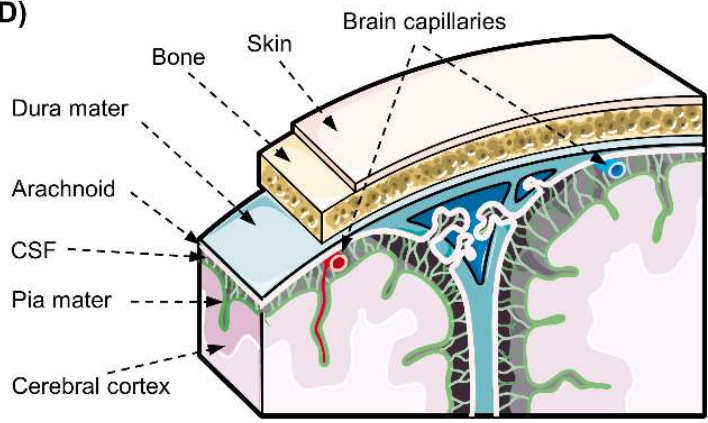

Figure 1. Human blood-brain interfaces. (A) There are three main interfaces regulating the exchanges between blood and brain (A), left), either directly to the parenchyma or through the cerebrospinal fluid (CSF; A), right). (B) The blood-brain barrier (BBB) is formed mainly by the brain microvascular endothelial cells (EC), attached by tight junctions (TJ), but their specialized phenotype and function are regulated and maintained by the neurovascular unit (NVU) formed by the basement membrane and neighboring cells including pericytes, astrocytes, neurons, and microglia. (C) The blood-cerebrospinal fluid barrier (BCSFB) is formed by the tightly jointed epithelial cells of the choroid plexus (CP), which cover the fenestrated EC of the CP capillaries. (D) The meninges are composed of three layers: the outermost fibrous sheet of dura mater, the arachnoid mater and the pia, both enclosing CSF in the subarachnoid space; the arachnoid cells present tight junctions and form the blood-arachnoid barrier (BAB). Created using images from "smart Servier Medical Art", Creative Commons License, 2019.

The BBB function depends on the dynamic interaction between the BMVEC and its surrounding environment, the neurovascular unit (NVU). The endothelial cells are dynamically regulated by their interactions with the basement membrane surrounding the capillaries, with neighboring cells including pericytes, astrocytes, neurons, and microglia; but also with circulating cells, such as leucocytes, through the glycocalyx on the luminal membrane of endothelial cells (Figure 1B). They maintain a constant communication by direct cell-to-cell interactions, modulations of the extracellular matrix, and the exchanges of soluble factors. This complex and dynamic structure is known as the NVU, whose components are indispensable for the acquisition of the BMVEC phenotype and the maintaining of 
the BBB functions $[4,6]$. In addition, it has been observed that the glycocalyx acts as a barrier to large molecules, while the basement membrane and astrocyte endfeet further hinder the entry of small and large molecules into the brain parenchyma, contributing directly to the brain function of the BBB [24].

The BBB is often considered the most important brain barrier for drug delivery. Although some neurotherapeutics, including chemotherapeutics, are now administered by intralumbar injection into the CSF of the subarachnoid space (intrathecally) [25] and there have been tests using intracranial drug administration [26], intravenous injection is still the main way for drug delivery in CNS diseases. The BMVEC forming the BBB comprise the largest exchange interface between blood and parenchyma, with a total area between 12 and $18 \mathrm{~m}^{2}$ in the average human adult [27]. Nevertheless, their selective permeability constitutes an obstacle for drug entry into the brain [3,6,18]; the tight junctions block the passage of molecules at the intracellular space [28]; hydrophobic therapeutics that would normally diffuse through the membranes are effluxed by the highly unspecific $A B C$ transporters $[3,20]$; meanwhile, those that enter into the endothelial cells are inactivated by the battery of metabolic enzymes mentioned above [21,22] before being effluxed [23].

\subsection{The Blood-Cerebrospinal Fluid Barrier}

The choroid plexus (CP) is composed of capillaries formed by fenestrated endothelial cells, enveloped by a basement membrane and a monolayer of tightly jointed epithelium which form the blood-cerebrospinal fluid barrier (BCSFB), as the CSF is enclosed between this layer and a layer of ependyma [19]. The endothelial cells of the choroid plexus are fenestrated and do not present tight junctions; thus, they do not form a barrier for small molecules, but the exchange of substances between blood and CSF is precisely controlled by the tightly jointed epithelial cells at the apical CSF-facing side, forming the BCSFB (Figure 1C), while the exchange between the CSF and the brain is facilitated by the non-jointed ependymal cells. The transport of molecules is selectively regulated by proteins specifically expressed at the luminal and/or basolateral membranes of the epithelial cells, including $A B C$ and SLC $[17,19]$. The BCSFB also expresses diverse metabolizing enzymes that inactivate endogenous and exogenous molecules, such as CYPs450, GSTs, and UGTs [29,30]. Additionally, the epithelial cells present infoldings on the basolateral membrane and microvilli on the apical membrane, increasing the transfer surface area to improve fluid secretion [31]. Thus, the BCSFB forms a physical, transport, and metabolic barrier controlling the exchanges between blood in the fenestrated capillaries and CSF to protect the brain from possibly toxic substances, but also affecting the entry of therapeutic molecules; thus, its role must be considered when evaluating drug pharmacokinetics [18].

\subsection{The Blood-Arachnoid Barrier}

The arachnoid cells present in the middle layer of the meninges covering the brain and spinal cord constitute the blood-arachnoid barrier (BAB). The meninges are composed of three layers; starting with the outermost pachymeninx composed of a fibrous sheet of dura mater; then, the two innermost layers form the leptomeninges, including the arachnoid mater followed by the pia mater lining the brain, both enclosing CSF in the subarachnoid space [32] (Figure 1D). Blood vessels within the dura mater are fenestrated, but blood vessels in the subarachnoid space present tight junctions. While pia cells do not present tight junctions, the arachnoid cells are tight-junctioned (Figure 2D), and recent studies in human, mouse, and rat models have shown that the BAB cells express metabolizing enzymes such as CYPs450 as well as ABC and SLC transporters specifically localized at the apical and/or basolateral membranes to regulate the passage of substances between the CSF and the fenestrated blood capillaries in the dura matter, acting as a selective barrier [33-35].

There has been a growing interest in the role of the $\mathrm{BAB}$ in drug delivery to the CNS and its clearance. As the BAB is avascular and presents a small exchange area compared to the BCSFB, its contribution to the blood-brain exchange is often neglected [36]. Nevertheless, its role in drug influx and efflux at the CNS could be more important than thought [32], considering their barrier phenotype. The amount of unbound drug in the interstitial fluid in the brain is often assessed using 
its concentration in the CSF as a surrogate [37], but this may differ due to drug clearance into the capillaries in the dura matter performed by transporters present in the BAB cells [33,34]. Furthermore, some chemotherapies and other drugs are administered through intralumbar injection, intrathecally into the CSF of the subarachnoid space [25]. For instance, it is used to treat meningitis, leptomeningeal tumors, and particularly CSF lymphoblasts in childhood acute lymphoblastic leukemia patients [38]. Therefore, it is important to consider that the entry and distribution of intrathecally administered drugs depend on their passage across the BAB cells, which present a similar phenotype to the BBB and thus can metabolize and efflux drugs from the CSF to the fenestrated capillaries through phase I and phase II enzymes and ABC transporters, respectively [33-35].

A)

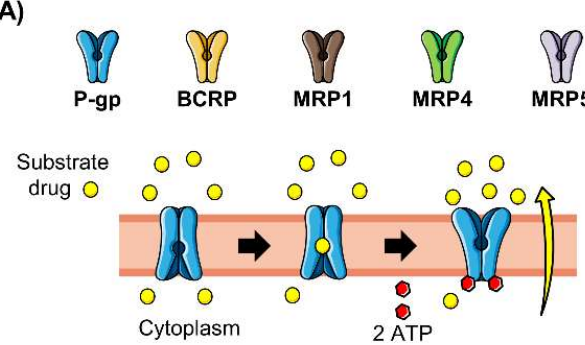

C) BCSFB

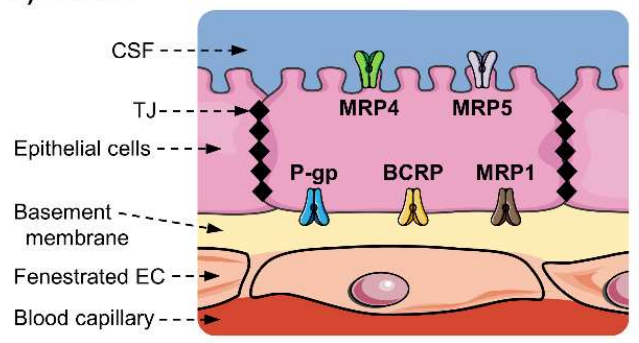

B) BBB

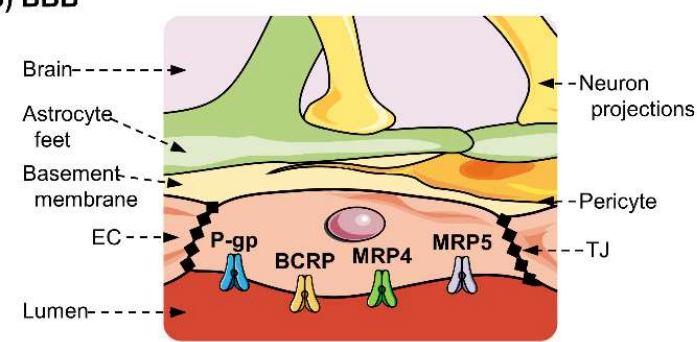

D) BAB

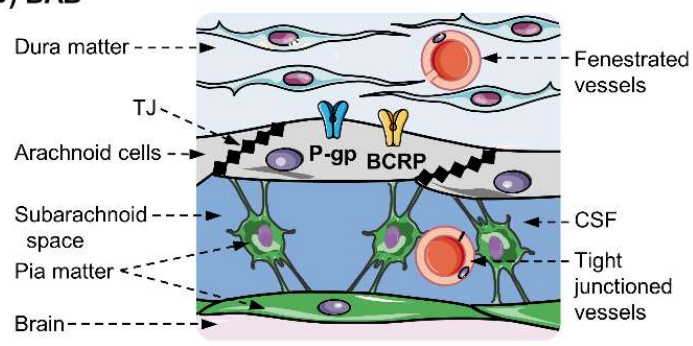

Figure 2. Efflux mechanism and localization of drug-related ATP-binding cassette (ABC) transporters at the human blood-brain interfaces: (A) (top) ABC transporters P-glycoprotein (P-gp/MDR1), breast-cancer resistance protein (BCRP), multidrug-resistance proteins 1, 4 and 5 (MRP1, MRP4 and MRP5) detected at the protein level at the blood-brain interfaces in non-pathological human brain; and (A) (bottom) simplified schema of their active transport mechanism, where substrates are effluxed against the concentration gradient in an ATP-dependent manner. Schemas showing the polarized localization of $\mathrm{ABC}$ transporters at the (B) blood-brain barrier (BBB), (C) the blood-cerebrospinal fluid barrier (BCSFB) at the choroid plexus and (D) the arachnoid barrier (BAB) at the meninges. EC, endothelial cells; TJ, tight junctions; CSF, cerebrospinal fluid. Created using images from "smart Servier Medical Art", Creative Commons License, 2019.

\subsection{Conclusion on the Blood-Brain Interfaces and Their Implication in Drug Delivery}

Together, the three blood-brain interfaces contribute to the selective permeability and clearance of substances in and out of the CNS to maintain its homeostasis. Their barrier function is performed by orchestrated mechanisms such as tight junctions to form physical barriers, selective permeability through passive and active transport mechanisms, and biochemical protection using specialized enzymes to degrade toxic molecules. The active transporters of the ABC superfamily are major gatekeepers of these interfaces, which selectively effluxes a high diversity of molecules, including xenobiotics and many chemotherapeutics, as it will be further explained in the next section.

\section{Drug-Related ABC Transporters and Their Role at the Blood-Brain Interfaces}

\subsection{The ABC Superfamily}

The ATP-binding cassette $(\mathrm{ABC})$ superfamily groups many membrane proteins that act as active efflux pumps of many substances, including therapeutics. ABC transporters comprise a highly 
conserved "cassette-like" domain that catalyzes the ATP hydrolysis providing the energy needed for the transport of substances against a concentration gradient [39] (Figure 2A). They actively transport both endogenous and exogenous substances and are implicated in the absorption, distribution, and excretion of several xenobiotics [39-42]. To date, 48 ABC genes and three pseudogenes can be found in humans and, according to the HUGO Gene Nomenclature Committee [43], they are grouped in seven subfamilies named with the letters A-G (i.e., ABCA, ABCB, .. , ABCG).

Due to their strategic tissue localization and low substrate specificity, the ABC transporters are fundamental for the protection from toxic substances, transport of important metabolites, and cell signaling. ABC transporters are found in the intestine, liver, kidney, hearth, lungs, brain, placenta, and testis. More particularly, they are expressed in the tissue interfaces such as endothelia and blood-tissue barriers; where they are located in the cellular plasma membrane, acting as efflux pumps of toxic molecules; or in the Golgi apparatus, mitochondria, or endoplasmic reticulum avoiding intra-organelle toxicity [44,45]. In the blood-brain interfaces, ABC transporters are located mostly in the luminal barriers [16,20,33,34,46], pumping out substances in a brain-to-blood sense; although members of the ABCC subfamily are located at the basolateral membrane of the CP [20,47]. Each ABC transporter can have a wide spectrum of substrates, which can include amino acids, sugars, peptides, diverse hydrophobic compounds, and their metabolites; and thus, diverse drugs of these characteristics. Therefore, they have a key role in the regulation of drug delivery into the central nervous system and an important impact in their pharmacology effects $[36,48,49]$. In this section, the ABC transporters with an important function in CNS drug delivery (Table 1), and their localization in the blood-brain interfaces (Table 2, Figure 2B-D)) will be reviewed.

Table 1. Classes of substrates and examples of chemotherapeutics transported by drug-related ABC transporters.

\begin{tabular}{|c|c|c|}
\hline $\begin{array}{l}\text { Gene; } \\
\text { Protein }\end{array}$ & Substrates Classes & Examples of Chemotherapeutics Substrates \\
\hline $\begin{array}{l}A B C B 1 \\
\text { P-gp } \\
\text { MDR1 } \\
{[16,42,50,51]}\end{array}$ & $\begin{array}{l}\text { Amphipathic cations, organic } \\
\text { molecules. } \\
\text { No structure-activity relationship } \\
\text { has been identified }\end{array}$ & 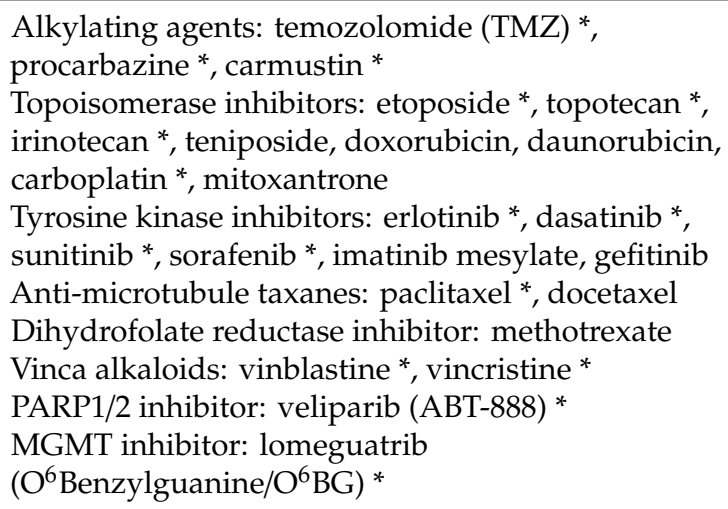 \\
\hline $\begin{array}{l}\text { ABCG2; } \\
\text { BCRP } \\
{[16,42,52-54]}\end{array}$ & $\begin{array}{l}\text { Partial overlap with } \\
\text { P-gp substrates }\end{array}$ & $\begin{array}{l}\text { Alkylating agents: temozolomide }(\mathrm{TMZ}){ }^{*} \\
\text { Topoisomerase inhibitors: etoposide *, topotecan *, } \\
\text { mitoxantrone, irinotecan *, SN-38, } \\
\text { 9-aminocamptothecin, doxorubicin } \\
\text { Tyrosine kinase inhibitors (TKI): erlotinib *, } \\
\text { dasatinib *, sunitinib *, sorafenib *, imatinib, } \\
\text { gefitinib, nilotinib } \\
\text { PARP1/2 inhibitor: veliparib (ABT-888)* } \\
\text { MGMT inhibitor: lomeguatrib } \\
\left(\mathrm{O}^{6} \text { Benzylguanine/O6 } \mathrm{BG}\right) *\end{array}$ \\
\hline
\end{tabular}


Table 1. Cont.

\begin{tabular}{|c|c|c|}
\hline $\begin{array}{l}\text { Gene; } \\
\text { Protein }\end{array}$ & Substrates Classes & Examples of Chemotherapeutics Substrates \\
\hline $\begin{array}{l}A B B C 1 \\
\text { MRP1 } \\
{[16,55-57]}\end{array}$ & $\begin{array}{l}\text { Organic anions, glutathione } \\
\text { conjugates. Glutathione } \\
\text { (GSH)-dependent }\end{array}$ & $\begin{array}{l}\text { Alkylating agents: cyclophosphamide } \\
\text { Topoisomerase inhibitors: doxorubicin, etoposide *, } \\
\text { campathecin, camptothecin, irinotecan * (CPT-11) } \\
\text { Anti-microtubule taxanes: paclitaxel * } \\
\text { Dihydrofolate reductase inhibitor: methotrexate } \\
\text { Vinca alkaloids: vinblastine }{ }^{*} \text {, vincristine * }\end{array}$ \\
\hline $\begin{array}{l}A B C C 2 ; \\
\text { MRP2 } \\
{[16,55-57]}\end{array}$ & $\begin{array}{l}\text { Organic anions, glutathione } \\
\text { conjugates. Allosteric stimulation } \\
\text { by bile acids, sulfinpyranzone, } \\
\text { penicillin G, and indomethacin; } \\
\text { but not GSH }\end{array}$ & $\begin{array}{l}\text { Alkylating agents: chlorambucil, cyclophosphamide, } \\
\text { cisplatin *, oxaliplatin } \\
\text { Topoisomerase inhibitors: doxorubicin, etoposide *, } \\
\text { epirubicin mitoxantrone, irinotecan *, } \\
\text { glucuronidated SN-38 } \\
\text { Vinca alkaloids: vinblastine *, vincristine * } \\
\text { Antineoplastic, dihydrofolate reductase } \\
\text { inhibitor: methotrexate } \\
\text { Antineoplastic, angiotensin inhibitors: } \\
\text { valsartan, olmesartan }\end{array}$ \\
\hline $\begin{array}{l}A B C C 3 \\
\text { MRP3 } \\
{[16,55-57]}\end{array}$ & $\begin{array}{l}\text { Organic anions, glutathione } \\
\text { conjugates. Not stimulated by } \\
\text { GSH nor bile acids }\end{array}$ & $\begin{array}{l}\text { Alkylating agents: cisplatin * } \\
\text { Antineoplastic, dihydrofolate reductase inhibitor: } \\
\text { methotrexate } \\
\text { Topoisomerase inhibitors: etoposide }{ }^{*} \\
\text { teniposide, doxorubicin } \\
\text { Vinca alkaloids: vincristine * } \\
\text { Conjugates: dinitrophenyl S-glutathione, } \\
\text { acetaminophen glucuronide }\end{array}$ \\
\hline $\begin{array}{l}A B B C 4 \\
\text { MRP4 } \\
{[16,55-57]}\end{array}$ & $\begin{array}{l}\text { Organic anions, glutathione } \\
\text { conjugates, cyclic nucleotides. } \\
\text { GSH requirement depending on } \\
\text { substrate; but not for } \\
\text { cAMP or cGMP }\end{array}$ & $\begin{array}{l}\text { Antineoplastic, dihydrofolate reductase inhibitor: } \\
\text { methotrexate } \\
\text { Topoisomerase inhibitors: topotecan * } \\
\text { Nucleotide analogues: 6-mercaptopurine, } \\
\text { 6-thioguanine }\end{array}$ \\
\hline $\begin{array}{l}A B B C 5 \\
\text { MRP5 } \\
{[16,55-57]}\end{array}$ & $\begin{array}{l}\text { Organic anions, glutathione } \\
\text { conjugates, cyclic nucleotides. } \\
\text { GSH requirement not exactly } \\
\text { established, depending on } \\
\text { substrate; but not for } \\
\text { cAMP or cGMP }\end{array}$ & $\begin{array}{l}\text { Antineoplastic, dihydrofolate reductase inhibitors: } \\
\text { methotrexate } \\
\text { Platinum-based drugs: cisplatin * } \\
\text { Nucleotide analogues: 6-mercaptopurine, } \\
\text { 6-thioguanine } \\
\text { Conjugates: dinitrophenyl S-glutathione } \\
\text { Heavy metals: cadmium chloride, potassium } \\
\text { antimonyl tartrate }\end{array}$ \\
\hline $\begin{array}{l}\text { ABCC6; } \\
\text { MRP6 } \\
{[16,55-57]}\end{array}$ & $\begin{array}{l}\text { Organic anions, glutathione } \\
\text { conjugates. GSH requirement } \\
\text { not stablished }\end{array}$ & $\begin{array}{l}\text { Alkylating agents: cisplatin * } \\
\text { Topoisomerase inhibitors: etoposide *, } \\
\text { doxorubicin, daunorubicin }\end{array}$ \\
\hline
\end{tabular}

${ }^{*}$ Reported use in glioblastoma multiforme (GBM) [16,42]; PARP(1/2): Poly(ADP-ribose) polymerase (1/2); MGMT:

$\mathrm{O}^{6}$-methylguanine methyltransferase.

\subsection{ABC Transporters Related to Drug Transport}

The $A B C B, A B C C$ and $A B C G$ subfamilies include transporters related to xenobiotics efflux and drug resistance, notably ABCB1 (P-gp), ABCG2 (BCRP), and the multidrug resistance subfamily (MRPs) of ABCCs [36,56]. Due to the broad spectrum of ABC substrates, including many therapeutics (Table 1 ), they play an important role in drug ADME. In addition, their expression can be modulated as a cause or a part of pathological states such as epilepsy [97] and many tumors and cancer cells, including brain tumors (Section 5.4) [6,16]. In addition, $A B C$ transporters can present a synergic or complementary function, and it has been observed that they may relay one to another $[53,98,99]$. This can lead to the development or improvement of multidrug resistance by preventing the drug from reaching the tissue 
and the molecular target, hampering thus the therapeutic effect. The function of $A B C$ transporters in drug transport will be briefly summarized below, with a focus on anticancer therapeutics.

Table 2. Subcellular localization and level of evidence (protein and/or mRNA) of ABC transporters at the brain barriers of humans and rodents under non-pathological conditions.

\begin{tabular}{|c|c|c|c|c|}
\hline Gene; Protein & BBB & Parenchymal Cells & BCSFB & $\mathrm{AB}$ \\
\hline $\begin{array}{c}A B C B 1 ; \\
\text { P-gp/MDR1 } \\
A b c b 1 a \text { and } A b c 1 b \\
\text { Mdr1a and Mdr1b } \\
(\mathrm{r}, \mathrm{m})\end{array}$ & $\begin{array}{c}\text { Luminal: } \mathrm{h}, \mathrm{r} \\
\text { (Mdr1a), m (Mdr1a) } \\
\text { mRNA and protein: } \\
\text { h, r }(A b c b 1 a), \mathrm{m} \\
(A b c b 1 a) \\
{[22,58-63]}\end{array}$ & $\begin{array}{c}\text { Not detected in } \\
\text { healthy tissue } \\
(h, r, m) \\
{[64-69]}\end{array}$ & $\begin{array}{c}\text { Apical: } \mathrm{h}, \mathrm{r}, \mathrm{m} \\
\text { mRNA and protein: } \\
\text { h, } \mathrm{r}(A b c b 1 a \\
\text { Abcb1b), } \mathrm{m}(A b c b 1 a) \\
{[70-73]}\end{array}$ & $\begin{array}{c}\text { Apical: } h, r, m \\
\text { mRNA and protein: } \\
\text { h, r, m } \\
{[33,34,74-77]}\end{array}$ \\
\hline $\begin{array}{c}\text { ABCG2; } \\
\text { BCRP }\end{array}$ & $\begin{array}{c}\text { Luminal: } \mathrm{h}, \mathrm{r}, \mathrm{m} \\
\text { mRNA and protein: } \\
\text { h, r, m, p } \\
{[22,63,78-83]}\end{array}$ & $\begin{array}{c}\text { Unclear } \\
\text { mRNA and protein: } \\
\text { Neuropil (h); } \\
\text { cultured astrocytes } \\
(\mathrm{h}, \mathrm{r}) \\
\text { mRNA: Microglia } \\
(\mathrm{h}, \mathrm{m}) \\
{[65,68,84,85]}\end{array}$ & $\begin{array}{c}\text { Apical: } \mathrm{h}, \mathrm{m} \\
\text { mRNA and protein: } \\
\text { h, r, } \mathrm{m} \\
{[20,33,70,81]}\end{array}$ & $\begin{array}{c}\text { Apical: } h, r, m \\
\text { mRNA and protein: } \\
\text { h, r, m } \\
{[33,34,74-77]}\end{array}$ \\
\hline $\begin{array}{l}A B B C 1 ; \\
\text { MRP1 }\end{array}$ & $\begin{array}{c}\text { Luminal: } \mathrm{h}^{*} \\
\text { protein: } \mathrm{h}^{*} \\
\text { mRNA: } \mathrm{h} \text { * } \mathrm{r}, \mathrm{m}, \mathrm{c} \\
(\mathrm{low}) \\
{[46,86]}\end{array}$ & $\begin{array}{c}\text { Not detected } \\
{[64]}\end{array}$ & $\begin{array}{c}\text { Basolateral: } h, r, m \\
\text { Protein and mRNA: } \\
h, m, r \\
{[70,71,73,83,87-89]}\end{array}$ & $\begin{array}{c}\text { mRNA: } h, r, m \\
\text { Protein: } r \\
{[33,34]}\end{array}$ \\
\hline $\begin{array}{l}A B C C 2 ; \\
\text { MRP2 }\end{array}$ & $\begin{array}{c}\text { Luminal: } \mathrm{r}, \mathrm{m} \\
\text { protein: } \mathrm{r}, \mathrm{m} \\
\text { mRNA: } \mathrm{r}(\mathrm{low}), \mathrm{m} \text {, } \\
\text { c (low) } \\
{[46,86,90,91]}\end{array}$ & $\begin{array}{c}\text { mRNA and protein: } \\
\text { neuropil, glial and } \\
\text { neuronal cells (h) } \\
\text { [64] }\end{array}$ & $\begin{array}{c}\text { mRNA: h, r } \\
{[87,88]}\end{array}$ & $\begin{array}{l}\text { Not detected } \\
\qquad(h, r, m) \\
{[33,34]}\end{array}$ \\
\hline $\begin{array}{l}A B C C 3 ; \\
\text { MRP3 }\end{array}$ & $\begin{array}{c}\text { mRNA: } \mathrm{h} *(\text { low }), \mathrm{r} \\
(\text { low }), \mathrm{m} \\
{[46,86]}\end{array}$ & $\begin{array}{c}\text { Not detected } \\
{[64]}\end{array}$ & $\begin{array}{c}\text { mRNA: h, r } \\
{[87,88]}\end{array}$ & $\begin{array}{l}\text { Not detected } \\
\qquad(h, r, m) \\
{[33,34]}\end{array}$ \\
\hline $\begin{array}{l}A B B C 4 ; \\
\text { MRP4 }\end{array}$ & $\begin{array}{l}\text { Luminal: } h, r, m \\
\text { Protein: } h, r, m \\
\text { mRNA: } h, r, m \\
{[22,46,86,92-95]}\end{array}$ & $\begin{array}{c}\text { Not detected } \\
{[64]}\end{array}$ & $\begin{array}{c}\text { Basolateral: } h, r, m \\
\text { Protein \& mRNA: } \\
\text { h, r, m } \\
{[83,87,88,96]}\end{array}$ & $\begin{array}{c}\text { mRNA: } h, r, m \\
\text { Protein: } r \\
\text { [34] }\end{array}$ \\
\hline $\begin{array}{l}A B B C 5 \\
\text { MRP5 }\end{array}$ & $\begin{array}{c}\text { Luminal: h, r, m } \\
\text { mRNA: h, r, m } \\
{[46,86]}\end{array}$ & $\begin{array}{c}\text { mRNA \& protein: } \\
\text { Neuropil (h) } \\
{[64]}\end{array}$ & $\begin{array}{c}\text { Basolateral: } \mathrm{r} \\
\text { mRNA \& protein: } \\
\text { h, r } \\
{[83,87,88]}\end{array}$ & $\begin{array}{l}\text { Not detected } \\
\qquad(h, r, m) \\
{[33,34]}\end{array}$ \\
\hline $\begin{array}{l}\text { ABCC6; } \\
\text { MRP6 }\end{array}$ & $\begin{array}{c}\text { mRNA: } \mathrm{h}^{*}, \mathrm{r}, \mathrm{m} \\
{[46,86]}\end{array}$ & Not analyzed & $\begin{array}{c}\text { mRNA: } \mathrm{h}, \mathrm{r} \\
{[87,88]}\end{array}$ & $\begin{array}{l}\text { mRNA \& protein: } \mathrm{r} \\
{[34]}\end{array}$ \\
\hline
\end{tabular}

h: human, r: rats, m: mice, p: porcine; ${ }^{*}$ only in samples from diseased patients.

The P-glycoprotein (P-gp/MDR1) was the first ABC transporter to be associated with multidrug resistance in cancer cell lines [100]. In humans, P-gp is encoded by the $A B C B 1$ (MDR1) gene, while in rodents, two isoforms have been found, $A b c b 1 a$ and $A b c b 1 b$ (Mdr1a and Mdr1b proteins) with different tissue-specific localization $[85,101,102]$. P-gp can transport a very broad spectrum of molecules with different chemical structure, molecular weight, and properties. It is difficult to define canonical properties of P-gp substrates, but they are typically hydrophobic or amphipathic, with a planar mainly aromatic ring system and positively charged (at physiological $\mathrm{pH}$ ), although some neutral substrates are also observed [50] (Table 1). It is implicated in the translocation of many anti-cancer 
drugs including anthracyclines, vinca alkaloids, taxanes, and tyrosine kinase inhibitors (gefitinib, imatinib mesylate) $[16,103,104])$.

Breast-cancer resistance protein (BCRP) functional form is formed by a homo-oligomer of the $72 \mathrm{KDa}$ polypeptides encoded by the $A B C G 2$ gene. The structure of the functional protein is still debated but it has been observed that the BCRP polypeptide can be assembled in homodimers, tetramers, or even duodecamers (reviewed in [105]). The list of BCRP substrates is also large (over 200) and diverse; it includes some common substrates with P-gp or the multidrug resistance protein 1 (MRP1/ABCC1) [52,53], but also contains a lot of distinct compounds (Table 1). Many of the substrates identified are chemotherapeutics, including camptothecin derivatives (topotecan), anthracyclines (mitoxantrone), polyglutamates (methotrexate), as well as tyrosine kinase inhibitors such as imatinib and gefitinib $[105,106]$. No structure-activity relationship has been properly identified between the many BCRP substrates, which complicates drug development and screening.

The ABCC subfamily comprise 13 protein-coding genes for humans, while nine are related to the multidrug-resistance protein (MRP) subclass: MRP1-6 (ABCC1-6), MRP7-9 (ABCC10-12), and $A B C 13$, a non-functional pseudogene [55]. The other three are the sulfonylurea receptors 1 and 2 (SUR1, 2/ABCC8, 9) and the cystic fibrosis transmembrane conductance regulator (ABCC7). Each MRP has a specific substrate profile and although overlap can occur, their kinetics are often different [107] (reviewed in [55], Table 1). Generally, MRPs transport a variety of organic anions which can be or not conjugated with glutathione (GSH), glucuronide, sulfate, or phosphate [3]. In some cases, GSH acts as an activator, while in others, it is not needed $[55,56,108,109]$. Thus, the MRPs work together with metabolism enzymes to efflux endogenous substances as oestradiol $17-\beta$-D-glucuronide $\left(\mathrm{E}_{2} 17 \beta \mathrm{G}\right)$, the pro-inflammatory cytokine $\mathrm{LTC}_{4}$ (leukotriene $\mathrm{C}_{4}$ ), and bile acids. They also extrude xenobiotics, including many anticancer drugs such as doxorubicin, vincristine, etoposide, campathecin, topotecan, and methotrexate $[55,56,108,109]$. MRP4 and MRP5 can also transport nucleotides as cyclic AMP and cyclic GMP [110] and confers resistance to several antiviral and anticancer nucleotide analogues [111-113].

\subsection{ABC Transporters Expressed at the BBB and the NVU}

P-gp/MDR1 (ABCB1) is expressed at the luminal (apical) membrane of brain microvessels endothelial cells and is not found in healthy parenchymal cells (Table 2, Figure 2B)). P-gp/MDR1 ( $A B C B 1)$ has been detected in the brain endothelial cells of many mammals including humans, rats, mice, bovines, porcines, and other primates by different techniques $[22,63,86,114,115]$, where it is located to the luminal side of the cell [58-63]. In mouse and rat, the transcript of $A b c b 1 a$ isoform is predominant in BMVEC, while a low expression of $A b c b 1 b$ was observed $[85,101,102]$. P-gp expression has been reported in parenchymal cells in culture or from pathological origins, but its function has not been proved in in vivo healthy samples. Functional Mdr1b/MDR1 has been detected in cultured mouse [116], rat [117,118], and human [69] astrocytes as well as cultured rat microglia [119]. However, P-gp expression could be induced by culture conditions [16]. In rat and mouse, low mRNA expression of $M d r 1 b$ was observed in astrocytes, microglia, and endothelial cells, but this was not confirmed at the protein level $[85,101,102]$. Furthermore, no local translation of ABC transporters was observed at the mouse astrocytes' endfeet surrounding the vascular surface [64], where P-gp was believed to be expressed. In humans, it has been detected in parenchymal cells of tissues obtained from patients with epilepsy $[62,67,69]$ or gliomas [66], but the pathology may have induced the P-gp de novo expression, as it was not expressed in the healthy (control) tissue neither at the mRNA $[65,66]$ nor at the protein levels [66-69].

BCRP ( $A B C G 2)$ is located to the luminal membrane of microvessels endothelial cells, and its expression in parenchymal cells has not been proved (Table 2, Figure 2B)). ABCG2 mRNA transcript has been detected in human, mouse, rat, and porcine microvessels, where the BCRP protein is located at the luminal membrane [63,78-83]. According to the RNA-Seq brain transcriptome, $A b c g 2$ in mouse [85] and $A B C G 2$ in humans [65] is expressed mostly in endothelial cells, but low transcript levels could 
be found in microglia. Abcg2 has also been detected in a pericyte cell line [120] and in primary cultured astrocytes [84]. Immunohistochemistry assays by the Human Protein Atlas indicate a high BCRP expression in the endothelial cells and low in neuropil [68], which includes cell processes from neurons and glial cells, indicating possible expression in parenchymal cells. Nevertheless, the protein expression and function of Bcrp/BCRP in vivo in parenchymal cells needs to be clarified.

MRP4 and MRP5 are expressed at the luminal membrane of brain microvessels endothelial cells in humans, but interspecies differences may occur (Table 2, Figure 2B). Different studies have shown the mRNA expression of $A B C C 1$ to $A B C C 10$ in human, rat, mouse, porcine, and bovine models, [21,46,86] with important differences between the species [86]. Nevertheless, the human samples in these studies consisted of perilesional and cortex (far from lesions) biopsies from glioma or epileptic patients undergoing surgical resections, and the expression may be induced by the pathology $[6,14,16]$. Nevertheless, MRP3 expression at the protein level has not been detected by immunohistochemistry (IHC) $[46,86,96,121]$, and no MRP1 function was observed in mouse microvessels [122], suggesting that they are not expressed at the BBB in basal conditions. In humans, MRP4 and MRP5 proteins are located in the luminal membrane [46]. Some publications have reported the expression of MRP1 in the BBB, but it is very likely that this results from hazardous extrapolations from in vitro data to the in vivo situation, because MRP1 function was not detected in human microvessels from healthy human samples [46] and function was not proven by in situ brain perfusion in mice [122]. Indeed, it has been observed that MRP1 may be overexpressed due to cell culture conditions or the origin of the samples from diseased patients $[15,66]$. Mrp2 has been observed in the luminal membrane of BMVEC only in rat and mouse [90,91], indicating important differences between the species. MRP4 has been quantified using mass spectrometry (MS) in humans, rodents, marmosets, and monkey isolated brain microvessels [22,92-95], but it is expressed in very low levels, around 10 to 20-fold lower than P-gp; while other MRPs were under the limit of quantification.

MRP5 is lowly expressed in neuropil and MRP2 in neuropil, glial, and neuronal cells (in human) (Table 2, Figure 2B). mRNA transcripts of Mrp1, Mrp3, Mrp4 and Mrp5 have been observed in primary cultures of rat microglia and oligodendroglia [123], but it is highly likely that expression was triggered by culture conditions or the disease origin of samples. Particularly, it has been suggested that functional MRP1 is expressed in astrocytes, as Mrp1 mRNA expression and function were observed in rat cultured astrocytes [117], and the MRP1 protein was detected in astrocytes by IHC in tissue slices from glioma human patients, and function was proven using primary cultures $[15,66]$. Nevertheless, no local translation of $A b c c$ transporters was observed at the mouse astrocytes' endfeet surrounding the vascular surface [64]. MRP4 and MRP5 have been detected in human astrocytes, while MRP5 has also been observed in human pyramidal neurons [46] and astrocytes [15], as well as primary cultures of rat astrocytes [123] and microglia [47,124]; nevertheless, these experiments were performed in samples from patients with epilepsy or glioma, and the expression may be tuned by the disease. In the contrary, the IHC assays reported at the Human Protein Atlas were performed on healthy tissue and better represent the basal expression of proteins. According to this database, in the human brain cortex, MRP1 and MRP4 are not detected in glial or neuronal cells, MRP3 was not detected in the brain cortex, MRP5 was detected in low levels in neuropil, and MRP2 was observed in low levels in glial and neuronal cells, as well as in the neuropil in medium level but not in the endothelial cells [68].

\subsection{ABC Transporters Expression at the BCSFB}

P-gp is lowly expressed at the apical membrane of the CP epithelial cells (Table 2, Figure 2C)). It has been detected in the mRNA and protein levels at the BCSFB of humans and rats (mdr1a and $m d r 1 b$ ) [70-73], and it has been located as weakly expressed at the apical side of the human, rat, and mouse CP [33,71-73]. Nevertheless, its protein expression in rat was shown to be 77.8-fold lower in the $\mathrm{CP}$ than in brain microvessels $\left(0.320\right.$ vs. $\left.24.9 \mathrm{fmol} / \mathrm{\mu g}_{\text {protein }}\right)$ [70,93]. In humans, P-gp is 1.9 times lower in CP than in brain microvessels ( $\left.2.10 \mathrm{vs.} 3.98 \mathrm{fmol} / \mathrm{\mu g}_{\text {protein }}\right)$ [22,70]. 
BCRP is lowly expressed at the apical membrane of CP epithelial cells (Table 2, Figure 2C). BCRP has been detected in mouse, rat, and human CP [20,33,70,81], and low BCRP expression has been located at the apical side of human and mouse CP [20,33,81]. Although it could not be detected by IHC in rat CP [83], the Bcrp protein has been quantified using LC-MS/MS in rats and humans [70]. Its protein expression in rat was shown to be 21 -fold lower in the $\mathrm{CP}$ than in brain capillaries $(0.330$ Vs $6.95 \mathrm{fmol}_{\text {monomer }} / \mu \mathrm{g}_{\text {protein }}$ [ [70,93]. In humans, BCRP is 8.7 times lower in the CP than in brain microvessels (0.706 Vs $6.15 \mathrm{fmol}_{\text {monomer }} / \mu g_{\text {protein }}$ ) [22,70].

MRP1 and MRP4 in humans, rats, and mice, and MRP5 in rats are expressed at the basolateral membrane of the CP epithelial cells (Table 2, Figure 2C). In humans, MRP1 to MRP6 have been detected at the mRNA level [87], but only proteins MRP1 and MRP4 have been observed [71,96]. Similarly, in rats, Mrp1 to Mrp6 mRNA transcripts have been detected [88], but only proteins Mrp1, Mrp4, and Mrp5 have been observed [70,83]. In mouse, Mrp1/Mrp1 and Mrp4/Mrp4 were detected at the mRNA and protein level $[89,96]$. MRP1 and MRP4 have been located at the basolateral side of the CP epithelial cells from humans, mice, and rats [71,73,83,89,96] as well as MRP5 in rat [83]. Interestingly, MRP4 is the only $\mathrm{ABC}$ transporter found at the basolateral membrane of the CP epithelium and in the luminal membrane of the BMVEC [96] endothelial cells of the brain capillaries. It has been observed that MRP1 is the $\mathrm{ABC}$ transporter with the highest expression at the $\mathrm{CP}$ in rats $\left(5.47 \mathrm{fmol} / \mu \mathrm{g}_{\text {protein }}\right)$ and the second highest in humans $\left(1.36 \mathrm{fmol} / \mu g_{\text {protein }}\right)$, after P-gp (2.10 fmol/ $\left.\mu g_{\text {protein }}\right)$ [70]; additionally, in both cases, MRP1 is higher at the CP than in BMVEC (below the limit of quantification) [22,93].

\subsection{ABC Transporters Expression at the $B A B$}

The study of the $\mathrm{ABC}$ transporters at the $\mathrm{BAB}$ is relatively recent and few studies have been performed, but it has been shown that P-gp and BCRP are expressed in the apical membrane of arachnoid barrier cells in humans, rats, and mice. MRP1 and MRP4 transcripts are detected in human BAB, and Mrp1, Mrp4, Mrp6, and Mrp7 proteins are expressed in rat (Table 2, Figure 2D)). P-gp ( $A B C B 1, A b c b 1 a$ in mouse) and Bcrp (Abcg2) have been detected at the mRNA and protein levels in human, rat, mouse, pig, and monkey BAB cells, where they are located at the apical membrane [33,34,74-77,125]. MRP4 was also detected in pig and rat apical membranes by quantitative proteomics [34,125]. Importantly, other meningeal cells did not show the expression of these transporters in these studies. Moreover, Yasuda et al. [33] proved the functionality of P-gp at the AB, as they observed that its substrate daunomycin was accumulated in cultured mouse BAB cells after P-gp inhibition. Additionally, they showed the mRNA expression of $A B C C 1$ and $A B C C 4$ in human and mouse BAB cells, as well as other ADME-related genes (transporters and metabolism enzymes). More recently, Zhang et al. [34] used targeted MS proteomics to quantify several ABC and SLC transporters at the rat AB; obtaining the absolute expression of several ABC transporters (values in fmol/ $\mu g_{\text {protein }}$ ): P-gp/Mdr1a (16.6), Bcrp (3.27), Mrp1 (0.671), Mrp4 (0.510), Mrp6 (0.165), and Mrp7 (0.118), showing a high expression of P-gp and Bcrp, which was roughly twofold lower than in the rat BBB $\left(24.9\right.$ and $6.95 \mathrm{fmol}$ monomer/ $/ \mathrm{g}_{\text {protein, }}$ respectively). Additionally, both studies showed the presence of other ADME-related genes' mRNA transcripts and/or protein expression in the BAB cells, such as SLC transporters and metabolism enzymes. These results suggest that BAB could contribute importantly to the efflux of drugs from the brain, and thus it should not be neglected during drug delivery and clearance studies.

\subsection{ABC Transporters Expression Differences between Animals}

Care should be taken when translating results between different specifies and even animal strains or human populations because of differences in enzyme and transporters expression [93,126] (Table 2), and activity have been observed [127]. One important interspecies differences is MRP2/Mrp2 expression, which has been detected in rodents BMVEC (as mice and rats) but not in humans [128]. This can lead to the misinterpretation of pharmacokinetics studies of MRP2 substrates such as the anticancer drugs teniposide and etoposide [129], which are used clinically for recurrent the glioblastoma multiforme (GBM) treatment. In addition, absolute protein quantification using targeted tandem 
mass-spectrometry coupled to liquid chromatography (LC-MS/MS) has revealed different levels of $\mathrm{ABC}$ transporters in isolated brain microvessels in rodents and primates [93]. In rodents, P-gp has the highest expression among these proteins, followed by Bcrp and Mrp4. In primates, BCRP functional protein is slightly higher or at similar levels regarding P-gp and the expression of MRP4 is even smaller than in rodents. For instance, in the rat BBB, P-gp expression ( $24.9 \mathrm{fmol} / \mu g p r o t e i n)$ is seven times higher than the functional homodimeric Bcrp (3.475 fmol homodimer/Mgprotein) [93]. On the contrary, in human BBB, BCRP functional protein expression ( $3.07 \mathrm{fmol}_{\text {homodimer }} / \mu g$ protein) is similar to P-gp (3.98 fmol//ugprotein) [22]. Interestingly, these studies showed that BCRP expression in humans was nearer to rodents than to other primates [93]. Importantly, these interspecies differences should be considered during drug development and specially when translating preclinical results to the design of clinical assays.

\subsection{Conclusion on the Multidrug Resistance Related to ABC Transporters at the Blood-Brain Interfaces}

$\mathrm{ABC}$ transporters are found in the three blood-brain interfaces to help maintain the brain homoeostasis. P-gp, BCRP, and the MRP family efflux diverse drugs, hindering their delivery for the treatment of CNS diseases. For a long time, research to study their function and overcome drug resistance has focused on the $\mathrm{BBB}$, but recent works have located and shown their importance at the BCSFB and the BAB for drug clearance; therefore, they should not be neglected. Many models and methodologies have been useful to deepen our knowledge on the molecular and functional characterization of these barriers and to test new drugs and delivery strategies. Therefore, in the next section, we will summarize some of the most important methods related to the study of the localization, modulation, function, and implication in drug resistance of $A B C$ transporters and the evaluation of drug penetration into the brain.

\section{Methods to Study the Blood-Brain Interfaces}

The development of new drugs or delivery strategies must pass through thorough evaluation in accordance to the regulatory agencies such as the American Food and Drug Administration (FDA) and the European Medicines Agency (EMA) $[130,131]$. This often includes testing for the physicochemical and pharmacological properties of drugs, such as lipophilicity and solubility, permeability prediction using Lipinski's "rule of 5" [132], in vitro and ex vivo tests for pharmacological effect and toxicity of the molecule and its metabolites, in vivo analyses in animal models and eventually clinical trials. Particularly, in the case of CNS therapeutics, the pharmacokinetics of the drug or the effect of the delivery strategy should be assessed, considering its passage into the brain, and its clearance, through the blood-brain interfaces (the main pharmacokinetics calculations have been previously reviewed $[5,133,134])$. Therefore, many animal and human models have been developed for the study of the barriers' phenotype, function, and changes, each one with its inherent advantages and disadvantages (further detailed in [4-8]). Some of the most used approaches to study the permeability and transport of drugs and to evaluate delivery strategies will be briefly described in this section.

\subsection{In Vitro Models and Assays for Drug Evaluation}

In vitro models mimic the barrier's functional and/or anatomical characteristics with the advantage of being simpler and allowing the realization of experiments with higher control of the conditions and without the ethical concerns compared to in vivo assays. These models should present similar characteristics to the biological barriers, including the formation of a tightly closed monolayer, often measured as transendothelial electrical resistance (TEER) [135] or studying the permeability of hydrophilic tracer molecules such as Lucifer yellow, sodium fluorescein, sucrose, or mannitol. In addition, the cells should express the correspondent proteins at specific subcellular localization (polarized), including tight junctions, transporters, enzymes, signaling receptors and pathways, as well as macromolecular and immune cell trafficking $[7,136,137]$. In vitro assays are required for the screening and validation of new drugs; they are used to evaluate cytotoxicity, metabolism-mediated interactions, 
transporter-mediated interactions, and drug-drug interactions according to drug regulatory agencies such as the FDA and EMA $[130,131]$ In the case of CNS drug delivery, they are useful to address BBB permeability and evaluate delivery strategies [5,7].

Permeability studies can be performed using devices consisting of a permeable filter separating an apical (luminal) and a basal (abluminal) compartments such as the Transwell removable inserts (Figure 3A). The endothelial cells are grown to confluence on the filter to form a tight monolayer which should obtain a polarized phenotype as similar as possible to the in vivo, including specifically located transporters and high tightness $[7,136,137]$. Two different mediums can be used to mimic the apical space on top of the filter and the basolateral below. After adding the testing molecule to the acceptor compartment, samples are taken overtime from the donor medium. The incremental clearance volume $\left(\Delta \mathrm{V}_{\mathrm{Cl}}\right)$ on each time is calculated as the product of the concentration in acceptor $\left(\mathrm{C}_{\mathrm{a}}\right)$ by its volume $\left(V_{a}\right)$, which is divided by the concentration in the donor $\left(C_{d}\right)\left(\Delta V_{C l}=\left[C_{a} * V_{a}\right] / C_{d}\right)$; the slope of the linear curve is divided by the surface of the filter to obtain the total permeability, which is corrected to account for cell-free areas of the filter. Normally, the permeability from the apical to basal compartment is assessed, but the opposite sense can be used to evaluate efflux transport [133,134].

Brain endothelial cell uptake can be evaluated by incubating the cell monolayer (Figure 3C) with a tracer molecule. The uptake process is quenched at serial time points using a cold buffer solution or adding transport inhibitors; then, the cells are lysed, and the total proteins and tracer concentrations are measured using scintillation (for radio-labeled compounds) or other methods such as liquid chromatography (LC) coupled to UV-visible detection (LC-UV) or to mass spectrometry (LC-MS), for instance. The volume of distribution of the test substance $\left(\mathrm{V}_{\mathrm{d}}\right.$, in $\mu \mathrm{L} \mathrm{mg}^{-1}$ protein $)$ is calculated as the ratio of counts or amount of the substance per milligram of proteins to the ratio of counts or amount of the substance per microliter of incubation medium. If the uptake is mediated by transporters, Michaelis-Menten kinetics can be obtained using nonlinear regression analysis of the concentration dependence of the influx [133].

Diverse strategies can be employed to evaluate the implication of ABC transporters in the drug efflux $[5,133,134]$. Inhibitors of the ABC transporters specifically targeting one or more of them can be employed to evaluate their implication in the substance permeability or efflux by comparing with the uninhibited condition. For instance, tariquidar and elacridar can inhibit both P-gP and BCRP, while verapamil, N-desmethyl-loperamide, and loperamide can target P-gp specifically (detailed in Section 6.1). Similarly, the transporter expression can be knocked-out or knocked-down, or models overexpressing an ABC transporter can be compared [133]. Endothelial cell models can be used as a surrogate of the blood-brain interfaces to study the ABC-related transport [5], such as the human colonic epithelial cell line (Caco-2) or the Madin-Darby canine kidney cell line (MDCK) epithelial cells used to predict the gastrointestinal permeability of a compound or drug. These have the advantage of being simple, widely used, and MDCK having been engineered to specifically overexpress ABC transporters, such as P-gp [138]. Nonetheless, results should be interpreted carefully, as these cells do not represent exactly the mechanisms driving brain permeability due to considerably lower tightness and differences in the expression of ABC transporters [133]. Therefore, there are continuous efforts to develop in vitro models of the blood-brain interfaces to improve the evaluation of drug delivery into the CNS, which will be briefly summarized in the following subsections, as their advantages, disadvantages and molecular characterization have been thoroughly reviewed recently [4,7,136,139-143]. Importantly, for a wide review on the receptor and transporter expression in diverse in vitro models of the BBB, including data on $\mathrm{ABC}$ transporters, please refer to [7].

\subsection{In Vitro Models of the $B B B$}

Drug permeation is often studied using models of the BBB, which is considered as the main interface for brain delivery into the brain. These cell models are generated from primary cultures or immortalized cell lines of brain capillary endothelial cells [4] from mouse [144], rat [145-149], bovine [150], porcine [151], Rhesus macaque [152] and human [153-155] models, and more recently from 
endothelial cells derived from human stem cells [156-159] (reviewed in $[6,7,136,160])$. Primary cultures of endothelial cells are obtained by culturing brain microvessels obtained by an enzymatic dissociation and cultured with specialized media to eliminate astrocytes and pericytes $[147,149,155,161]$. Endothelial cells can be immortalized using different strategies (e.g., the E1A adenovirous gene, [162]) and have the advantage that they can be used repeatedly and shared between laboratories. The human immortalized endothelial cell line hCMEC/D3 [153,154] is widely used for the study of drug transport [163-166] because it has been thoroughly characterized and it expresses ABC and SLC transporters, as well as tight junctions [167-169], despite the fact that the tightness of its monolayer is lower than in intact microvessels due to a lower expression of claudin-5 [169]. Recently, human brain endothelial cells have been obtained from stem cells such as human cord blood-derived stem cells of circulating endothelial progenitor and hematopoietic lineages [156,157], human pluripotent stem cells (hPSCs) [158], and induced pluripotent stem cells (iPSCs) [170,171]. After differentiation and isolation, the hPSC-derived brain endothelial cells monolayers present key BBB characteristics, including tight junctions and functional ABC transporters [158,159,172].

Several strategies have been employed to improve the BBB functions of cultured endothelial cells. As mentioned in Section 2.1, the BMVEC phenotype and the BBB function depend on their dynamic interactions with the NVU (Figure 3B); therefore, monocultures of endothelial cells may present lower tightness (Figure 3C), different ABC transporters expression and higher permeability [6,7,136,160]. The indirect interactions have been studied in vitro and they have been exploited to improve the tightness and functional expression of transporters in BBB models [4,7]. Diverse studies have employed, for instance, soluble factors such as retinoic acid, cAMP, cytokines, growth factors, and neurotrophic factors [147,159,173]; astrocyte-, pericyte-, or neuron-conditioned media [82,173-175]; or glial-derived extracellular matrix [175]. An improvement in the expression of tight junctions and BBB phenotypes have been observed when brain endothelial cells are cocultured in two-chamber systems with astrocytes [144,149,176-178], pericytes [179], neurons [180], or microglia [181]; furthermore, a synergic effect is seen when several cell types of the NVU are cocultured (Figure 3C) [6,7,136,160,182]. The different cells can be placed in direct or indirect contact in these models, but this can also impact the BBB phenotype [182]. Therefore, the nearest to an in vivo model should be used, but this can be time and resource consuming; thus, simple models can also be useful for drug screening, depending on the objective of the experiment.

Cocultures have been widely employed in the recent years for the evaluation of drug permeability. A commonly used approach to better mimic the BBB consists on the coculture of a rat primary culture [183] or cell line of astrocytes [184] with BMVEC from rat [147,149,185], porcine [183,184], bovine $[177,178,186]$ or human cells to obtain an improved barrier phenotype characterized by a higher TEER or even increased functionality of ABC transporters [186], as observed for P-gp in a rat astrocyte-bovine brain endothelial cells system [187]. For instance, the tightness of the monolayer formed by hPSC-derived brain endothelial cells is increased by coculture with rat astrocytes [158]. In addition, some enterprises commercialize human primary cells of astrocytes, pericytes, BMVEC, and neurons that can be used for in vitro modeling of the BBB, which recently allowed the evaluation and comparison of complex cocultures containing combinations of these components of the NVU [182].

\subsection{Dynamic In Vitro Model, Toward the BBB-on-Chip}

The BBB phenotype depends on the interaction of the endothelial and glial cells, but the hemodynamic forces, such as the shear stress and cyclic strain, are also a key factor modulating vascular endothelial cells [190], which has been exploited to improve BBB models. When endothelial cells are cultured under a laminar flow, their morphology is more similar to the in vivo than in the absence of flow [142,191-193]. The frictions forces applied by the flow at the apical surface of the endothelium activate diverse mechanosensors such as caveolae, ion channels, PECAM-1, integrins, cadherins, G proteins, and kinases, which are involved in the signaling pathways that regulate cell differentiation [194-198]. This results in larger and flattened endothelial cells, with improved tightness 
(higher TEER), increased gene and protein expression of primary metabolism pathways, adhesion and tight junctions, CYPs450, ABC transporters, and ion channels [142,196,197,199]. Importantly, flow contributes to the polarization of the endothelial cells, including the localized (apical or basolateral) expression of functional transport systems such as ABC and SLC transporters and endocytosis mechanisms [142,200-202]. Diverse devices have been employed to study the effects of shear forces on the endothelial cells phenotype, starting with the use of a viscosimeter adapted with a cone plate to induce the fluid shear stress in culture plates [198,203]. However, the need for a precise control of the laminal flow and of coculturing the endothelial cells with glial cells to improve the BBB phenotype has pushed forward the development of more performant and more complex "BBB-on-chip" models.

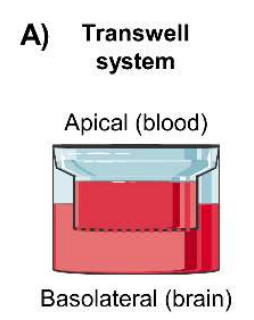

\section{B)}

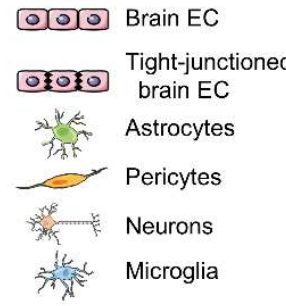

D)

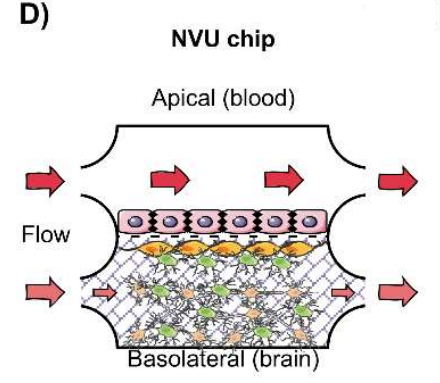

E)

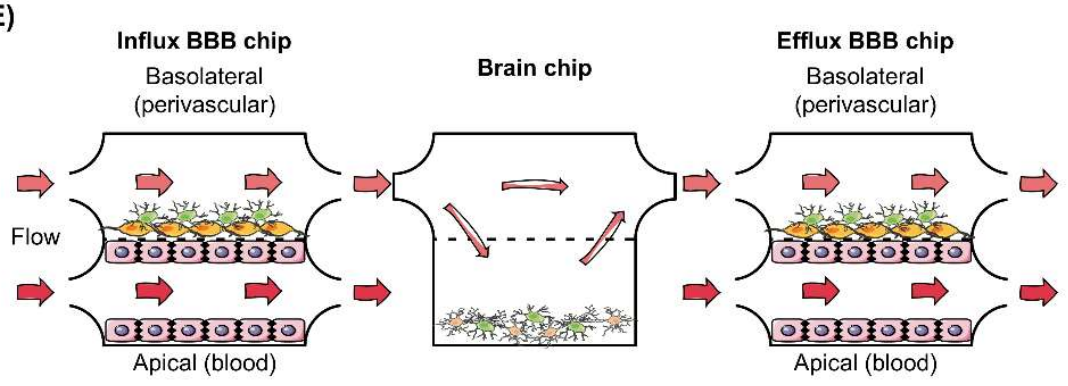

Figure 3. Schemas of examples of in vitro models of the blood-brain barrier (BBB). (A) Cells conforming the neurovascular unit (NVU) used for cell culture, usually in (B) Transwell systems with an apical (blood) and basolateral (brain) space, separated by a permeable membrane (dashed line). (C) Primary or cell lines of brain endothelial cells (EC) can be cultured (a) directly in wells to study drug absorption or (b) in transwells for permeability assays; (c to f) cocultures with other cells from the NVU can improve the BBB phenotype, including the tight junctions (black rhombus $\downarrow$ ); (g and $\mathbf{h}$ ). Furthermore, a synergic effect is observed when several cell types are cocultured. (D) and (E) are examples of BBB-on-chip systems. (D) Two-chamber microfluidics system developed by Brown et al. [188]. (E) Multichamber system developed by Maoz et al. [189] consisting of a brain chip connected to an influx BBB chip and an efflux BBB chip, which allowed the study of drug BBB permeability and clearance. Created using images from "smart Servier Medical Art", Creative Commons License, 2019.

BBB-on-chip models created using 3D devices allow a better representation of the barrier function by including a laminal flow of culture medium to mimic the blood stream and often coculturing endothelial and glial cells (reviewed in $[139,141]$ ). The team of professor Janigro pioneered the development of BBB coculture models under flux in the late 1990s, allowing for the first time the real time measurement of permeability for dynamic studies [200,202,204,205]. They developed a tridimensional device consisting of a hollow-fiber tube with medium flowing inside it, where endothelial cells can be cocultured with astrocytes, obtaining an improved formation of tight junctions, a resistivity nearer to in vivo conditions, the polarized expression of transporters, and selective permeability [202]. Diverse systems have been assessed, using mono and cocultures of animals, human, cell lines or mixed-origin cells and different devices. Although none of these was perfect, the 3D models are nearer to the in vivo assays, while conserving the advantages of controlled conditions of in vitro assays. Furthermore, using differentiated human iPSC cells, these in vitro systems can better mimic the human BBB and its changes in disease by using patient cells, which could even lead to the development precision medicine strategies (reviewed in [139]). 
Recent advances in microfluidics (reviewed in [206]) and cell culture have allowed the creation of very complex models of the "NVU-on-chip". Brown et al. [188] developed a device consisting of a two-chamber system separated by a porous membrane, which is covered at the blood side with a monolayer of endothelial cells and with pericytes and astrocytes at the side of the brain chamber, filled with iPSC-derived human cortical neurons and codifferentiated astrocytes fixed in a collagen gel [188] (Figure 3D), allowing the dynamic study of the BBB response to inflammation [207]. Maoz et al. [189] modeled not only brain permeability but also the clearance through the BBB by connecting a brain chip between the perivascular spaces of two BBB chips (influx and efflux) (Figure 3D). The BBB compartments consisted of a monolayer of human brain microvascular endothelial cells at the vascular chamber and pericytes and astrocytes at the perivascular chamber, while the brain compartment contained neurons and astrocytes at the lower chamber. This multichamber system allowed the study of the individual contribution of the NVU cells to the maintain of brain functions through metabolic interactions [189]. More recently, the same team developed a single two-chamber chip improved model using pluripotent stem cell-derived human brain microvascular endothelium interfaced with primary human brain astrocytes and pericytes (but not neurons) and including a period of differentiation under hypoxic conditions using a "developmentally-inspired induction protocol", which resulted in an increase in the expression of ABC and SLC transporters compared to normoxic conditions [208].

\subsection{In Vitro Models of the BCSFB and $B A B$}

There has been a lower interest in the development, use, and characterization of in vitro models of the BCSFB and BAB, but they should not be neglected, considering their barrier function and their importance for drug delivery into the CNS and its clearance, as mentioned in Section 3. Nevertheless, the new discoveries on their implication in drug delivery and clearance may push forward to the development of more complex and better models. Furthermore, interconnected multichamber microfluidics systems, similarly to the one employed by Maoz et al. to study the BBB [189] (Figure 3D), could be employed to create a "brain-on-chip" system including all the three blood-brain interfaces and used to improve our understanding of brain pharmacokinetics.

Several in vitro models of the CP have been developed to study the BCSFB function [209], including mouse [210], rat [211], porcine [212,213] and Rhesus macaque [214] primary epithelial cells and immortalized mouse and rat cells $[209,211,215,216]$. These models can be used to study drug delivery and clearance, as well as transporter function; for instance, the porcine model of CP epithelial cells developed by Baeh et al. [213] formed a monolayer with key characteristics of the BCSFB; such as the expression of Mrp1 in the basolateral (blood-facing) membrane, similarly to its location in tissue.

Cultured primary or immortalized arachnoid cells have been used as in vitro models of the $B A B$ [217]. These models have been of great importance for the discovery of their barrier function; this includes the discovery of ABC and SLC transporters in immortalized cultures of mouse BAB cells [33], the study of junctional proteins in a human primary line obtained from arachnoid granulations [218], and its interaction with blood in immortalized [217] and primary rat arachnoid cells [219].

\subsection{Ex Vivo Models}

Ex vivo models try to represent the architecture of the blood-brain interfaces better than in in vitro assays, while allowing a faster and easier evaluation of drug transport or distribution than in in vivo models. The living tissue is extracted from the organism and placed in an artificial environment, taking care of minimizing the disruption of the sample to achieve a maximum similarity to in vivo conditions. This allows performing studies in very controlled conditions that would be impossible in living specimens [4]. Tissue slices are advantageous as they conserve the cytoarchitecture of the tissue, maintaining thus the interactions between the cells and miming the brain environment. They can be used to study the bound and unbound amount of a compound incubated with the brain slice, allowing the study of transporter function [220]. In addition, immunohistochemistry (IHC) studies, in 
situ hybridation, mass-spectrometry imaging, or other studies can be performed to study molecular pathways and their modulation after compound administration for drug development [4,221].

Diverse strategies have been devised for the ex vivo study of the brain barriers separately. Isolated microvessels can be employed for the molecular characterization of the BBB and NVU [21, $22,95,168,222]$, used immediately for functionality studies [223-227], or cultured with specific media for a limited time [149]. Whole brains or specific sections (e.g., cortex) are homogenized either mechanically, employing a Potter-Evenheilm homogenizer $[115,161,228]$ by enzymatic dissociation with collagenases that partly degrade the basement membrane [146] or using both [229]; then, the microvessels (diameter $<10 \mu \mathrm{m}$ ) are separated from other cells using a density gradient and isolated from bigger vessels by sequential filtration on nylon meshes. Choroid plexus explants can be obtained by carefully dissecting the choroid plexus from the brain ventricles and immediately placing it in specialized media for functional studies of the BCSFB [230]. For instance, this has been employed to evaluate peptides for ligand-mediated targeting to $\mathrm{CP}$ epithelial cells as a strategy for CNS drug delivery [231,232]. Similarly, the BAB can be studied using meninges explants by carefully dissecting the meningeal layer, then separating the leptomeninges containing the arachnoid cells from the dura mater [34]. Furthermore, permeability assays can be performed using the whole meningeal layer in a diffusion chamber system [233] or a perfusion system [234].

\subsection{In Vivo Models and Assays}

In vivo assays are necessary to study drug delivery to the brain. Preclinical tests using animal models are necessary to study the pharmacokinetics and pharmacodynamics of new drugs and delivery strategies, as well as the processes driving their ADME, as required by drug validation agencies [130]. In the case of CNS therapeutics, the entry into the brain and its clearance are key factors for drug efficacy, and their ADME is governed by complex mechanisms that are not perfectly mimicked by in vitro or ex vivo models; in addition to that, other organs also interfere in their ADME $[5,6,8]$. The methods and conditions that can be used for the study of animal specimens are limited due to ethical and practical considerations, as well as due to the equipment availability and prices; therefore, in vivo experiments should be carefully planned, complying with the local regulations $[130,131]$.

Many animal models and techniques have been developed to obtain valuable information about drug ADME at the brain. Mouse and rat models are often used to characterize the brain barriers and study CNS drug delivery and ADME, but dog and non-human primates such as the as monkey and Rhesus macaque have also been employed. Similarly to in in vitro assays, inhibitors of the ABC transporters can be employed to evaluate their implication in the substance permeability or efflux by comparing with the uninhibited condition [5]. In addition, knock-out and knock-down models of one or more of the $\mathrm{ABC}$ transporters have been developed to evaluate their implication in the permeability and efflux of testing molecules [5,235]. It is important to remember that there can be molecular and physiological differences between species, such as expression levels, substrate specificity, and transport efficiency in the case of $A B C$ transporters (see Section 3.6). Therefore, models with humanized $\mathrm{ABC}$ transporters, as P-gp and BCRP, have been developed to better represent drug transport in humans [236-239]. Diverse techniques are used to evaluate the permeability of molecules into the brain and their clearance and obtain important ADME, toxicity, and PK-PD parameters (reviewed in $[5,6,8,133,240]$. Some of the most important will be summarized below.

In intravenous (IV) infusion, a labeled or unlabeled version of the studied compound is injected or infused (to maintain a steady level in plasma) and the concentration in plasma across the time and in a terminal brain sample is measured using, for instance, scintillation, LC-UV, or LC-MS, as well as imaging techniques (Section 4.7). The concentration versus time plot in plasma is used to calculate the area under the curve (AUC), and the concentration in the brain is corrected for residual intravascular tracer to estimate the amount entering the brain parenchyma [6].

In situ brain perfusion (ISBP) is an invasive method used on animals for the study of the compound's permeability through the BBB [241]. In this method, the animals are infused in a time 
and flow-controlled manner with a perfusate (bicarbonate buffer, plasma, or blood) via the carotid artery. The flow rate and composition of the perfusate can be modulated to study different kinetic parameters such as blood and brain concentration (i.e., permeability and clearance) or transport modulation [227,242-244].

\subsection{Imaging Methods}

Imaging methods allow the evaluation not only of pharmacokinetics parameters, but also of the specific distribution of drugs and their metabolites. Although they are mostly used for in vivo analyses, they can also be employed to study in vitro models. This includes nuclear imaging techniques that are non-invasive or minimally invasive such as positron emission tomography (PET), single photon emission computed tomography (SPECT), and magnetic resonance imaging (MRI); but also mass spectrometry (MS)-based imaging (MSI) that although is a destructive technique, its multiplexing capacity and spatial resolution can be exploited for preclinical studies. The nuclear imaging techniques for the study drug transporter function have been thoroughly reviewed recently [245]; thus, in this section, we will only address PET as an example, and then summarize MSI application to the study of drug delivery.

Positron emission tomography (PET) is a functional imaging technique used to study drug distribution in the body and the CNS and is increasingly being used in all stages of CNS drug development (reviewed in [245-248]). A molecule labeled with short half-life radioactive isotopes is administrated to an animal or human, and the positrons emitted by this tracer are detected and interpreted by the PET detector, allowing the study of compound's spatial distribution and its quantification in function of time [245,247]. Although PET depends on the availability or production of the radiolabeled analyte, it has the advantages of being a non-invasive technique that can provide dynamic data for in vitro, animal in vivo or human clinical analyses.

Radiolabeled substrates or inhibitors of the ABC transporters can be used to study their function, but one of the difficulties encountered is the need for specific probes due to overlapping substrate and inhibitor affinities (Section 3.2). [ ${ }^{11}$ C]erlotinib [249-251], [ ${ }^{11}$ C]elacridar [252-255], [ ${ }^{11}$ C]tariquidar [253,254,256,257], and [ ${ }^{11} \mathrm{C}$ ]temozolomide [258] have been used to trace the concomitant function of P-gp and BCRP in the brain. [ $\left.{ }^{11} \mathrm{C}\right]$ verapamil [259-262], [ $\left.{ }^{11} \mathrm{C}\right]$ loperamide, and [ $\left.{ }^{11} \mathrm{C}\right] \mathrm{N}$-desmethyl-loperamide [263-265] have been used to specifically visualize P-gp function because they are not transported by BCRP. To date, there is no specific PET tracer for BCRP, as the compounds developed as specific molecules, such as [ $\left.{ }^{67} \mathrm{Ga}\right]$ Galmydar, showed no significant difference between BCRP knockout and wild-type mice or rats [266-268], and it would not be ideal to substrate the specific activity of P-gp from that of a P-gp/BCRP common substrate, as their function is synergic and not additive [53,98]. Thus, other strategies have been proposed, such as the use of the P-gp/BCRP substrate $\left[{ }^{11} \mathrm{C}\right]$ tariquidar, which was coadministered with unlabeled tariquidar to inhibit P-gp at the BBB [256]. 6-bromo-7-[ $\left.{ }^{11} \mathrm{C}\right]$ methylpurine has been employed to specifically visualize MRP1 function in the brain, as it is transformed to its glutathione conjugate after passively crossing the BBB and then effluxed by MRP1 [269].

Among other applications, TEP has been used to asses P-gp and BCRP function and inhibition in mouse [238,253,270], rat [261,271], primate [250,264] and human [251,254] models; and it could be used for precision medicine through the evaluation of individual variability in response to CNS drugs [272]. In addition, diverse strategies have been developed to study for instance drug-drug interactions of unlabeled molecules in combination with already available tracers [246]. PET was recently employed to validate the permeability and transporter function of a human iPSCs BBB model [172] and the evaluation of ABC transporter-humanized mice models [238,270]. Importantly, it has been used to evaluate drug delivery strategies, such as inhibition [250,251] or focused ultrasounds [273] (see Section 6.5 for details).

Mass spectrometry-based imaging (MSI) can be used to assess the localization of small and large molecules in tissues and in vitro samples. Employing a mass spectrometer, molecules are desorbed from the sample and ionized using one of many techniques such as matrix-assisted laser desorption 
(MALDI) or desorption electrospray ionization (DESI). The ions are detected by MS in a position-specific manner, which allows the reconstruction of the distribution of one or hundreds of molecules, such as metabolites, lipids, peptides, or proteins, over the sample's surface. MSI has the advantage of allowing the location and even quantification of a large diversity of molecules in a single assay, including drugs and their metabolites, without the need for the labeled analyte, although the spiking of heavy stable isotope standards is preferred for quantification. Nevertheless, it is a destructive method that cannot be used for true in vivo imaging and needs method optimization depending on the characteristics of the searched analytes [274,275].

MSI can be used for the molecular characterization of proteins and small molecules of tissues or tumors [276-278], drug distribution, and BBB permeability [279] for pharmacokinetics and pharmacodynamics analyses [280] and is becoming a powerful tool for drug development. MALDI-MSI has been used to visualize drug penetration in brain tissue in an elegant strategy where the hemoglobin cofactor heme was used as a marker of brain and glioma vasculature [279]. They showed that RAF265 (CHIR-265), a small molecule inhibitor of the RAF serine/threonine protein kinases' permeability into the brain, is limited by the BBB. Using a spatial resolution of $25 \mu \mathrm{m}$, they were able to determine that RAF265 accumulated within the vascular lumen of intracranial tumor implants in mice, but did not cross the BBTB, which could not be resolved using PET. Both MALDI-MSI and DESI-MSI have been suggested as powerful tools for the rapid molecular diagnosis of human brain tumors by studying lipid [281-283] or protein signatures [284] in tumor biopsies; in addition, DESI-MSI has the advantage of needing minimal to null sample treatment, which could be used for intraoperative diagnosis and exploited for the development of precision medicine strategies [280].

\subsection{In Silico Models}

In silico models can be used to computationally predict the ADME of compounds during CNS drug development. Using mathematical modeling, the permeability of a molecule across the BBB, its distribution in the brain, the binding to its target and/or its clearance can be predicted based on the compound's physicochemical properties, allowing the screening of thousands of drug candidates using computer calculations [6,132]. Although it still needed to perform some experiments to feed the models or to confirm their results, this is considerably diminished, reducing this time and money-consuming step of drug development to fewer molecules with better pharmacokinetic and pharmacodynamic characteristics. In addition, there is a continuous work in developing more accurate and faster algorithms as tools for drug screening and many exist today, as has been reviewed previously [4,6,285]; thus, some of the most important will be explained below.

Some models are based on physicochemical properties as the lipophilicity [286] or quantitative structure-property relationships (QSPR) [287] to predict the BBB permeability and brain distribution of compounds [285]. Artificial intelligence (AI) models [288], such as machine learning, have been employed to predict the BBB permeability represented as unbound brain to a plasma concentration ratio of small molecules [289] or even peptides [290]. Machine learning uses a training dataset with known parameters to predict those parameters of an unknown dataset employing linear regression or more complex algorithms such as artificial neural networks. For instance, the QSPRs of diverse molecules with known physicochemical properties and permeability can be used to predict the permeability of a larger group of new untested molecules [289,290].

In physiologically based pharmacokinetic (PBPK) models, in silico predictions or experimental data from in vitro or in vivo studies are used as input parameters in an algorithm to predict the time-dependent distribution of the molecule between compartments (fluid chambers, tissues, or groups of tissues with similar characteristics) [291,292]. This compartment-based approach allows taking into account physiologically meaningful parameters such as tissue volumes and blood flows in addition to drug-specific biochemical parameters such as the transport mechanisms and enzymatic metabolism [293,294]. 
In in vitro to in vivo extrapolation (IVIVE), in vivo drug transport, or metabolism is predicted from data obtained in vitro, using correction parameters such as the relative expression factor (REF) and relative activity factors (RAF). This allows a reduction of the number of assays using animals, by employing data acquired with cultured cells [126,295,296].

\subsection{Recent Molecular Characterization Techniques}

Although the mechanisms underlaying the brain barriers phenotypes and function have not been completely elucidated, there has been continuous work for their molecular characterization in health disease and in response to drugs, using a broad range of methods. Classical technologies have been largely used for this purpose, including RT-qPCR, Western blot, IHC, and in situ hybridization. Nevertheless, the advent of new "omics" technologies has allowed a broader and deeper understanding of the blood-brain interfaces and their role in drug delivery; including diverse transcriptomics and proteomics of brain microvessels, as well as cell-specific studies [64,65,85,297-300]. In addition, in vitro models and NVU-on-chip systems have been characterized using transcriptomics, proteomics, and metabolomics allowing not only the validation of the models, but also improving our knowledge on the interactions between brain cells $[22,188,189,207,208]$. Large-scale programs as the Human Protein Atlas [68] are also an important tool for the study of protein expression in the brain, cancer, and cultured cells. Altogether, new and classic technologies help the scientific community to obtain a broader understanding of brain cancer and its drug resistance in order to develop better treatment and drug delivery strategies.

Proteomics is a powerful tool used to study dynamic protein expression and their regulation, mainly using MS. Diverse strategies have been used for this purpose, as the work performed by the team of Professor Karamanos using 2D-gel electrophoresis and MS protein identification (reviewed in [301]). Nevertheless, membrane proteins such as ABC transporters are difficult to detect by this method due to their physicochemical properties and low abundance. Targeted liquid chromatography coupled to tandem mass spectrometry (LC-MS/MS) analysis of digested proteins gives the sensitivity need for the quantification of ABC transporters, SLCs, and CYPs450 [94,297,302,303]. Furthermore, using stable-isotope labeled standards [304], protein abundance can be reported in non-arbitrary units as fmol of molecule per $\mu \mathrm{g}$ of total protein with high accuracy, precision, and selectivity [303]. The results of this absolute quantification can be used to study transporter expression modulation due to diseases or drug exposure [223], interspecies [93], or even human interindividual variability [305]; besides, results have been used to calculate the relative expression factors (REF) for IVIVE [126,295] and PBPK modeling (see [306] for recommendations). In addition, the specificity of these methods has been exploited to characterize and validate murine models with humanized ABC transporters [236-238,270].

\subsection{Conclusion on Methods to Study the Blood-Brain Interfaces}

Diverse in vitro, in vivo and in silico models have helped us to study the implication of $A B C$ transporters in drug resistance, and they are needed for the development and validation of new drugs and delivery strategies to treat CNS diseases. Gliomas are brain cancers that represent a particular challenge as they are highly disabling for the patients and are often recursive, causing high mortality rates $[9,10]$. This is partly due to the multidrug resistance of cancerous cells and the difficulty of delivering chemotherapeutics to the brain, both being highly related with the efflux by $\mathrm{ABC}$ transporters, as will be explained in the next section.

\section{Implication of ABC Transporters in the Multidrug Resistance of Glioma}

Cancers of the central nervous system (CNS), and particularly gliomas, represent a worldwide problem for healthcare because of its high morbidity and mortality. Patients of CNS cancers become highly disabled by the disease, treatments are expensive, and prognosis is low, due to the tumor's aggressiveness and resistance to multiple chemotherapeutic drugs [9,10]. Importantly, the blood-brain tumor barrier (BBTB) can be disrupted in glioblastomas, but glioma cells can invade zones with intact 
barrier function [307]. Additionally, lower grade gliomas can present a BBTB similar to the BBB and even an increased barrier function, hindering the entry of therapeutics [14,16]. In this section, we will briefly introduce the pathology of glioma and summarize the implication of the blood-brain interfaces in drug resistance, particularly the role of $A B C$ transporters, and some strategies to study and improve anticancer drug transport and delivery.

\subsection{Glioma Classification}

Gliomas are brain tumors originated from astrocytes, oligodendrocytes, or ependymal cells. According to the World Health Organization (WHO) Classification of Tumors of the Nervous System, gliomas are classified by their histology and molecular features, in addition to their grade of malignancy (from grade I to grade IV) [10,11]. Grade I gliomas are benign tumors; the cells look almost normal in microscopy, they grow slowly, they are compartmentalized, and surgery alone may be enough for their treatment. Grade II (low grade diffuse glioma) tumors are slow growing, with an abnormal phenotype, and some can diffuse to nearby normal tissue, which can lead to recurrence after surgery. Grade III (malignant/anaplastic diffuse glioma) tumors are malignant, the cells reproduce at abnormal rates and diffuse into nearby normal brain tissue; they can evolve into grade IV tumors. Grade IV tumors present abnormal cells, reproduce rapidly, may be resistant to apoptosis; these often diffuse into the surrounding normal brain tissue and have angiogenic capacities to maintain the blood supply and support the rapid growth. They also may present necrotic zones in the interior. The most common example of a grade IV tumor is the glioblastoma multiforme (GBM) that is characterized by a very low rate/time of survival [11]. GBMs are subdivided in primary GBM, which are originated de novo, and secondary GBM, which displays evidence of progression from a lower-grade tumor. Primary GBMs are more frequent, representing around $95 \%$ of the diagnosed cases $[9,308]$.

Gliomas are subclassified in diverse groups with different histologic and molecular characteristics. Historically, gliomas have been grouped mainly by histologic studies [11], but the most recent WHO classification $[10,13$ ] includes molecular diagnostic criteria that can be important for treatment and prognosis, such as the analysis of isocitrate dehydrogenase (IDH) mutation, histone mutations, and chromosome $1 \mathrm{p} / 19 \mathrm{q}$ deletion. For instance, (IDH) mutation generates proteins that metabolize $\alpha$-ketoglutarate into 2-hydroxyglutarate (2HG), which is a possible oncometabolite [309]. Mutated IDH has been detected in many low-grade gliomas (mainly astrocytomas and oligodendrogliomas) and secondary GBMs, but only in some primary GBMs [13,310,311], and it has been related with a better progression-free survival than IDH wild-type gliomas [312]. This has driven to the development of methods to diagnose IDH mutation status before biopsy using magnetic resonance spectroscopy [313] and strategies to target IDH using inhibitors and targeted vaccines [314]. Thus, it is important to consider genomic, epigenomic, and proteomic markers for the classification and subclassification of gliomas, not only for the diagnostic, but also for the treatment and prognosis of patients.

\subsection{Epidemiology and Prognosis}

Gliomas are the prevailing category of CNS cancers, whose incidence rate has increased in the last decades [9,315]. Gliomas represent more than 77\% of the brain neoplasms diagnosed globally [315,316], and according to the Global Burden of Disease Study, 330,000 (with 95\% uncertainty intervals [95\% UI] 299,000 to 349,000 ) new cases of primary malignant brain tumors were diagnosed in 2016 . This study reported a significant increase of $17.3 \%$ in the global age-standardized incidence rate between 1990 and 2016 [9], growing in almost all geographical regions (except for eastern Europe) and Socio-demographic Index (SDI) quintiles.

The prognosis of glioma patients depends on several factors, including the grade and subtype, age at diagnosis, extent of tumor resection, and the Karnofsky performance status (KPS) [316-318]. The five-year survival rate in several regions including US, Korea, and Europe has been reviewed previously by Ostrom et al. (2014) [316]. In general, gliomas with the oligodendroglial phenotype have a greater survival rate than astrocytic gliomas. Grade I astrocytomas (pilocytic astrocytomas) can be 
treated by surgical resection and have the highest rate of survival. Prognosis for grade II gliomas is relatively good, with $47.8 \%$ to $79.1 \%$ of the oligodendrogliomas patients surviving for five years and $28 \%$ to $51.6 \%$ surviving for five years in the case of astrocytomas. Nevertheless, grade II gliomas can be infiltrative, become more malignant due to genetic alterations, and evolve to grade III (anaplastic gliomas) [318]. Grade III gliomas present a reduced prognosis, with a five-year survival inferior to $50 \%$ for anaplastic oligodendrogliomas and inferior to 30\% for anaplastic astrocytoma. GBM is the most aggressive type and less than $5 \%$ of patients survive for more than five years after diagnosis, despite the implementation of different therapies (e.g., chemotherapy, irradiation, etc.) [316,317,319].

\subsection{Multidrug Resistance in Glioma and the Blood-Brain Tumor Barrier (BBTB)}

Gliomas are normally treated by surgically extracting the tumor as full as possible, which is difficult for infiltrating tumors, followed by radiotherapy. Systemic chemotherapy can be used for patients with progressive disease or high grade gliomas (e.g., GBM), but its efficacy is often poor because most of the brain tumors are resistant to multiple structurally unrelated classes of anticancer drugs $[12,14,16]$. Thus, none of the treatments currently available is curative, and the prognosis in high grade gliomas is very low [316,317,319].

The mechanisms of multidrug resistance in cancer cells are multifactorial and have not been completely elucidated. The tumors' drug resistance can be improved due to genetic and epigenetic alterations, the up- or down-regulation of genes, and changes in the post-translational regulation of protein activity $[12,14,16,320]$. These mechanisms can include an increased drug efflux due to the presence and possible up-regulation of drug efflux transporters such as ABC transporters [16] and some members of the SLC superfamily [14,108,121]. In addition, a reduced uptake without increased efflux has also been observed, as in the case of the antifolate methotrexate [321]. Detoxifying systems such as drug metabolizing enzymes such as CYPs450 can convert the anticancer drug to less toxic metabolites [309,322]. The down-regulation of apoptotic pathways, either as a result of the malignant transformation (e.g., p53 mutations [323]) or during exposure to chemotherapy such as the alteration of ceramide levels [324]; additionally, modifications in the cell-cycle machinery or DNA repairing mechanisms can prevent apoptosis [325]. This multidrug resistance leads to poor treatment efficiency, cancer relapse, and eventually death $[16,316,317,326]$. In addition to these mechanisms, drug distribution to brain tumors is often hampered by the natural barriers protecting the brain [14].

The blood-brain tumor barrier (BBTB) is formed by vascular capillaries with altered barrier function. Each tumor case is different, presenting its own morphological and physiological characteristics both in the cancer and endothelial cells. Normally, low-grade gliomas show a normal vascularization where the BBB remains mostly intact, although some molecular changes can occur, such as transporter expression modulation [327]. High-grade gliomas present more alterations, including an increased vascularization $[307,328]$ with heterogeneous undisrupted and disrupted leaky zones that allow the exchange of big molecules as proteins and even cells, which can lead to cancer metastasis [329]. The levels of $\mathrm{ABC}$ transporters normally expressed at the BBB can be up-regulated at the BBTB, and $\mathrm{ABC}$ transporters can also be expressed in non-vascular tumor cells, improving their defense against chemotherapeutics (Section 5.4) [14,16,108,121,325,326]. In summary, both the BBB and the BBTB represent major obstacles for anticancer drug delivery in low and high-grade glioma [14].

The BBTB is heterogeneous and can present leaky zones but still forms a barrier against drug penetration into the tumor. It is often assumed that the BBTB is completely disrupted; thus, its barrier function is often neglected during GBM drug design [329,330], but there are increasing clinical evidences showing that all the GBM present tumor zones with intact BBB, hindering drug permeability into the tumor (reviewed in [330]). This is supported by diverse murine studies showing a low drug penetration into tumors of xenografted mice [331-333] and PDGF-B-driven brainstem glioma models [334], due to ABC transporters P-gp and Bcrp [333,334]. In addition, a recent study using 3D-MSI showed a higher but non-homogeneous accumulation of erlotinib in the GBM tumors of 
xenografted mice than in brain parenchyma, proving that the BBTB is heterogeneously disrupted across the tumor [335].

\subsection{ABC Transporters Role in Glioma Drug Resistance}

The expression of $\mathrm{ABC}$ transporters in cancer cells and the BBB/BBTB has been directly related to chemoresistance against several of their anticancer drug substrates $[42,52,53,56,336]$. The presence of $\mathrm{ABC}$ transporters in both the BBTB and the tumor cancer cells indicate a multibarrier system defending the cancer cells from chemotherapeutics, coupled to detoxifying systems and the anti-apoptotic machinery. ABCB1/P-gp, ABCG2/BCRP, ABCC1/MRP1, ABCC4/MRP4, and ABCC5/MRP5 [14,16,104] up-regulation has been observed in glioma cells at the mRNA and/or protein level (Table 3); moreover, MRP3 de novo protein expression has also been detected in high grade gliomas (detailed below) [16,337]. This can lead to resistance to their multiple chemotherapeutic substrates (Table 2), as it has been proven for doxorubicin, vincristine, etoposide, camptothecin, topotecan, methotrexate, sunitinib, imatinib mesylate (Gleevec), and palbociclib [16,104,106,108,333,338-340]. Furthermore, their expression is heterogenous even between tumors of the same class and grade and can be further enhanced after drug administration, as it has been observed for doxorubicin [107,340,341], which is a common substrate of P-gp, BCRP, MRP1, MRP2, MRP3 and MRP6; this complicates the development precise strategies against the tumor.

Table 3. ABC transporters expression in human brain tumors the brain and gliomas.

\begin{tabular}{cc}
\hline Gene; Protein & Location in Human BRAIN Tumors \\
\hline $\begin{array}{c}\text { ABCB1; } \\
\text { P-gp/MDR1 }\end{array}$ & $\begin{array}{c}\text { Tumor capillaries; schwannomas, gangliogliomas, meningiomas, low-grade } \\
\text { gliomas (astrocytomas, pilocytic astrocytomas) and high-grade gliomas } \\
\text { (glioblastoma multiforme (GBM), anaplastic astrocytomas and anaplastic } \\
\text { oligodendrogliomas) }\end{array}$ \\
\hline $\begin{array}{c}\text { ABBC1; } \\
\text { MRP1 }\end{array}$ & Tumor capillaries, glioma cells, neuronal components of gangliosomas \\
\hline $\begin{array}{c}\text { ABCC2; } \\
\text { MRP2 }\end{array}$ & ND \\
\hline $\begin{array}{c}\text { ABCC3; } \\
\text { MRP3 }\end{array}$ & Anaplastic astrocytomas (grade III), GBM; cultured cancer and ECs from GBM \\
\hline $\begin{array}{c}\text { ABBC4; } \\
\text { MRP4 }\end{array}$ & Tumor capillaries; astrocytic tumors; and astrocytic portions of oligoastrocytomas \\
\hline $\begin{array}{c}\text { ABBC5; } \\
\text { MRP5 }\end{array}$ & Tumor capillaries; astrocytic tumors; and astrocytic portions of oligoastrocytomas \\
\hline $\begin{array}{c}\text { ABCC6; } \\
\text { MRP6 }\end{array}$ & Tumor capillaries; ND in glioma cells in situ \\
\hline $\begin{array}{c}\text { ABCG2; } \\
\text { BCRP }\end{array}$ & NAn \\
\hline
\end{tabular}

ECs: endothelial cells; ND: Not detected; NAn: not analyzed/no data available.

Multiple studies have proven the de novo expression of MRP3 in gliomas. In 2000, Loging et al. found an overexpression of the ABCC3 gene in a GBM gene expression database [342]. The MRP3 protein expression in tumor samples from high-grade glioma patients was confirmed using IHC by the studies of Haga et al. (2001) [343] and Calatozzolo et al. (2005) [15], as well as in GBM cell lines by our laboratory in 2002 [337]. In 2010, Kuan et al. detected MRP3 expression by rRT-qPCR, IHC. Western blot and FACS analyzes in 90\% of GBM samples analyzed [344]. In a recent meta-study, Wang et al. (2016) observed high ABCC3 mRNA levels in GBM patients compared to normal counterparts and validated these results in GBM cell lines by RT-PCR [345]. Furthermore, in both studies, the MRP3 
mRNA correlated with a higher risk of death of the GBM patients [344,345]. These results indicate that MRP3 could be used as a prognosis prediction factor.

Most tumors express $A B C B 1 / \mathrm{P}-g \mathrm{p}$ in high levels [346], including schwannomas, meningiomas, low-grade gliomas (astrocytomas, pilocytic astrocytomas), and high-grade gliomas (GBMs, anaplastic astrocytomas, and anaplastic oligodendrogliomas) [66,346]. BCRP is often detected in the capillaries from brain tumors, but not in the surrounding tumor cells $[79,80]$. ABCB1 is the most studied $A B C$ transporter and the principal target for transporter inhibition treatment, with the aim of increasing drug delivery [14]. Nevertheless, the importance of other multidrug-resistance related transporters has been highlighted during the last two decades.

ABCC1/MRP1 overexpression has been observed in several types of glioma, including GBMs, GBMs with an oligodendroglial component (GBMO) [347], anaplastic astrocytomas (grade III) [343], and meningiomas [66]. Similarly, $A B C C 3 / \mathrm{MRP} 3$ has been observed in high-grade gliomas such as anaplastic astrocytomas (grade III), GBM [15,343,344]. ABCC4 and ABCC5 mRNA overexpression and immunostaining has been observed in the glioma cells of astrocytic tumors and in the astrocytic portions of oligoastrocytomas [121]. This indicates that the expression of $A B C C 4$ and ABCC5 may be associated with an astrocytic phenotype, which is probably due to its constitutive expression in astrocytes [46]. Calatozzolo et al. (2005) showed a higher expression of ABC transporters in high-grade than in in low-grade glioma using IHC. The high-grade glioma samples showed significantly higher levels of $A B C C 3 / \mathrm{MRP} 3$ and $A B C B 1 / \mathrm{P}$-gp in the endothelial cells, but higher levels of $A B C C 1 / \mathrm{MRP} 1$, $A B C C 3 / \mathrm{MRP} 3$ and $A B C C 5 / \mathrm{MRP5}$ [15].

Results from in vitro analysis should be carefully designed and evaluated. Interspecies differences in $A B C$ transporters can be observed (Section 3.6), but culture-derived expression can be observed also. For instance, some glioma-derived cells resistant to anticancer drugs have shown to overexpress MRP2; nevertheless, MRP2 has not been detected in healthy brain or in glioma tumors neither in the mRNA nor protein level [129].

Study of ABC transporters could lead to personalized medicine strategies. It has been observed that gliomas and its surrounding tissue can present overexpression and even the de novo expression of ABC transporters $[14,16,41,42,104]$, but they are not considered as markers for their subclassification, because there is a high variability in this phenomena, even when the same type and grade of glioma are compared [15,348]. Nevertheless, evaluation of the transporter's expression or activity from biopsy or noninvasive methods (such as PET) could be used to devise personalized strategies for chemotherapies, such as the inhibition of $\mathrm{ABC}$ transporters (Section 6) [41].

\subsection{Glioma Models to Study Drug Transport and Delivery}

Drug permeability and delivery to gliomas, as well as the characteristics of the BBTB can be studied using similar methods as those described in Section 4 . Some of the cancer or glioma-specific models will be briefly summarized below.

There are few in vitro models mimicking the BBTB, where the interaction of tumor cells with barrier cells can have an important impact on their function. In the specific case of gliomas, it is important to consider that the BBB and other brain barriers can be disrupted (especially in high-grade gliomas) and present a metabolic imbalance and different protein expression, as explained in Section 5.4, due to the influence of the nearby cancer cells $[14,349,350]$. There have been some attempts to develop BBTB models with a coculture of endothelial cells in the upper chamber of a Transwell and cancer cells in the lower chamber [350-353]. Recently, a microfluidic model was developed using human umbilical vein endothelial cells (HUVEC) and astrocytes to model the BBB or brain metastases cells to model the BBTB [354]. Comparing these models, they showed that metastases cells caused a disruption of the barrier phenotype at the BBTB, while conserving the transporter function, as observed by the P-gp efflux of accumulation of its substrate Rhodamine 123 in the luminal chamber, similarly to in vivo observations. These models can be key tools for the study of drug delivery to glioma cells across the $\mathrm{BBB}$ and the BBTB. 
Anticancer drugs are often tested in vivo using xenograft animals or genetically engineered murine models (reviewed in $[235,355]$ ). Xenograft models are obtained by injecting with primary tumor cells or immortalized cell lines either subcutaneously or into the site of the original tumor (orthotopically) into immunocompetent or immunonaive mice or rats. This approach can be implemented easily and at relative low cost. Nevertheless, the generated tumor can misrepresent the cellular and molecular characteristics of the original tumor, due to mutations during cell passing, differences in the microenvironment of the transplanted tumor, or issues concerning the perturbed stromal setting of the immunodeficient murine host [235,356]. More recently, several distinct murine models of medulloblastoma and glioma (both oligodendroglial and astrocytic) have been developed by including into the mouse genome one or more genetic alterations previously reported to be related with the tumor formation such as mutations in the Nf1, p53 [357], kRas [358], PDGF-B [359], and GFAP [360] genes (reviewed in [235]).

Ex vivo models for the study of drugs in glioma can be obtained from dissected tumors from human patients, xenografted, or genetically modified animals to mimic the pathological conditions. As discussed in Section 4.4, tissue slices, isolated microvessels, or explants of the CP or BAB can be used for functional, physiological, drug delivery, and permeability studies, as well as for biomarkers screening [361-365].

\subsection{Conclusion on the Implication of ABC Transporters in the Multidrug Resistance of Glioma}

$\mathrm{ABC}$ transporters expressed in the blood-brain interfaces, the BBTB, and cancerous cells represent a selective barrier hindering the delivery of chemotherapeutics to gliomas and contribute importantly to their multidrug resistance, which is one of the causes of their high morbidity and mortality. In addition, the molecular heterogeneity between different grades of glioma, between patients, and even in tumor regions of a same individual, further complicate their treatment. Therefore, there have been many efforts to overcome the ABC-mediated multidrug resistance of gliomas and improve the treatment of brain cancers. Some important examples of these methodologies will be summarized in the next section.

\section{Strategies to Improve CNS Drug Delivery in Brain Cancer}

Diverse strategies have been devised to improve drug delivery into the brain for the treatment of CNS diseases (reviewed in $[18,41,366]$ ) and in the particular case of brain tumors (reviewed in [14,367-369]). Most of them have been concentrated in overcoming the BBB to obtain enough drug concentration for a pharmacological effect (Figure 4A). The modulation of the function or expression of $\mathrm{ABC}$ transporters showed promising results in preclinical studies, but it is not used in clinical due to systemic toxicity. Therefore, other methodologies have been developed, such as rationally designed drugs that are not ABC substrates; bypassing the BBB by locally delivering the drugs into the brain parenchyma and tumors; disrupting the BBB to allow the entry of chemotherapeutics; or using nanocarriers to take advantage of other transport pathways at the BBB and even target the brain or tumors. It is important to highlight that the $A B C$ transporters can provoke the rapid clearance of drugs despite their local delivery, the disruption of the BBB tight junctions, or after drug release from nanoparticles; avoiding the chemotherapeutic to accumulate into the cancerous cells. However, interestingly, some strategies combining the use of $\mathrm{ABC}$ inhibitors have shown positive results.

\subsection{Inhibition of $A B C$ Transporters}

As previously mentioned, many chemotherapeutics are effluxed by ABC transporters (Table 1; Figure $4 \mathrm{~B}(\mathrm{a})$ ), which are major actors of the multidrug resistance phenotype of glioma and other cancers. Therefore, there have been many efforts to improve tumor drug delivery by using competitive or non-competitive inhibitors (Figure $4 \mathrm{~B}(\mathrm{~b}, \mathrm{c})$ ), and many P-gp and BCRP inhibitors have been clinically evaluated for their use as adjuvants on chemotherapy to treat non-brain tumors, including valspodar, dexverapamil, tariquidar, biricodar, and elacridar; as well as indirect inhibition by anti-P-gp monoclonal antibodies $[14,41,106]$. Their use to overcome the BBB has also been evaluated in animals and humans 
(further explained in [41,57]). For instance, higher brain accumulation of erlotinib was observed when it was coadministered with elacridar to rats [273] and in a rat xenograft model of glioma [331]. In a clinical study on healthy volunteers, the penetration of ${ }^{11} \mathrm{C}$-verapamil was enhanced when coadministered with cyclosporine A [262]. However, the inhibition of ABC transporters has not been translated to clinical application due to adverse effects observed, including the cardiovascular toxicity of first-generation inhibitors [370,371] and pharmacokinetics interactions with the chemotherapeutic (e.g., the inhibition of CYPs450) leading to increased systemic cytotoxicity. In addition, many modulators inhibit more than one ABC transporter, such as elacridar and tariquidar that inhibit both P-gp and BCRP [372], which can result in other adverse effects such as the accumulation of toxic substances in brain, kidneys, liver, and other tissues.
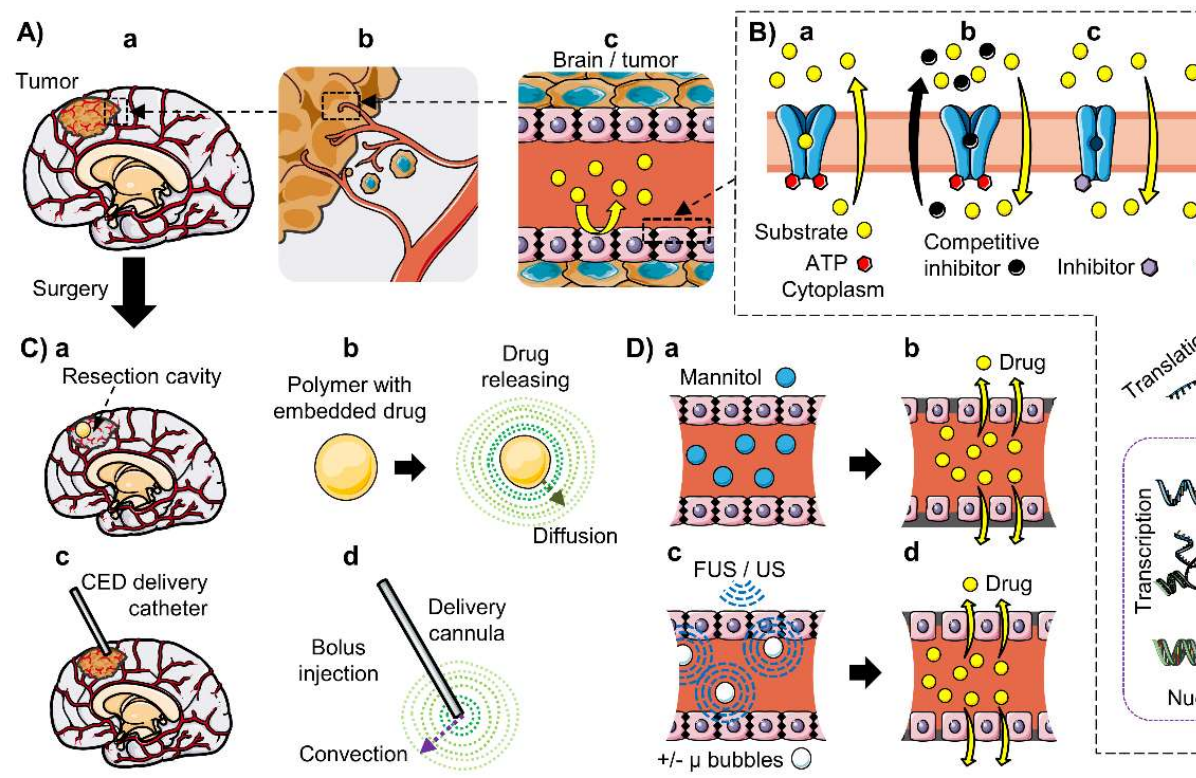

$$
\text { D) }
$$
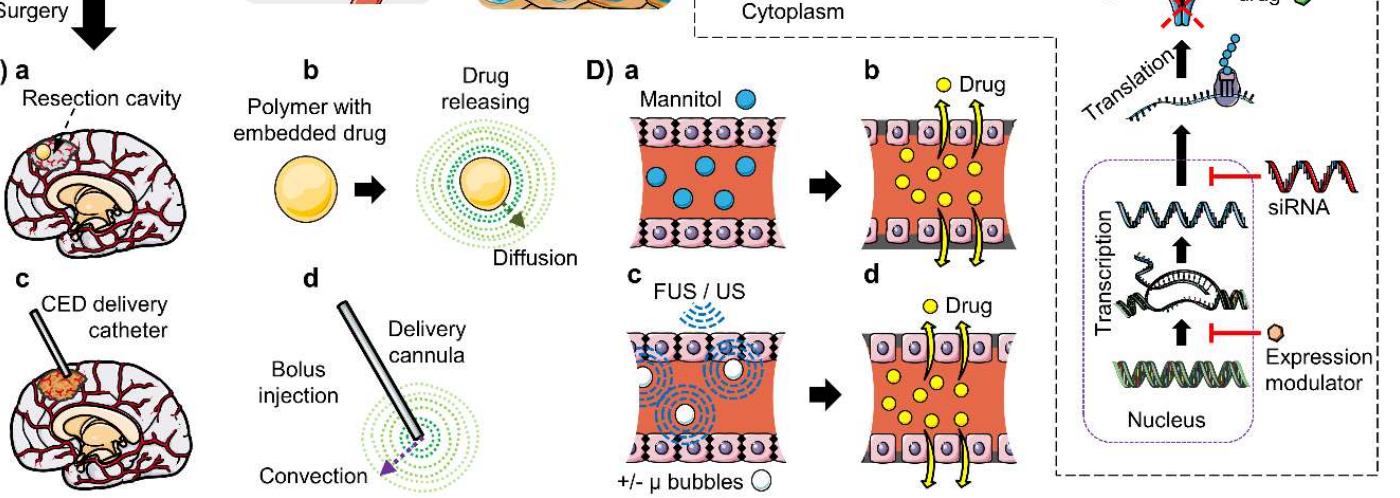

Figure 4. Schemas of some of the main drug delivery strategies to overcome the blood-brain barrier (BBB) and the blood-brain tumor barrier (BBTB) to treat glioma with chemotherapeutics. (A) (a) Brain gliomas may be extensively blood irrigated, (b) and infiltrative cells may spread to the vascularized parenchyma; (c) therefore, drug delivery is strongly restricted by the BBB and the BBTB. Diverse drug delivery strategies have been developed, for instance: (B) Modulation of the ABC transporters, (a) which are responsible for the brain to blood efflux of many xenobiotics, whose activity can be tuned by (b) competitive or (c) non-competitive inhibitors, or (d) their expression may be downregulated using siRNA or other expression modulators; (e) in addition, non-ABC substrates can be discovered among natural products or developed using rational design. (C) The BBB may be bypassed by the local delivery of chemotherapeutics; ( $\mathbf{a}$ and $\mathbf{b}$ ) after surgery, polymers containing an embedded drug can be implanted, (b) which slowly release the compound that spread by diffusion; (c) a catheter can be implanted to (d) allow the localized delivery of a chemotherapeutic compound that spread by convection. (D) BBB disruption can be provoked: (a) through osmotic disruption using a hyperosmotic product such as mannitol, (b) causing the shrinking of the endothelial cells and the opening of the BBB; (c) or through focused or unfocused ultrasounds (FUS/US) that may be aided by micro bubbles, (d) whose vibration breaks the tight junctions (black rhombus $\downarrow$ ) and allows the entry of the drug. Created using images from "smart Servier Medical Art", Creative Commons License, 2019.

Although the inhibition of $\mathrm{ABC}$ transporters itself has not proven efficiency for the clinical delivery of drugs, they have been a key resource to deepen our knowledge of the function of ABC transporters, and the multidrug resistance in cancer, glioma, and other CNS pathologies, as well as their implications in the blood-brain interfaces. As previously mentioned, (Section 4.1, Section 4.6, and Section 4.7), ABC modulators have been employed to study the function of $\mathrm{ABC}$ transporters in vitro, in animals and in humans. They can be co-administered with drugs to evaluate if their BBB permeability is restricted by 
ABC transporters, to image the transporters' function [262], or to evaluate their substrate or inhibitor interactions with ABC transporters [130], and new inhibitors are continuously under development. Furthermore, promising results have been observed when combined with other strategies for bypassing the BBB such as convection enhanced delivery [373] (Section 6.4) and nanoparticles or targeting nanocarriers (Section 6.6) [374]. Therefore, it is worthwhile to summarize them in this section.

Many efforts have focused on the development P-gp inhibitors due to its high expression at diverse barriers of the body barriers and because it was the first ABC transporter to be associated with multidrug resistance (Section 3.2), resulting in three generations of P-gp inhibitors [41]. The first generation was composed mainly of repurposed drugs, such as verapamil, cyclosporine $\mathrm{A}$, and tamoxifen. These acted as competitive inhibitors (Figure $4 \mathrm{~B}(\mathrm{~b})$ ), requiring the administration of high doses [375] and thus leading to cardiovascular toxicity in vivo [370,371] and pharmacokinetics interactions between the chemotherapeutic and the modulator [370]. Second-generation modulators were developed by modifying the structure of first-generation molecules to improve specificity and potency, achieving reduced systemic toxicity, including dexverapamil, biricodar citrate (VX-70), dexniguldipine, and valspodar (PSC-833). Some of these molecules arrived at clinical trials, such as the cyclosporine D derivative valspodar (PSC-833), which inhibits P-gp 10-20 times more than cyclosporine-A. Nevertheless, it was observed that these chemosensitizers could also inhibit CYPs450 enzymes, inducing the higher toxicity of the coadministered agents in other tissues and cells [41]. Then, third-generation P-gp modulators were designed using the structure-activity relationship and combinatorial chemistry, achieving a 300-fold improvement in inhibition potency with an effective function at the nanomolar range while minimizing pharmacokinetic interactions due to a reduced cross-inhibition of other ABC transporters and CYPs450. This group includes tariquidar (XR-9576), elacridar (F12091), laniquidar (R101933), zosuquidar (LY.336979), and diarulimidazole (ONT-093). For instance, tariquidar showed an improved permeation of sunitinib, sorafenib, dasatinib, or temozolomide and veliparib [14].

BCRP and the MRPs can be inhibited by P-gp modulators or specific inhibitors. For instance, the structurally related P-gp inhibitors elacridar and tariquidar are also BCRP inhibitors [372]. BCRP-specific inhibitors contain more nitrogen atoms and aromatic moieties than those shared with P-gp [53] and include, for instance, natural substances as fumitremorgin C (FTC) [376] and its less toxic and more active tetracyclic analog Ko143 [377]. Interestingly, tyrosine kinase inhibitors such as gefitinib, erlotinib, and imatinib (Gleevec) can block the ATPase activity of BCRP, while also having a chemotherapeutic effect [378], and they could be used as both inhibitors and effectors. The MRP family also presents specific inhibitors. For instance, MRP1-3 are inhibited by several non-nucleoside and nucleoside reverse transcriptase inhibitors used as anti-HIV-drugs, but specially tenofovir, delavirdine, efavirenz, and emtricitabine [379]. MRP4 is inhibited by the anti-inflammatory molecules celecoxib and diclofenac, while MRP5 function is altered by phosphodiesterase inhibitors zaprinast and trequinsin [112,380].

\subsection{Other Modulators of ABC Transporter-Dependent Multidrug Resistance}

Another strategy to modulate $\mathrm{ABC}$ function that is being investigated in vitro and in vivo, but still not in clinical assays, is the downregulation of their expression using either small xenobiotics, natural products or small interfering RNAs (siRNAs) (Figure 4B(d)). For instance, Tanshinon II-A from Salvia miltiorrhiza downregulated the expression of P-gP, MRP1, and BCRP in dox-resistant breast cancer cells (MCF/dox), improving Dox sensitivity [381]. Recently, it was reported that Fasudil (HA-1077), an inhibitor of Rho-associated protein kinases (ROCKs) used in China and Japan for the treatment of cerebral vasospam, increases the temozolomide (TMZ) sensitivity of TMZ-resistant gliomas in vitro and in xenografted mouse and rat by suppressing the expression of BCRP through the ROCK2/moesin/ $\beta$-catenin pathway [382]. Recently, siRNAs have emerged as tools to selectively downregulate protein expression using a double-stranded RNA of between 21 and 28 nucleotides that selectively blocks and induces the degradation of a specific mRNA [383]. It has been observed 
that blocking $A B C B 1$ or $A B C G 2$ with the specific exogenous siRNAs can reverse multidrug resistance in diverse cancer cells [384,385]; even more, the concomitant application of both siRNAs using a nanoparticle-facilitated delivery showed a synergic effect in breast cancer cells [386].

Other natural products and xenobiotics have shown to diminish the multidrug resistance phenotype, although the modulation mechanism (inhibition or expression) has not been elucidated for all of them, such as polyphenols, flavonoids, and stilbenes from Chinese plant extracts [387]. Furthermore, trabedectedin, halaven, and cytarabine reverse multidrug resistance and have been recently accepted for clinical use [388,389]. Interestingly, JL-17 presents a higher inhibition of P-gp than verapamil, increasing anticancer drug accumulation in K562/A02 cells [390]. These molecules have not been tested in the case of glioma drug delivery, but they could be an interesting alternative.

\subsection{Rational Drug Design}

Rational drug design to obtain BBB-permeable molecules can achieve improved efficacy (Figure 4B(e)). Using in silico tools (Section 4.8), existing drugs can be improved, or chemical libraries can be screened, to obtain molecules that are able to pass through the BBB $[289,290,391]$. For instance, Salphati et al. used a central nervous system multiparameter optimization (CNS-MPO) model to improve the physiochemical properties of PI3K inhibitors and developed two molecules, GNE-317 and GDC-0084, with improved BBB penetration and tumor distribution and growth inhibition in xenograft mice [392-394]. Although a later study did not observe an improved survival in a murine glioma model compared to GDC-0980, a PI3K inhibitor with low brain penetrance [395], GDC-0084 is currently in phase II clinical trials for newly diagnosed GBM (ID NCT03522298 [396]).

\subsection{Local Delivery: Polymeric Drug Delivery Systems and Convection-Enhanced Delivery}

Other methodologies have been devised to locally deliver chemotherapeutics into the brain parenchyma or the tumor aiming to bypass the $\mathrm{BBB}$, avoiding the need to overcome the $\mathrm{ABC}$ transporters acting as gatekeepers and diminish the systemic toxicity (Figure 4C). These methodologies depend on the effective diffusion of the compound through the tumor; thus, lipophilic molecules that can passively enter the tumor cell membranes are used. Nevertheless, although they are still subject to the CNS clearance mechanisms, the drugs can be rapidly ejected into the bloodstream by the BMVEC through passive transport or active efflux, significantly reducing the volume of distribution of the molecules in the brain [367].

Polymeric drug delivery systems containing a chemotherapeutic molecule can be implanted during surgery and locally release the drug for a prolonged time (Figure $4 \mathrm{C}(\mathrm{a}, \mathrm{b})$ ). Biodegradable hydrophobic polymers that slowly degrade after placement into the brain are used to release the embedded drug in a nearly constant rate (reviewed in [397]). Gliadel wafers are small implantable polymer wafers that are placed into the tumor-resection cavity and locally deliver over several days or weeks the encased carmustine (BCNU), which is a nitrosourea that is used to treat GBM and other tumors [398-400]. These devices were approved by the FDA in 1996 for the treatment of recurrent GBM and in 2004 for primary GBM, but they are not widely used because of the need of trained surgeons for their implantation, possible complications, and high cost of therapy regarding a small prognosis improvement $[367,401]$; indeed, patient trials have shown only a modest increase in survival of 8 to 9 weeks compared to a placebo [398,399]. In addition, carmustine is a small lipophilic molecule that is not effluxed by $A B C$ transporters, but it passively diffuses into systemic circulation rapidly upon release from the wafers [397]. Nevertheless, there is a continuous development on these devices, searching to improve their efficiency [397].

Convection-enhanced delivery (CED) uses catheters implanted during surgery to constantly deliver chemotherapeutics into the tumor area, where the drug is supposed to reach all the tumor cells via convective flow due to the hydrostatic pressure gradient created [402,403] (Figure 4C(c,d); reviewed in [404,405]). Nevertheless, depending on the compound, the tissue around the catheter may receive enough drug, but its concentration may rapidly decrease in nearby zones due to efflux 
into the vessels $[367,406]$. The co-infusion of imaging tracers allows the real-time tracking of the convective infusate flow to evaluate the volume effectively targeted with the chemotherapeutic compound [407,408]. Although there have been several phase I and phase II clinical trials using CED, they have not shown a positive effect on patient outcomes [404]. A phase III trial where CED was used to administrate interleukin-13 bound to Pseudomonas exotoxin to GBM patients did not show a significant improvement compared to Gliadel wafers [409]. Nevertheless, other preclinical studies have shown promising results [410], and continuous efforts have been made to improve the efficiency of CED, including works in catheter technology and optimal positioning [406]. Recently, a chronic CED administration system was used to infuse the topoisomerase inhibitor topotecan in a pig model for up to 32 days without toxicity [411]. The use of $A B C$ inhibitors has been suggested as a strategy to improve CED and could be further explored. For instance, a recent study showed an improvement of tumor apoptosis in a transgenic H3.3K27M mutant murine model of diffuse intrinsic pontine glioma by a pretreatment of dexamethasone plus tariquidar before convection-enhanced delivery (Section 6.5) of dasatinib [373].

\subsection{BBB Disruption: Osmotic Disruption and Ultrasound-Enhanced Delivery}

Osmotic disruption of the BBB can be achieved by infusing a hyperosmotic compound such as mannitol into the carotid artery through a catheter [412], which causes the endothelial cells to shrink, disrupting the tight junctions and opening the paracellular space, followed by the administration of a chemotherapeutic (Figure $4 \mathrm{D}(\mathrm{a}, \mathrm{b})$ ). The first clinic assays using this method in six patients with malignant brain tumors showed an increase in methotrexate tumor delivery, overcoming the $\mathrm{ABC}$ transporters mediated efflux of the chemotherapeutic. It has been used for the treatment of chemosensitive primary CNS lymphoma (PCNSL), showing a prolonged response without using radiotherapy in a multicenter clinical trial between 1982 and 2005 [413]. The use of intraarterial administration of bevacizumab after osmotic BBB disruption with mannitol has shown an increase in progression-free survival in GBM patients in phase I trials [414,415] and is undergoing phase II trials (ID NCT01238237 [416]). Nevertheless, opening the BBB is not without risk, as it has been observed that it can increase the risk of other neurological problems, such as edema, stroke, and epileptic seizures $[414,417]$.

Focused ultrasound-enhanced delivery (FUS) methods use directed low-frequency ultrasound waves to temporally open the tight junctions between the endothelial cells [418] (Figure 4D(c,d)). This has been employed to enhance the delivery of BBB-impermeable liposome-encapsulated doxorubicin in a rat glioma model [419]. Disruption of the BBB with FUS can have harmful effects such as intracerebral hemorrhage, erythrocyte extravasation, and edema [420]. Thus, there are continuous efforts to diminish these effects, such as microbubble (MB)-enhanced (Figure $4 \mathrm{D}(\mathrm{c})$ ) FUS and the use of sonosensitizers that provoke a localized cytotoxic effect. The oscillation of MBs stimulated by ultrasounds provoke a mechanical disruption of the BBB at lower frequencies of ultrasounds than FUS alone; for instance, this strategy has been employed to improve carmustine (BCNU) penetration into the rat brain [421]. Sonodynamic therapy using the 5 -aminolevulinic acid (5-ALA) has been combined with transcranial MRI-guided focused ultrasound (MRgFUS) and real-time MRI thermometry to monitor and optimize the therapy in a rat brain tumor model, achieving an improved survival time [422]. Nevertheless, in a recent study, physical BBB disruption provoked by MB-enhanced FUS did not impact the brain kinetics of ${ }^{11} \mathrm{C}$-erlotinib, while elacridar did increased its brain penetration (with or without FUS), indicating that erlotinib delivery into the brain is governed by ABC transporters efflux and not by the physical integrity of the brain and suggesting that the selection of the chemotherapeutic for FUS is critical, as this strategy may not overcome the ABC-mediated efflux [273].

After obtaining positive results in rabbit and primates [423,424], an implantable unfocused ultrasound device has undergone a phase I/IIa clinical trial (ID NCT02253212 [425]) with 19 patients of recurrent GBM who received 4 to 16 min of low-intensity pulsed ultrasounds for BBB disruption followed by IV carboplatin chemotherapy every four weeks, during one to 10 sessions. Although one patient 
presented a transient edema, the results were promising with no carboplatin-related neurotoxicity, progression-free survival of 2.73 months, and a median overall survival of 8.64 months [426].

\subsection{Nanoparticles and Targeting Nanocarriers}

Nanoparticles can be used to entrap or encapsulate chemotherapeutics drugs aiming to improve their BBB permeability and specifically target the BBB or brain tumors through specific ligands. These nanocarriers can present diverse chemistries, including the material and surface functionalization strategies; the characteristics, studies, advantages, and limitations of nanocarriers are extensively reviewed in this special issue by Teleanu et al. [427]. For instance, diverse reports use polymeric nanoparticles, solid lipid nanoparticles, liposomes, dendrimers, micelles, inorganic nanoparticles, carbon nanotubes, and quantum dots. Depending on this chemistry and their functionalization, they may pass through the BBB by diverse pathways, mainly: paracellular, transcellular, or carrier-mediated transport; and receptor-mediated or adsorptive transcytosis [427]. They can be functionalized, for instance, with ligands to cross the BBB via receptor-mediated transcytosis (such as glutathione) or more specific ligands to target tumor cells, such as PEG and glioma homing peptides [428], as well as sialic acid, glucosamine, and concanavalin A, which have shown higher brain accumulation of paclitaxel in rats [429].

Some nanoparticles have shown promising results in preclinical and clinical studies for the treatment of brain tumors. For instance, PEGylated liposomal doxorubicin showed higher brain penetration than free doxorubicin in an intracranial model of breast cancer brain metastasis mouse model [430]. Glutathione pegylated liposomal doxorubicin (2B3-101) [430] showed higher penetration into the brain of a murine model and underwent a phase I/IIa clinical study, obtaining a progression free survival of three months in 58\% of treated patients of breast cancer brain metastasis [431]. In addition, studies with micellar formulations for the delivery of curcumin [432] and multi-walled carbon nanotubes [433] have shown increased cancer cell uptake in vitro and brain tumor penetration in in vivo assays. Once the drug is released, it may be subjected to passive or active transport mechanisms; thus, some studies have evaluated the use of multi-compound nanoparticles to overcome the multidrug resistance in cancer (reviewed in [374]). For instance, doxorubicin-curcumin nanoparticles have proven an increased accumulation in vitro [434] and in vivo in cancer preclinical models, which has been accompanied by a reduced cardiotoxicity [435]. Similarly, a liposomal cocktail including a pH-responsive molecule (i.e., malachite green carbinol base (MG)) and liposome conjugated with Her-2 antibody has been employed for the codelivery of doxorubicin and verapamil, overcoming the doxorubicin resistance in vitro and enhancing tumor inhibition in a xenografted mouse model of breast cancer [436]. Although nanoparticles codelivering a chemotherapeutic and an ABC inhibitor have not been tested in human patients nor in glioma models, this could be an interesting approach to treat CNS cancers.

\subsection{Conclusion on Strategies to Improve CNS Drug Delivery in Brain Cancer}

Many of the strategies and technologies for the delivery of medicines into the CNS and glioma have focused on bypassing the BBB and the ABC transporter mediated efflux of chemotherapeutics. Few of them have been approved by regulating agencies such as the FDA and EMA because of systemic toxicity or insufficient improvements in prognosis; nevertheless, they are constantly under development. In addition, there have been promising results with new technologies such as ultrasound-mediated BBB disruption and nanoparticles. It is important to highlight that $A B C$ transporters may drive the rapid clearance of their drug substrates despite BBB disruption or localized delivery into the parenchyma. Thus, it would be recommendable to combine these technologies with rationally designed drugs that are not effluxed by $\mathrm{ABC}$ transporters or by the coadministration of modulators, which has also shown positive results. 


\section{Conclusions}

It is fundamental to consider the barrier function of the blood-brain interfaces during the development of CNS therapeutics or drug brain-delivery strategies. Importantly, the $A B C$ transporters found in the blood-brain barrier (BBB), the blood-cerebrospinal fluid barrier (BCSFB), the arachnoid barrier (BAB), and the blood-brain tumor barrier (BBTB) regulate the exchange of a wide variety of molecules between the blood and the brain parenchyma. Additionally, $\mathrm{ABC}$ transporters expressed in glioma cells constitute a second barrier against chemotherapeutics.

A large diversity of drug delivery strategies has been developed with promising results at the preclinical stage, but many have not shown an important improvement in the clinical fight against brain tumors, especially for high-grade gliomas such as glioblastoma multiforme. Considering the delicate homeostasis of the brain and the systemic importance of $\mathrm{ABC}$ transporters, special care should be taken when designing chemotherapeutic drugs, $\mathrm{ABC}$ modulators, or strategies to disrupt or circumvent the BBB. Therefore, deepening our knowledge on the blood-brain interfaces and particularly on $A B C$ transporters' function and expression is of extreme utility, not only to better understand the multidrug resistance phenomena, but also to develop better strategies to improve drug delivery.

Author Contributions: Conceptualization, D.G.-Z. and M.-C.M.; Investigation, D.G.-Z., M.T., J.-M.S., X.D. and M.-C.M.; Resources, M.-C.M.; Writing-Original Draft Preparation, D.G.-Z.; Writing-Review and Editing, M.T., J.-M.S., X.D., and M.-C.M.; Visualization, D.G.-Z.; Supervision, X.D. and M.-C.M.; Project Administration, M.-C.M.; Funding Acquisition, J.-M.S. and M.-C.M. All authors have read and agreed to the published version of the manuscript.

Funding: This work was partly financed by Servier Laboratories (Orléans, France).

Acknowledgments: Figures in this manuscript were created based on the medical images from "smart Servier Medical Art" (https://smart.servier.com), published by Servier Laboratories (Orléans, France) under Creative Commons License.

Conflicts of Interest: The authors report no conflict of interest. The founding sponsors had no role in the design of the study; in the collection, analyses, or interpretation of data; in the writing of the manuscript, and in the decision to publish the results.

\section{References}

1. Abbott, N.J.; Friedman, A. Overview and introduction: The blood-brain barrier in health and disease. Epilepsia 2012, 53, 1-6. [CrossRef] [PubMed]

2. Scherrmann, J.-M. Drug delivery to brain via the blood-brain barrier. Vascul. Pharmacol. 2002, 38, 349-354. [CrossRef]

3. Chaves, C.; Shawahna, R.; Jacob, A.; Scherrmann, J.-M.; Declèves, X. Human ABC Transporters at blood-CNS Interfaces as Determinants of CNS Drug Penetration. Curr. Pharm. Des. 2014, 20, 1450-1462. [CrossRef] [PubMed]

4. Cardoso, F.L.; Brites, D.; Brito, M.A. Looking at the blood-brain barrier: Molecular anatomy and possible investigation approaches. Brain Res. Rev. 2010, 64, 328-363. [CrossRef]

5. Palmer, A.M.; Alavijeh, M.S. Overview of experimental models of the blood-brain barrier in CNS drug discovery. Curr. Protoc. Pharmacol. 2013, 1, 1-30. [CrossRef]

6. Abbott, N.J. Blood-brain barrier structure and function and the challenges for CNS drug delivery. J. Inherit. Metab. Dis. 2013, 36, 437-449. [CrossRef]

7. Helms, H.C.; Abbott, N.J.; Burek, M.; Cecchelli, R.; Couraud, P.-O.; Deli, M.A.; Förster, C.; Galla, H.J.; Romero, I.A.; Shusta, E.V.; et al. In vitro models of the blood-brain barrier: An overview of commonly used brain endothelial cell culture models and guidelines for their use. J. Cereb. Blood Flow Metab. 2016, 36, 862-890. [CrossRef]

8. Amore, B.; Gibbs, J.; Emery, M. Application of In Vivo Animal Models to Characterize the Pharmacokinetic and Pharmacodynamic Properties of Drug Candidates in Discovery Settings. Comb. Chem. High Throughput Screen. 2010, 13, 207-218. [CrossRef] 
9. Patel, A.P.; Fisher, J.L.; Nichols, E.; Abd-Allah, F.; Abdela, J.; Abdelalim, A.; Abraha, H.N.; Agius, D.; Alahdab, F.; Alam, T.; et al. Global, regional, and national burden of brain and other CNS cancer, 1990-2016: A systematic analysis for the Global Burden of Disease Study 2016. Lancet Neurol. 2019, 18, 376-393. [CrossRef]

10. Louis, D.N.; Perry, A.; Reifenberger, G.; von Deimling, A.; Figarella-Branger, D.; Cavenee, W.K.; Ohgaki, H.; Wiestler, O.D.; Kleihues, P.; Ellison, D.W. The 2016 World Health Organization Classification of Tumors of the Central Nervous System: A summary. Acta Neuropathol. 2016, 131, 1-18. [CrossRef]

11. Louis, D.N.; Ohgaki, H.; Wiestler, O.D.; Cavenee, W.K.; Burger, P.C.; Jouvet, A.; Scheithauer, B.W.; Kleihues, P. The 2007 WHO classification of tumours of the central nervous system. Acta Neuropathol. 2007, 114, 97-109. [CrossRef] [PubMed]

12. Weller, M.; Wick, W.; Aldape, K.; Brada, M.; Berger, M.; Pfister, S.M.; Nishikawa, R.; Rosenthal, M.; Wen, P.Y.; Stupp, R.; et al. Glioma. Nat. Rev. Dis. Prim. 2015, 1, 15017. [CrossRef] [PubMed]

13. Reifenberger, G.; Wirsching, H.G.; Knobbe-Thomsen, C.B.; Weller, M. Advances in the molecular genetics of gliomas-implications for classification and therapy. Nat. Rev. Clin. Oncol. 2017, 14, 434-452. [CrossRef] [PubMed]

14. van Tellingen, O.; Yetkin-Arik, B.; de Gooijer, M.C.C.; Wesseling, P.; Wurdinger, T.; de Vries, H.E.E. Overcoming the blood-brain tumor barrier for effective glioblastoma treatment. Drug Resist. Updat. 2015, 19, 1-12. [CrossRef] [PubMed]

15. Calatozzolo, C.; Gelati, M.; Ciusani, E.; Sciacca, F.L.; Pollo, B.; Cajola, L.; Marras, C.; Silvani, A.; Vitellaro-Zuccarello, L.; Croci, D.; et al. Expression of Drug Resistance Proteins Pgp, MRP1, MRP3, MRP5 AND GST- $\pi$ in Human Glioma. J. Neurooncol. 2005, 74, 113-121. [CrossRef]

16. Declèves, X.; Amiel, A.; Delattre, J.-Y.; Scherrmann, J.-M.; Decleves, X.; Amiel, A.; Delattre, J.-Y.; Scherrmann, J.-M. Role of ABC Transporters in the Chemoresistance of Human Gliomas. Curr. Cancer Drug Targets 2006, 6, 433-445. [CrossRef]

17. Ghersi-Egea, J.F.; Strazielle, N.; Catala, M.; Silva-Vargas, V.; Doetsch, F.; Engelhardt, B. Molecular anatomy and functions of the choroidal blood-cerebrospinal fluid barrier in health and disease. Acta Neuropathol. 2018, 135, 337-361. [CrossRef]

18. Saunders, N.R.; Habgood, M.D.; Møllgård, K.; Dziegielewska, K.M. The biological significance of brain barrier mechanisms: Help or hindrance in drug delivery to the central nervous system? F1000Research 2016, 5, 313. [CrossRef]

19. Ueno, M.; Chiba, Y.; Murakami, R.; Matsumoto, K.; Kawauchi, M.; Fujihara, R. Blood-brain barrier and blood-cerebrospinal fluid barrier in normal and pathological conditions. Brain Tumor Pathol. 2016, 33, 89-96. [CrossRef]

20. Morris, M.E.; Rodriguez-Cruz, V.; Felmlee, M.A. SLC and ABC Transporters: Expression, Localization, and Species Differences at the Blood-Brain and the Blood-Cerebrospinal Fluid Barriers. AAPS J. 2017, 19, 1317-1331. [CrossRef]

21. Dauchy, S.; Dutheil, F.; Weaver, R.J.; Chassoux, F.; Daumas-Duport, C.; Couraud, P.-O.; Scherrmann, J.-M.; De Waziers, I.; Declèves, X. ABC transporters, cytochromes P450 and their main transcription factors: Expression at the human blood-brain barrier. J. Neurochem. 2008, 107, 1518-1528. [CrossRef] [PubMed]

22. Shawahna, R.; Uchida, Y.; Declèves, X.; Ohtsuki, S.; Yousif, S.; Dauchy, S.; Jacob, A.; Chassoux, F.; Daumas-Duport, C.; Couraud, P.-O.; et al. Transcriptomic and quantitative proteomic analysis of transporters and drug metabolizing enzymes in freshly isolated human brain microvessels. Mol. Pharm. 2011, 8, 1332-1341. [CrossRef] [PubMed]

23. Dutheil, F.; Jacob, A.; Dauchy, S.; Beaune, P.; Scherrmann, J.-M.; Declèves, X.; Loriot, M.-A. ABC transporters and cytochromes $\mathrm{P} 450$ in the human central nervous system: Influence on brain pharmacokinetics and contribution to neurodegenerative disorders. Expert Opin. Drug Metab. Toxicol. 2010, 6, 1161-1174. [CrossRef] [PubMed]

24. Kutuzov, N.; Flyvbjerg, H.; Lauritzen, M. Contributions of the glycocalyx, endothelium, and extravascular compartment to the blood-brain barrier. Proc. Natl. Acad. Sci. USA 2018, 115, E9429-E9438. [CrossRef] [PubMed]

25. Stapleton, S.; Blaney, S. New Agents for Intrathecal Administration. Cancer Invest. 2006, 24, 528-534. [CrossRef] 
26. Liu, Y.X.; Liu, W.J.; Zhang, H.R.; Zhang, Z.W. Delivery of bevacizumab by intracranial injection: Assessment in glioma model. Onco. Targets. Ther. 2018, 11, 2673-2683. [CrossRef]

27. Nag, S.; Begley, D.J. Blood-brain barrier, exchange of metabolites and gases. In Pathology and Genetics. Cerebrovascular Diseases; Kalimo, H., Ed.; ISN Neuropath Press: Basel, Switzerland, 2005; pp. 22-29.

28. Schulze, C.; Firth, J.A. Immunohistochemical localization of adherens junction components in blood-brain barrier microvessels of the rat. J. Cell Sci. 1993, 104, 773-782.

29. Wang, Q.; Zuo, Z. Impact of transporters and enzymes from blood-cerebrospinal fluid barrier and brain parenchyma on CNS drug uptake. Expert Opin. Drug Metab. Toxicol. 2018, 14, 961-972. [CrossRef]

30. Strazielle, N.; Ghersi-Egea, J.-F. Demonstration of a Coupled Metabolism-Efflux Process at the Choroid Plexus as a Mechanism of Brain Protection Toward Xenobiotics. J. Neurosci. 1999, 19, 6275-6289. [CrossRef]

31. Keep, R.F.; Jones, H.C. A morphometric study on the development of the lateral ventricle choroid plexus, choroid plexus capillaries and ventricular ependyma in the rat. Dev. Brain Res. 1990, 56, 47-53. [CrossRef]

32. Weller, R.O.; Sharp, M.M.; Christodoulides, M.; Carare, R.O.; Møllgård, K. The meninges as barriers and facilitators for the movement of fluid, cells and pathogens related to the rodent and human CNS. Acta Neuropathol. 2018, 135, 363-385. [CrossRef] [PubMed]

33. Yasuda, K.; Cline, C.; Vogel, P.; Onciu, M.; Fatima, S.; Sorrentino, B.P.; Thirumaran, R.K.; Ekins, S.; Urade, Y.; Fujimori, K.; et al. Drug transporters on arachnoid barrier cells contribute to the blood-cerebrospinal fluid barrier. Drug Metab. Dispos. 2013, 41, 923-931. [CrossRef] [PubMed]

34. Zhang, Z.; Tachikawa, M.; Uchida, Y.; Terasaki, T. Drug Clearance from Cerebrospinal Fluid Mediated by Organic Anion Transporters 1 (Slc22a6) and 3 (Slc22a8) at Arachnoid Membrane of Rats. Mol. Pharm. 2018, 15, 911-922. [CrossRef] [PubMed]

35. Yaguchi, Y.; Tachikawa, M.; Zhang, Z.; Terasaki, T. Organic Anion-Transporting Polypeptide 1a4 (Oatp1a4/Slco1a4) at the Blood-Arachnoid Barrier is the Major Pathway of Sulforhodamine-101 Clearance from Cerebrospinal Fluid of Rats. Mol. Pharm. 2019, 16, 2021-2027. [CrossRef]

36. Abbott, N.J.; Patabendige, A.A.K.; Dolman, D.E.M.; Yusof, S.R.; Begley, D.J. Structure and function of the blood-brain barrier. Neurobiol. Dis. 2010, 37, 13-25. [CrossRef]

37. Kodaira, H.; Kusuhara, H.; Fujita, T.; Ushiki, J.; Fuse, E.; Sugiyama, Y. Quantitative Evaluation of the Impact of Active Efflux by P-Glycoprotein and Breast Cancer Resistance Protein at the Blood-Brain Barrier on the Predictability of the Unbound Concentrations of Drugs in the Brain Using Cerebrospinal Fluid Concentration as a. J. Pharmacol. Exp. Ther. 2011, 339, 935-944. [CrossRef]

38. Pui, C.-H.; Campana, D.; Pei, D.; Bowman, W.P.; Sandlund, J.T.; Kaste, S.C.; Ribeiro, R.C.; Rubnitz, J.E.; Raimondi, S.C.; Onciu, M.; et al. Treating Childhood Acute Lymphoblastic Leukemia without Cranial Irradiation. N. Engl. J. Med. 2009, 360, 2730-2741. [CrossRef]

39. Higgins, C.F. ABC transporters: From microorganisms to man. Annu. Rev. Cell Biol. 1992, 8, 67-113. [CrossRef]

40. Mahringer, A.; Fricker, G. ABC transporters at the blood-brain barrier. Expert Opin. Drug Metab. Toxicol. 2016, 5255, 1-10. [CrossRef]

41. Mohammad, I.S.; He, W.; Yin, L. Understanding of human ATP binding cassette superfamily and novel multidrug resistance modulators to overcome MDR. Biomed. Pharmacother. 2018, 100, 335-348. [CrossRef]

42. Wijaya, J.; Fukuda, Y.; Schuetz, J.D. Obstacles to brain tumor therapy: Key ABC transporters. Int. J. Mol. Sci. 2017, 18, 2544. [CrossRef] [PubMed]

43. HUGO Gene Nomenclature Committee: ABC Family. Available online: http://www.genenames.org/cgi-bin/ genefamilies/set/417 (accessed on 5 August 2016).

44. DeGorter, M.K.; Xia, C.Q.; Yang, J.J.; Kim, R.B. Drug Transporters in Drug Efficacy and Toxicity. Annu. Rev. Pharmacol. Toxicol. 2012, 52, 249-273. [CrossRef] [PubMed]

45. Gottesman, M.M.; Ambudkar, S.V. Overview: ABC Transporters and Human Disease. J. Bioenerg. Biomembr. 2001, 33, 453-458. [CrossRef] [PubMed]

46. Nies, A.T.; Jedlitschky, G.; König, J.; Herold-Mende, C.; Steiner, H.H.; Schmitt, H.P.; Keppler, D. Expression and immunolocalization of the multidrug resistance proteins, MRP1-MRP6 (ABCC1-ABCC6), in human brain. Neuroscience 2004, 129, 349-360. [CrossRef] [PubMed]

47. Dallas, S.; Miller, D.S.; Bendayan, R. Multidrug Resistance-Associated Proteins: Expression and Function in the Central Nervous System. Pharmacol. Rev. 2006, 58, 140-161. [CrossRef]

48. Begley, D. ABC Transporters and the Blood-Brain Barrier. CPD 2004, 10, 1295-1312. [CrossRef] 
49. Scherrmann, J.-M. ABC Superfamily Transporters at the Human Blood-Brain Barrier. In ABC Transporters and Multidrug Resistance; John Wiley \& Sons, Inc.: Hoboken, NJ, USA, 2005; pp. 363-384, ISBN 9780470495131.

50. Schinkel, A.H. P-Glycoprotein, a gatekeeper in the blood-brain barrier. Adv. Drug Deliv. Rev. 1999, 36, 179-194. [CrossRef]

51. Sharom, F.J. The P-glycoprotein multidrug transporter. Essays Biochem. 2011, 50, 161-178. [CrossRef]

52. Stacy, A.E.; Jansson, P.J.; Richardson, D.R. Molecular Pharmacology of ABCG2 and Its Role in Chemoresistance. Mol. Pharmacol. 2013, 84, 655-669. [CrossRef]

53. Agarwal, S.; Hartz, A.M.S.; Elmquist, W.F.; Bauer, B. Breast cancer resistance protein and P-glycoprotein in brain cancer: Two gatekeepers team up. Curr. Pharm. Des. 2011, 17, 2793-2802. [CrossRef]

54. Robey, W.R.; Ierano, C.; Zhan, Z.; Bates, E.S. The Challenge of Exploiting ABCG2 in the Clinic. Curr. Pharm. Biotechnol. 2011, 12, 595-608. [CrossRef] [PubMed]

55. Toyoda, Y.; Hagiya, Y.; Adachi, T.; Hoshijima, K.; Kuo, M.T.; Ishikawa, T. MRP class of human ATP binding cassette (ABC) transporters: Historical background and new research directions. Xenobiotica 2008, 38, 833-862. [CrossRef] [PubMed]

56. Slot, A.J.; Molinski, S.V.; Cole, S.P.C. Mammalian multidrug-resistance proteins (MRPs). Essays Biochem. 2011, 50, 179-207. [PubMed]

57. Zhou, S.-F.; Wang, L.-L.; Di, Y.; Xue, C.; Duan, W.; Li, C.; Li, Y. Substrates and Inhibitors of Human Multidrug Resistance Associated Proteins and the Implications in Drug Development. Curr. Med. Chem. 2008, 15, 1981-2039. [CrossRef]

58. Beaulieu, E.; Demeule, M.; Ghitescu, L.; Béliveau, R. P-glycoprotein is strongly expressed in the luminal membranes of the endothelium of blood vessels in the brain. Biochem. J. 1997, 326 Pt 2, 539-544. [CrossRef]

59. Virgintino, D.; Robertson, D.; Errede, M.; Benagiano, V.; Girolamo, F.; Maiorano, E.; Roncali, L.; Bertossi, M. Expression of P-Glycoprotein in Human Cerebral Cortex Microvessels. J. Histochem. Cytochem. 2002, 50, 1671-1676. [CrossRef]

60. Pardridge, W.M.; Golden, P.L.; Kang, Y.-S.; Bickel, U. Brain Microvascular and Astrocyte Localization of P-Glycoprotein. J. Neurochem. 2002, 68, 1278-1285. [CrossRef]

61. Soontornmalai, A.; Vlaming, M.L.H.; Fritschy, J.-M. Differential, strain-specific cellular and subcellular distribution of multidrug transporters in murine choroid plexus and blood-brain barrier. Neuroscience 2006, 138, 159-169. [CrossRef]

62. Bendayan, R.; Ronaldson, P.T.; Gingras, D.; Bendayan, M. In Situ Localization of P-glycoprotein (ABCB1) in Human and Rat Brain. J. Histochem. Cytochem. 2006, 54, 1159-1167. [CrossRef]

63. Kubo, Y.; Ohtsuki, S.; Uchida, Y.; Terasaki, T. Quantitative Determination of Luminal and Abluminal Membrane Distributions of Transporters in Porcine Brain Capillaries by Plasma Membrane Fractionation and Quantitative Targeted Proteomics. J. Pharm. Sci. 2015, 104, 3060-3068. [CrossRef]

64. Boulay, A.C.; Saubameá, B.; Adam, N.; Chasseigneaux, S.; Mazaré, N.; Gilbert, A.; Bahin, M.; Bastianelli, L.; Blugeon, C.; Perrin, S.; et al. Translation in astrocyte distal processes sets molecular heterogeneity at the gliovascular interface. Cell Discov. 2017, 3, 1-20. [CrossRef] [PubMed]

65. Zhang, Y.; Sloan, S.A.; Clarke, L.E.; Caneda, C.; Plaza, C.A.; Blumenthal, P.D.; Vogel, H.; Steinberg, G.K.; Edwards, M.S.B.; Li, G.; et al. Purification and Characterization of Progenitor and Mature Human Astrocytes Reveals Transcriptional and Functional Differences with Mouse. Neuron 2016, 89, 37-53. [CrossRef] [PubMed]

66. Spiegl-Kreinecker, S.; Buchroithner, J.; Elbling, L.; Steiner, E.; Wurm, G.; Bodenteich, A.; Fischer, J.; Micksche, M.; Berger, W. Expression and functional activity of the ABC-transporter proteins P-glycoprotein and multidrug-resistance protein 1 in human brain tumor cells and astrocytes. J. Neurooncol. 2002, 57, 27-36. [CrossRef] [PubMed]

67. Aronica, E.; Gorter, J.A.; Ramkema, M.; Redeker, S.; Ozbas-Gerçeker, F.; van Vliet, E.A.; Scheffer, G.L.; Scheper, R.J.; van der Valk, P.; Baayen, J.C.; et al. Expression and cellular distribution of multidrug resistance-related proteins in the hippocampus of patients with mesial temporal lobe epilepsy. Epilepsia 2004, 45, 441-451. [CrossRef] [PubMed]

68. Uhlen, M.; Fagerberg, L.; Hallstrom, B.M.; Lindskog, C.; Oksvold, P.; Mardinoglu, A.; Sivertsson, A.; Kampf, C.; Sjostedt, E.; Asplund, A.; et al. Tissue-based map of the human proteome. Science 2015, 347, 1260419. [CrossRef] 
69. Marroni, M.; Agrawal, M.; Kight, K.; Hallene, K.; Hossain, M.; Cucullo, L.; Signorelli, K.; Namura, S.; Bingaman, W.; Janigro, D. Relationship between expression of multiple drug resistance proteins and p53 tumor suppressor gene proteins in human brain astrocytes. Neuroscience 2003, 121, 605-617. [CrossRef]

70. Uchida, Y.; Zhang, Z.; Tachikawa, M.; Terasaki, T. Quantitative targeted absolute proteomics of rat blood-cerebrospinal fluid barrier transporters: Comparison with a human specimen. J. Neurochem. 2015, 134, 1104-1115. [CrossRef]

71. Rao, V.V.; Dahlheimer, J.L.; Bardgett, M.E.; Snyder, A.Z.; Finch, R.A.; Sartorelli, A.C.; Piwnica-Worms, D. Choroid plexus epithelial expression of MDR1 P glycoprotein and multidrug resistance-associated protein contribute to the blood-cerebrospinal-fluid drug-permeability barrier. Proc. Natl. Acad. Sci. USA 1999, 96, 3900-3905. [CrossRef]

72. Matsumoto, K.; Chiba, Y.; Fujihara, R.; Kubo, H.; Sakamoto, H.; Ueno, M. Immunohistochemical analysis of transporters related to clearance of amyloid- $\beta$ peptides through blood-cerebrospinal fluid barrier in human brain. Histochem. Cell Biol. 2015, 144, 597-611. [CrossRef]

73. Mercier, C.; Masseguin, C.; Roux, F.; Gabrion, J.; Scherrmann, J.-M. Expression of P-glycoprotein (ABCB1) and Mrp1 (ABCC1) in adult rat brain: Focus on astrocytes. Brain Res. 2004, 1021, 32-40. [CrossRef]

74. GENSAT. Available online: http://www.gensat.org/index.html (accessed on 16 October 2019).

75. Allen Brain Atlas. Available online: http://mouse.brain-map.org/ (accessed on 16 October 2019).

76. Gong, S.; Zheng, C.; Doughty, M.L.; Losos, K.; Didkovsky, N.; Schambra, U.B.; Nowak, N.J.; Joyner, A.; Leblanc, G.; Hatten, M.E.; et al. A gene expression atlas of the central nervous system based on bacterial artificial chromosomes. Nature 2003, 425, 917-925. [CrossRef] [PubMed]

77. Lau, C.; Ng, L.; Thompson, C.; Pathak, S.; Kuan, L.; Jones, A.; Hawrylycz, M. Exploration and visualization of gene expression with neuroanatomy in the adult mouse brain. BMC Bioinformatics 2008, 9, 153. [CrossRef] [PubMed]

78. Eisenblätter, T.; Hüwel, S.; Galla, H.-J. Characterisation of the brain multidrug resistance protein (BMDP/ABCG2/BCRP) expressed at the blood-brain barrier. Brain Res. 2003, 971, 221-231. [CrossRef]

79. Cooray, H.C.; Blackmore, C.G.; Maskell, L.; Barrand, M.A. Localisation of breast cancer resistance protein in microvessel endothelium of human brain. Neuroreport 2002, 13, 2059-2063. [CrossRef] [PubMed]

80. Aronica, E.; Gorter, J.A.; Redeker, S.; van Vliet, E.A.; Ramkema, M.; Scheffer, G.L.; Scheper, R.J.; van der Valk, P.; Leenstra, S.; Baayen, J.C.; et al. Localization of Breast Cancer Resistance Protein (BCRP) in Microvessel Endothelium of Human Control and Epileptic Brain. Epilepsia 2005, 46, 849-857. [CrossRef] [PubMed]

81. Tachikawa, M.; Watanabe, M.; Hori, S.; Fukaya, M.; Ohtsuki, S.; Asashima, T.; Terasaki, T. Distinct spatio-temporal expression of ABCA and ABCG transporters in the developing and adult mouse brain. J. Neurochem. 2005, 95, 294-304. [CrossRef]

82. Hori, S.; Ohtsuki, S.; Tachikawa, M.; Kimura, N.; Kondo, T.; Watanabe, M.; Nakashima, E.; Terasaki, T. Functional expression of rat ABCG2 on the luminal side of brain capillaries and its enhancement by astrocyte-derived soluble factor(s). J. Neurochem. 2004, 90, 526-536. [CrossRef]

83. Roberts, L.M.M.; Black, D.S.S.; Raman, C.; Woodford, K.; Zhou, M.; Haggerty, J.E.E.; Yan, A.T.T.; Cwirla, S.E.E.; Grindstaff, K.K.K. Subcellular localization of transporters along the rat blood-brain barrier and blood-cerebral-spinal fluid barrier by in vivo biotinylation. Neuroscience 2008, 155, 423-438. [CrossRef]

84. Lee, G.; Babakhanian, K.; Ramaswamy, M.; Prat, A.; Wosik, K.; Bendayan, R. Expression of the ATP-binding Cassette Membrane Transporter, ABCG2, in Human and Rodent Brain Microvessel Endothelial and Glial Cell Culture Systems. Pharm. Res. 2007, 24, 1262-1274. [CrossRef]

85. Zhang, Y.; Chen, K.; Sloan, S.A.; Bennett, M.L.; Scholze, A.R.; O’Keeffe, S.; Phatnani, H.P.; Guarnieri, P.; Caneda, C.; Ruderisch, N.; et al. An RNA-Sequencing Transcriptome and Splicing Database of Glia, Neurons, and Vascular Cells of the Cerebral Cortex. J. Neurosci. 2014, 34, 11929-11947. [CrossRef]

86. Warren, M.S.; Zerangue, N.; Woodford, K.; Roberts, L.M.; Tate, E.H.; Feng, B.; Li, C.; Feuerstein, T.J.; Gibbs, J.; Smith, B. Comparative gene expression profiles of ABC transporters in brain microvessel endothelial cells and brain in five species including human. Pharmacol. Res. 2009, 59, 404-413. [CrossRef] [PubMed]

87. Niehof, M.; Borlak, J. Expression of HNF4alpha in the human and rat choroid plexus-Implications for drug transport across the blood-cerebrospinal-fluid (CSF) barrier. BMC Mol. Biol. 2009, 10, 68. [CrossRef] [PubMed] 
88. Choudhuri, S.; Cherrington, N.J.; Li, N.; Klaassen, C.D. Constitutive expression of various xenobiotic and endobiotic transporter mRNAs in the choroid plexus of rats. Drug Metab. Dispos. 2003, 31, 1337-1345. [CrossRef] [PubMed]

89. Wijnholds, J.; de Lange, E.C.M.; Scheffer, G.L.; van den Berg, D.-J.; Mol, C.A.A.M.; van der Valk, M.; Schinkel, A.H.; Scheper, R.J.; Breimer, D.D.; Borst, P. Multidrug resistance protein 1 protects the choroid plexus epithelium and contributes to the blood-cerebrospinal fluid barrier. J. Clin. Invest. 2000, 105, 279-285. [CrossRef] [PubMed]

90. Miller, D.S.; Nobmann, S.N.; Gutmann, H.; Toeroek, M.; Drewe, J.; Fricker, G. Xenobiotic Transport across Isolated Brain Microvessels Studied by Confocal Microscopy. Mol. Pharmacol. 2000, 58, 1357-1367. [CrossRef] [PubMed]

91. Bauer, B.; Hartz, A.M.S.; Lucking, J.R.; Yang, X.; Pollack, G.M.; Miller, D.S. Coordinated nuclear receptor regulation of the efflux transporter, Mrp2, and the phase-II metabolizing enzyme, GST $\pi$, at the blood-brain barrier. J. Cereb. Blood Flow Metab. 2008, 28, 1222-1234. [CrossRef] [PubMed]

92. Uchida, Y.; Ohtsuki, S.; Katsukura, Y.; Ikeda, C.; Suzuki, T.; Kamiie, J.; Terasaki, T. Quantitative targeted absolute proteomics of human blood-brain barrier transporters and receptors. J. Neurochem. 2011, 117, 333-345. [CrossRef] [PubMed]

93. Hoshi, Y.; Uchida, Y.; Tachikawa, M.; Inoue, T.; Ohtsuki, S.; Terasaki, T. Quantitative atlas of blood-brain barrier transporters, receptors, and tight junction proteins in rats and common marmoset. J. Pharm. Sci. 2013, 102, 3343-3355. [CrossRef]

94. Kamiie, J.; Ohtsuki, S.; Iwase, R.; Ohmine, K.; Katsukura, Y.; Yanai, K.; Sekine, Y.; Uchida, Y.; Ito, S.; Terasaki, T. Quantitative Atlas of Membrane Transporter Proteins: Development and Application of a Highly Sensitive Simultaneous LC/MS/MS Method Combined with Novel In-silico Peptide Selection Criteria. Pharm. Res. 2008, 25, 1469-1483. [CrossRef]

95. Ito, K.; Uchida, Y.; Ohtsuki, S.; Aizawa, S.; Kawakami, H.; Katsukura, Y.; Kamiie, J.; Terasaki, T. Quantitative membrane protein expression at the blood-brain barrier of adult and younger cynomolgus monkeys. J. Pharm. Sci. 2011, 100, 3939-3950. [CrossRef]

96. Leggas, M.; Adachi, M.; Scheffer, G.; Sun, D.; Wielinga, P.; Du, G.; Mercer, K.; Zhuang, Y.; Panetta, J.; Johnston, B.; et al. MRP4 confers resistance to topotecan and protects the brain from chemotherapy. Mol. Cell. Biol. 2004, 24, 7612-7621. [CrossRef] [PubMed]

97. Potschka, H. Transporter hypothesis of drug-resistant epilepsy: Challenges for pharmacogenetic approaches. Pharmacogenomics 2010, 11, 1427-1438. [CrossRef] [PubMed]

98. de Vries, N.A.; Zhao, J.; Kroon, E.; Buckle, T.; Beijnen, J.H.; van Tellingen, O. P-Glycoprotein and Breast Cancer Resistance Protein: Two Dominant Transporters Working Together in Limiting the Brain Penetration of Topotecan. Clin. Cancer Res. 2007, 13, 6440-6449. [CrossRef] [PubMed]

99. Dufour, R.; Daumar, P.; Mounetou, E.; Aubel, C.; Kwiatkowski, F.; Abrial, C.; Vatoux, C.; Penault-Llorca, F.; Bamdad, M. BCRP and P-gp relay overexpression in triple negative basal-like breast cancer cell line: A prospective role in resistance to Olaparib. Sci. Rep. 2015, 5, 12670. [CrossRef] [PubMed]

100. Juliano, R.L.; Ling, V. A surface glycoprotein modulating drug permeability in Chinese hamster ovary cell mutants. BBA - Biomembr. 1976, 455, 152-162. [CrossRef]

101. Regina, A.; Koman, A.; Piciotti, M.; El Hafny, B.; Center, M.S.; Bergmann, R.; Couraud, P.O.; Roux, F. Mrp1 multidrug resistance-associated protein and P-glycoprotein expression in rat brain microvessel endothelial cells. J. Neurochem. 1998, 71, 705-715. [CrossRef]

102. Demeule, M.; Régina, A.; Jodoin, J.; Laplante, A.; Dagenais, C.; Berthelet, F.; Moghrabi, A.; Béliveau, R. Drug transport to the brain: Key roles for the efflux pump P-glycoprotein in the blood-brain barrier. Vascul. Pharmacol. 2002, 38, 339-348. [CrossRef]

103. Saraswathy, M.; Gong, S. Different strategies to overcome multidrug resistance in cancer. Biotechnol. Adv. 2013, 31, 1397-1407. [CrossRef]

104. Pavan, B.; Paganetto, G.; Rossi, D.; Dalpiaz, A. Multidrug resistance in cancer or inefficacy of neuroactive agents: Innovative strategies to inhibit or circumvent the active efflux transporters selectively. Drug Discov. Today 2014, 19, 1563-1571. [CrossRef]

105. Mo, W.; Zhang, J.T. Human ABCG2: Structure, function, and its role in multidrug resistance. Int. J. Biochem. Mol. Biol. 2012, 3, 1-27. 
106. Tivnan, A. Targeting Chemotherapy Resistance in Glioblastoma Through Modulation of ABC Transporters. In Resistance to Targeted Anti-Cancer Therapeutics; Tivnan, A., Ed.; Springer International Publishing: Cham, Switzerland, 2016; pp. 25-54, ISBN 978-3-319-46504-3.

107. Mercier, C.; Declèves, X.; Masseguin, C.; Fragner, P.; Tardy, M.; Roux, F.; Gabrion, J.; Scherrmann, J.-M. P-glycoprotein (ABCB1) but not multidrug resistance-associated protein 1 (ABCC1) is induced by doxorubicin in primary cultures of rat astrocytes. J. Neurochem. 2003, 87, 820-830. [CrossRef] [PubMed]

108. Nies, A.T. The role of membrane transporters in drug delivery to brain tumors. Cancer Lett. 2007, 254, 11-29. [CrossRef] [PubMed]

109. Leslie, E.M.; Deeley, R.G.; Cole, S.P.C.C. Multidrug resistance proteins: Role of P-glycoprotein, MRP1, MRP2, and BCRP (ABCG2) in tissue defense. Toxicol. Appl. Pharmacol. 2005, 204, 216-237. [CrossRef] [PubMed]

110. Wielinga, P.R.; van der Heijden, I.; Reid, G.; Beijnen, J.H.; Wijnholds, J.; Borst, P. Characterization of the MRP4and MRP5-mediated Transport of Cyclic Nucleotides from Intact Cells. J. Biol. Chem. 2003, 278, 17664-17671. [CrossRef] [PubMed]

111. Schuetz, J.D.; Connelly, M.C.; Sun, D.; Paibir, S.G.; Flynn, P.M.; Srinivas, R.V.; Kumar, A.; Fridland, A. MRP4: A previously unidentified factor in resistance to nucleoside-based antiviral drugs. Nat. Med. 1999, 5, 1048-1051. [CrossRef]

112. Jedlitschky, G.; Burchell, B.; Keppler, D. The Multidrug Resistance Protein 5 Functions as an ATP-dependent Export Pump for Cyclic Nucleotides. J. Biol. Chem. 2000, 275, 30069-30074. [CrossRef]

113. Lai, L.; Tan, T.M.C. Role of glutathione in the multidrug resistance protein 4 (MRP4/ABCC4)-mediated efflux of cAMP and resistance to purine analogues. Biochem. J. 2002, 361, 497-503. [CrossRef]

114. Thiebaut, F.; Tsuruo, T.; Hamada, H.; Gottesman, M.M.; Pastan, I.; Willingham, M.C. Cellular localization of the multidrug-resistance gene product P-glycoprotein in normal human tissues. Proc. Natl. Acad. Sci. USA 1987, 84, 7735-7738. [CrossRef]

115. Yousif, S.; Marie-Claire, C.; Roux, F.; Scherrmann, J.-M.; Declèves, X. Expression of drug transporters at the blood-brain barrier using an optimized isolated rat brain microvessel strategy. Brain Res. 2007, 1134, 1-11. [CrossRef]

116. Cordon-Cardo, C.; O’Brien, J.P.; Casals, D.; Rittman-Grauer, L.; Biedler, J.L.J.L.; Melamed, M.R.; Bertino, J.R.; Peschanski, M.; Cordon-Cardo, C.; O’Brien, J.P.; et al. Multidrug-resistance gene (P-glycoprotein) is expressed by endothelial cells at blood-brain barrier sites. Proc. Natl. Acad. Sci. USA 1989, 86, 695-698. [CrossRef]

117. Decleves, X.; Regina, A.; Laplanche, J.-L.; Roux, F.; Boval, B.; Launay, J.-M.; Scherrmann, J.-M. Functional expression of P-glycoprotein and multidrug resistance-associated protein (Mrp1) in primary cultures of rat astrocytes. J. Neurosci. Res. 2000, 60, 594-601. [CrossRef]

118. Ronaldson, P.T.; Bendayan, M.; Gingras, D.; Piquette-Miller, M.; Bendayan, R. Cellular localization and functional expression of P-glycoprotein in rat astrocyte cultures. J. Neurochem. 2004, 89, 788-800. [CrossRef] [PubMed]

119. Lee, G.; Schlichter, L.; Bendayan, M.; Bendayan, R. Functional expression of P-glycoprotein in rat brain microglia. J. Pharmacol. Exp. Ther. 2001, 299, 204-212. [PubMed]

120. Shimizu, F.; Sano, Y.; Maeda, T.; Abe, M.; Nakayama, H.; Takahashi, R.; Ueda, M.; Ohtsuki, S.; Terasaki, T.; Obinata, M.; et al. Peripheral Nerve pericytes originating from the blood-nerve barrier expresses tight junctional molecules and transporters as barrier-forming cells. J. Cell. Physiol. 2008, 217, 388-399. [CrossRef]

121. Bronger, H.; König, J.; Kopplow, K.; Steiner, H.-H.; Ahmadi, R.; Herold-Mende, C.; Keppler, D.; Nies, A.T. ABCC Drug Efflux Pumps and Organic Anion Uptake Transporters in Human Gliomas and the Blood-Tumor Barrier. Cancer Res. 2005, 65, 11419-11428. [CrossRef]

122. Cisternino, S.; Rousselle, C.; Lorico, A.; Rappa, G.; Scherrmann, J.M. Apparent lack of mrp1-mediated efflux at the luminal side of mouse blood-brain barrier endothelial cells. Pharm. Res. 2003, 20, 904-909. [CrossRef]

123. Hirrlinger, J.; König, J.; Dringen, R. Expression of mRNAs of multidrug resistance proteins (Mrps) in cultured rat astrocytes, oligodendrocytes, microglial cells and neurones. J. Neurochem. 2002, 82, 716-719. [CrossRef]

124. Dallas, S.; Schlichter, L.; Bendayan, R. Multidrug resistance protein (MRP) 4-and MRP 5-mediated efflux of 9-(2-phosphonylmethoxyethyl) adenine by microglia. J. Pharmacol. Exp. Ther. 2004, 309, 1221. [CrossRef]

125. Uchida, Y.; Goto, R.; Takeuchi, H.; Łuczak, M.; Usui, T.; Tachikawa, M.; Terasaki, T. Abundant expression of OCT2, MATE1, OAT1, OAT3, PEPT2, BCRP, MDR1 and xCT transporters in blood-arachnoid barrier of pig, and polarized localizations at CSF- and blood-facing plasma membranes. Drug Metab. Dispos. 2019, 53, dmd.119.089516. [CrossRef] 
126. Ball, K.; Bouzom, F.; Scherrmann, J.-M.; Walther, B.; Declèves, X. Physiologically based pharmacokinetic modelling of drug penetration across the blood-brain barrier-towards a mechanistic IVIVE-based approach. AAPS J. 2013, 15, 913-932. [CrossRef]

127. Syvänen, S.; Lindhe, O.; Palner, M.; Kornum, B.R.; Rahman, O.; Långström, B.; Knudsen, G.M.; Hammarlund-Udenaes, M.; Lindhe, Ö.; Palner, M. Species differences in blood-brain barrier transport of three positron emission tomography radioligands with emphasis on P-glycoprotein transport. Drug Metab. 2009, 37, 635-643. [CrossRef] [PubMed]

128. Hartz, A.; Bauer, B. ABC transporters in the CNS-an inventory. Curr. Pharm. Biotechnol. 2011, 12, 656-673. [CrossRef] [PubMed]

129. Matsumoto, Y.; Tamiya, T.; Nagao, S. Resistance to topoisomerase II inhibitors in human glioma cell lines overexpressing multidrug resistant associated protein (MRP) 2. J. Med. Invest. 2005, 52, 41-48. [CrossRef] [PubMed]

130. U.S. Department of Health and Human Services Administration, Food and Drug (CDER), Center for Drug Evaluation and Research. In vitro metabolism- and transporter-mediated drug-drug interaction studies guidance for industry. FDA Guidel. 2017, 1-45.

131. European Medicines Agency ICH topic S 7 A Safety Pharmacology Studies for Human Pharmaceuticals. Eur. Med. Agency 2002, 16, 79-81.

132. Lipinski, C.A.; Lombardo, F.; Dominy, B.W.; Feeney, P.J. Experimental and computational approaches to estimate solubility and permeability in drug discovery and development settings. Adv. Drug Deliv. Rev. 2012, 64, 4-17. [CrossRef]

133. Abbott, N.J. In Vitro Models for Examining and Predicting Brain Uptake of Drugs. In Comprehensive Medicinal Chemistry II; Elsevier: Amsterdam, The Netherlands, 2007; Volume 5, pp. 301-320, ISBN 9780080450445.

134. Bickel, U. How to measure drug transport across the blood-brain barrier. NeuroRX 2005, 2, 15-26. [CrossRef]

135. Srinivasan, B.; Kolli, A.R.; Esch, M.B.; Abaci, H.E.; Shuler, M.L.; Hickman, J.J. TEER Measurement Techniques for In Vitro Barrier Model Systems. J. Lab. Autom. 2015, 20, 107-126. [CrossRef]

136. Wilhelm, I.; Krizbai, I.A. In Vitro Models of the Blood-Brain Barrier for the Study of Drug Delivery to the Brain. Mol. Pharm. 2014, 11, 1949-1963. [CrossRef]

137. Puech, C.; Delavenne, X.; Perek, N. The expected characteristics of an in vitro human Blood Brain Barrier model derived from cell lines, for studying how ABC transporters influence drug permeability. J. Drug Deliv. Sci. Technol. 2018, 45, 159-167. [CrossRef]

138. Kuteykin-Teplyakov, K.; Luna-Tortós, C.; Ambroziak, K.; Löscher, W. Differences in the expression of endogenous efflux transporters in MDR1-transfected versus wildtype cell lines affect P-glycoprotein mediated drug transport. Br. J. Pharmacol. 2010, 160, 1453-1463. [CrossRef] [PubMed]

139. Phan, D.T.T.; Bender, R.H.F.; Andrejecsk, J.W.; Sobrino, A.; Hachey, S.J.; George, S.C.; Hughes, C.C.W. Blood-brain barrier-on-a-chip: Microphysiological systems that capture the complexity of the blood-central nervous system interface. Exp. Biol. Med. 2017, 242, 1669-1678. [CrossRef] [PubMed]

140. Pandey, P.K.; Sharma, A.K.; Gupta, U. Blood brain barrier: An overview on strategies in drug delivery, realistic in vitro modeling and in vivo live tracking. Tissue Barriers 2016, 4, e1129476. [CrossRef] [PubMed]

141. Wolff, A.; Antfolk, M.; Brodin, B.; Tenje, M. In Vitro Blood-Brain Barrier Models-An Overview of Established Models and New Microfluidic Approaches. J. Pharm. Sci. 2015, 104, 2727-2746. [CrossRef] [PubMed]

142. Naik, P.; Cucullo, L. In Vitro Blood-Brain Barrier Models: Current and Perspective Technologies. J. Pharm. Sci. 2012, 101, 1337-1354. [CrossRef] [PubMed]

143. Kaisar, M.A.; Sajja, R.K.; Prasad, S.; Abhyankar, V.V.; Liles, T.; Cucullo, L. New experimental models of the blood-brain barrier for CNS drug discovery. Expert Opin. Drug Discov. 2017, 12, 89-103. [CrossRef] [PubMed]

144. Coisne, C.; Dehouck, L.; Faveeuw, C.; Delplace, Y.; Miller, F.; Landry, C.; Morissette, C.; Fenart, L.; Cecchelli, R.; Tremblay, P.; et al. Mouse syngenic in vitro blood-brain barrier model: A new tool to examine inflammatory events in cerebral endothelium. Lab. Investig. 2005, 85, 734-746. [CrossRef]

145. Roux, F.; Couraud, P.-O. Rat Brain Endothelial Cell Lines for the Study of Blood-Brain Barrier Permeability and Transport Functions. Cell. Mol. Neurobiol. 2005, 25, 41-57. [CrossRef]

146. Bowman, P.D.; Betz, A.L.; AR, D.; Wolinsky, J.S.; Penney, J.B.; Shivers, R.R.; Goldstein, G.W. Primary culture of capillary endothelium from rat brain. In Vitro 1981, 17, 353-362. [CrossRef]

147. Perrière, N.; Demeuse, P.; Garcia, E.; Regina, A.; Debray, M.; Andreux, J.-P.; Couvreur, P.; Scherrmann, J.-M.; Temsamani, J.; Couraud, P.-O.; et al. Puromycin-based purification of rat brain capillary endothelial cell 
cultures. Effect on the expression of blood-brain barrier-specific properties. J. Neurochem. 2005, 93, 279-289. [CrossRef]

148. Calabria, A.R.; Weidenfeller, C.; Jones, A.R.; de Vries, H.E.; Shusta, E.V. Puromycin-purified rat brain microvascular endothelial cell cultures exhibit improved barrier properties in response to glucocorticoid induction. J. Neurochem. 2006, 97, 922-933. [CrossRef] [PubMed]

149. Perrière, N.; Yousif, S.; Cazaubon, S.; Chaverot, N.; Bourasset, F.; Cisternino, S.; Declèves, X.; Hori, S.; Terasaki, T.; Deli, M.; et al. A functional in vitro model of rat blood-brain barrier for molecular analysis of efflux transporters. Brain Res. 2007, 1150, 1-13. [CrossRef] [PubMed]

150. Culot, M.; Lundquist, S.; Vanuxeem, D.; Nion, S.; Landry, C.; Delplace, Y.; Dehouck, M.-P.; Berezowski, V.; Fenart, L.; Cecchelli, R. An in vitro blood-brain barrier model for high throughput (HTS) toxicological screening. Toxicol. Vitr. 2008, 22, 799-811. [CrossRef] [PubMed]

151. Patabendige, A.; Skinner, R.A.; Abbott, N.J. Establishment of a simplified in vitro porcine blood-brain barrier model with high transendothelial electrical resistance. Brain Res. 2013, 1521, 1-15. [CrossRef]

152. MacLean, A.G.; Orandle, M.S.; MacKey, J.; Williams, K.C.; Alvarez, X.; Lackner, A.A. Characterization of an in vitro rhesus macaque blood-brain barrier. J. Neuroimmunol. 2002, 131, 98-103. [CrossRef]

153. Weksler, B.; Romero, I.A.; Couraud, P.-O. The hCMEC/D3 cell line as a model of the human blood brain barrier. Fluids Barriers CNS 2013, 10, 16. [CrossRef]

154. Weksler, B.B.; Subileau, E.A.; Perrière, N.; Charneau, P.; Holloway, K.; Leveque, M.; Tricoire-Leignel, H.; Nicotra, A.; Bourdoulous, S.; Turowski, P.; et al. Blood-brain barrier-specific properties of a human adult brain endothelial cell line. FASEB J. 2005, 19, 1872-1874. [CrossRef]

155. Bernas, M.; Cardoso, F.; Daley, S. Establishment of primary cultures of human brain microvascular endothelial cells: A new and simplified method to obtain cells for an in vitro model of the blood. Nat. Protoc. 2010, 5, 1265-1272.

156. Cecchelli, R.; Aday, S.; Sevin, E.; Almeida, C.; Culot, M.; Dehouck, L.; Coisne, C.; Engelhardt, B.; Dehouck, M.-P.; Ferreira, L. A Stable and Reproducible Human Blood-Brain Barrier Model Derived from Hematopoietic Stem Cells. PLoS ONE 2014, 9, e99733. [CrossRef]

157. Ponio, J.B.-D.; El-Ayoubi, F.; Glacial, F.; Ganeshamoorthy, K.; Driancourt, C.; Godet, M.; Perrière, N.; Guillevic, O.; Couraud, P.O.; Uzan, G. Instruction of Circulating Endothelial Progenitors In Vitro towards Specialized Blood-Brain Barrier and Arterial Phenotypes. PLoS ONE 2014, 9, e84179. [CrossRef]

158. Lippmann, E.S.; Azarin, S.M.; Kay, J.E.; Nessler, R.A.; Wilson, H.K.; Al-Ahmad, A.; Palecek, S.P.; Shusta, E.V. Human Blood-Brain Barrier Endothelial Cells Derived from Pluripotent Stem Cells. Nat. Biotechnol. 2012, 30, 783-791. [CrossRef] [PubMed]

159. Lippmann, E.S.; Al-Ahmad, A.; Azarin, S.M.; Palecek, S.P.; Shusta, E.V. A retinoic acid-enhanced, multicellular human blood-brain barrier model derived from stem cell sources. Sci. Rep. 2015, 4, 4160. [CrossRef] [PubMed]

160. Cecchelli, R.; Berezowski, V.; Lundquist, S.; Culot, M.; Renftel, M.; Dehouck, M.-P.; Fenart, L. Modelling of the blood-brain barrier in drug discovery and development. Nat. Rev. Drug Discov. 2007, 6, 650-661. [CrossRef]

161. Boulay, A.-C.; Saubaméa, B.; Declèves, X.; Cohen-Salmon, M. Purification of Mouse Brain Vessels. J. Vis. Exp. 2015, e53208. [CrossRef] [PubMed]

162. Roux, F.; Durieu-Trautmann, O.; Chaverot, N.; Claire, M.; Mailly, P.; Bourre, J.M.; Strosberg, A.D.; Couraud, P.O. Regulation of gamma-glutamyl transpeptidase and alkaline phosphatase activities in immortalized rat brain microvessel endothelial cells. J. Cell. Physiol. 1994, 159, 101-113. [CrossRef]

163. Noack, A.; Noack, S.; Hoffmann, A.; Maalouf, K.; Buettner, M.; Couraud, P.-O.; Romero, I.A.; Weksler, B.; Alms, D.; Römermann, K.; et al. Drug-induced trafficking of p-glycoprotein in human brain capillary endothelial cells as demonstrated by exposure to mitomycin C. PLoS ONE 2014, 9, e88154. [CrossRef] [PubMed]

164. Vu, K.; Weksler, B.; Romero, I.; Couraud, P.-O.; Gelli, A. Immortalized human brain endothelial cell line HCMEC/D3 as a model of the blood-brain barrier facilitates in vitro studies of central nervous system infection by Cryptococcus neoformans. Eukaryot. Cell 2009, 8, 1803-1807. [CrossRef]

165. Chapy, H.; Smirnova, M.; Andre, P.; Schlatter, J.; Chiadmi, F.; Couraud, P.-O.; Scherrmann, J.-M.; Decleves, X.; Cisternino, S. Carrier-Mediated Cocaine Transport at the Blood-Brain Barrier as a Putative Mechanism in Addiction Liability. Int. J. Neuropsychopharmacol. 2015, 18, pyu001. [CrossRef] 
166. Yousif, S.; Chaves, C.; Potin, S.; Margaill, I.; Scherrmann, J.-M.; Declèves, X. Induction of P-glycoprotein and Bcrp at the rat blood-brain barrier following a subchronic morphine treatment is mediated through NMDA/COX-2 activation. J. Neurochem. 2012, 123, 491-503. [CrossRef]

167. Carl, S.M.; Lindley, D.J.; Couraud, P.O.; Weksler, B.B.; Romero, I.; Mowery, S.A.; Knipp, G.T. ABC and SLC Transporter Expression and Pot Substrate Characterization across the Human CMEC/D3 Blood-Brain Barrier Cell Line. Mol. Pharm. 2010, 7, 1057-1068. [CrossRef]

168. Ohtsuki, S.; Ikeda, C.; Uchida, Y.; Sakamoto, Y.; Miller, F.; Glacial, F.; Decleves, X.; Scherrmann, J.-M.; Couraud, P.-O.; Kubo, Y.; et al. Quantitative Targeted Absolute Proteomic Analysis of Transporters, Receptors and Junction Proteins for Validation of Human Cerebral Microvascular Endothelial Cell Line hCMEC/D3 as a Human Blood-Brain Barrier Model. Mol. Pharm. 2013, 10, 289-296. [CrossRef] [PubMed]

169. Urich, E.; Lazic, S.E.; Molnos, J.; Wells, I.; Freskgård, P.-O. Transcriptional Profiling of Human Brain Endothelial Cells Reveals Key Properties Crucial for Predictive In Vitro Blood-Brain Barrier Models. PLoS ONE 2012, 7 , e38149. [CrossRef] [PubMed]

170. Takahashi, K.; Tanabe, K.; Ohnuki, M.; Narita, M.; Ichisaka, T.; Tomoda, K.; Yamanaka, S. Induction of Pluripotent Stem Cells from Adult Human Fibroblasts by Defined Factors. Cell 2007, 131, 861-872. [CrossRef] [PubMed]

171. Grifno, G.N.; Farrell, A.M.; Linville, R.M.; Arevalo, D.; Kim, J.H.; Gu, L.; Searson, P.C. Tissue-engineered blood-brain barrier models via directed differentiation of human induced pluripotent stem cells. Sci. Rep. 2019, 9, 13957. [CrossRef]

172. Le Roux, G.; Jarray, R.; Guyot, A.-C.; Pavoni, S.; Costa, N.; Théodoro, F.; Nassor, F.; Pruvost, A.; Tournier, N.; Kiyan, Y.; et al. Proof-of-Concept Study of Drug Brain Permeability Between in Vivo Human Brain and an in Vitro iPSCs-Human Blood-Brain Barrier Model. Sci. Rep. 2019, 9, 16310. [CrossRef]

173. Shimizu, F.; Sano, Y.; Abe, M.-A.; Maeda, T.; Ohtsuki, S.; Terasaki, T.; Kanda, T. Peripheral nerve pericytes modify the blood-nerve barrier function and tight junctional molecules through the secretion of various soluble factors. J. Cell. Physiol. 2011, 226, 255-266. [CrossRef]

174. Siddharthan, V.; Kim, Y.V.; Liu, S.; Kim, K.S. Human astrocytes/astrocyte-conditioned medium and shear stress enhance the barrier properties of human brain microvascular endothelial cells. Brain Res. 2007, 1147, 39-50. [CrossRef]

175. Hartmann, C.; Zozulya, A.; Wegener, J.; Galla, H.-J. The impact of glia-derived extracellular matrices on the barrier function of cerebral endothelial cells: An in vitro study. Exp. Cell Res. 2007, 313, 1318-1325. [CrossRef]

176. Haseloff, R.F.; Blasig, I.E.; Bauer, H.-C.; Bauer, H. In Search of the Astrocytic Factor(s) Modulating Blood-Brain Barrier Functions in Brain Capillary Endothelial Cells In Vitro. Cell. Mol. Neurobiol. 2005, 25, 25-39. [CrossRef]

177. Helms, H.C.; Madelung, R.; Waagepetersen, H.S.; Nielsen, C.U.; Brodin, B. In vitro evidence for the brain glutamate efflux hypothesis: Brain endothelial cells cocultured with astrocytes display a polarized brain-to-blood transport of glutamate. Glia 2012, 60, 882-893. [CrossRef]

178. Cecchelli, R.; Dehouck, B.; Descamps, L.; Fenart, L.; Buée-Scherrer, V.; Duhem, C.; Lundquist, S.; Rentfel, M.; Torpier, G.; Dehouck, M. In vitro model for evaluating drug transport across the blood-brain barrier. Adv. Drug Deliv. Rev. 1999, 36, 165-178. [CrossRef]

179. Lai, C.-H.; Kuo, K.-H. The critical component to establish in vitro BBB model: Pericyte. Brain Res. Rev. 2005, 50, 258-265. [CrossRef] [PubMed]

180. Savettieri, G.; Di Liegro, I.; Catania, C.; Licata, L.; Pitarresi, G.L.; D’Agostino, S.; Schiera, G.; De Caro, V.; Giandalia, G.; Giannola, L.I.; et al. Neurons and ECM regulate occludin localization in brain endothelial cells. Neuroreport 2000, 11, 1081-1084. [CrossRef] [PubMed]

181. Sumi, N.; Nishioku, T.; Takata, F.; Matsumoto, J.; Watanabe, T.; Shuto, H.; Yamauchi, A.; Dohgu, S.; Kataoka, Y. Lipopolysaccharide-activated microglia induce dysfunction of the blood-brain barrier in rat microvascular endothelial cells co-cultured with microglia. Cell. Mol. Neurobiol. 2010, 30, 247-253. [CrossRef]

182. Stone, N.L.; England, T.J.; O'Sullivan, S.E. A Novel Transwell Blood Brain Barrier Model Using Primary Human Cells. Front. Cell. Neurosci. 2019, 13, 1-11. [CrossRef]

183. Malina, K.C.-K.; Cooper, I.; Teichberg, V.I. Closing the gap between the in-vivo and in-vitro blood-brain barrier tightness. Brain Res. 2009, 1284, 12-21. [CrossRef] 
184. Cantrill, C.A.; Skinner, R.A.; Rothwell, N.J.; Penny, J.I. An immortalised astrocyte cell line maintains the in vivo phenotype of a primary porcine in vitro blood-brain barrier model. Brain Res. 2012, 1479, 17-30. [CrossRef]

185. Molino, Y.; Jabès, F.; Lacassagne, E.; Gaudin, N.; Khrestchatisky, M. Setting-up an In Vitro Model of Rat Blood-brain Barrier (BBB): A Focus on BBB Impermeability and Receptor-mediated Transport. J. Vis. Exp. 2014, 88, e51278. [CrossRef]

186. Helms, H.C.; Hersom, M.; Kuhlmann, L.B.; Badolo, L.; Nielsen, C.U.; Brodin, B. An Electrically Tight In Vitro Blood-Brain Barrier Model Displays Net Brain-to-Blood Efflux of Substrates for the ABC Transporters, P-gp, Bcrp and Mrp-1. AAPS J. 2014, 16, 1046-1055. [CrossRef]

187. Gaillard, P.J.; Van Der Sandt, I.C.J.; Voorwinden, L.H.; Vu, D.; Nielsen, J.L.; De Boer, A.G.; Breimer, D.D. Astrocytes increase the functional expression of P-glycoprotein in an in vitro model of the blood-brain barrier. Pharm. Res. 2000, 17, 1198-1205. [CrossRef]

188. Brown, J.A.; Pensabene, V.; Markov, D.A.; Allwardt, V.; Neely, M.D.; Shi, M.; Britt, C.M.; Hoilett, O.S.; Yang, Q.; Brewer, B.M.; et al. Recreating blood-brain barrier physiology and structure on chip: A novel neurovascular microfluidic bioreactor. Biomicrofluidics 2015, 9, 054124. [CrossRef] [PubMed]

189. Maoz, B.M.; Herland, A.; FitzGerald, E.A.; Grevesse, T.; Vidoudez, C.; Pacheco, A.R.; Sheehy, S.P.; Park, T.-E.; Dauth, S.; Mannix, R.; et al. A linked organ-on-chip model of the human neurovascular unit reveals the metabolic coupling of endothelial and neuronal cells. Nat. Biotechnol. 2018, 36, 865-874. [CrossRef] [PubMed]

190. Patrick, C.W., Jr.; McIntire, L.V. Shear Stress and Cyclic Strain Modulation of Gene Expression in Vascular Endothelial Cells. Blood Purif. 1995, 13, 112-124. [CrossRef] [PubMed]

191. Ballermann, B.J.; Dardik, A.; Eng, E.; Liu, A. Shear stress and the endothelium. Kidney Int. 1998, 54, $100-108$. [CrossRef] [PubMed]

192. OTT, M.; BALLERMANN, B. Shear stress-conditioned, endothelial cell-seeded vascular grafts: Improved cell adherence in response to in vitro shear stress*. Surgery 1995, 117, 334-339. [CrossRef]

193. Tzima, E.; Irani-Tehrani, M.; Kiosses, W.B.; Dejana, E.; Schultz, D.A.; Engelhardt, B.; Cao, G.; DeLisser, H.; Schwartz, M.A. A mechanosensory complex that mediates the endothelial cell response to fluid shear stress. Nature 2005, 437, 426-431. [CrossRef]

194. Traub, O.; Berk, B.C. Laminar Shear Stress. Arterioscler. Thromb. Vasc. Biol. 1998, 18, 677-685. [CrossRef]

195. Ando, J.; Yamamoto, K. Vascular Mechanobiology. Circ. J. 2009, 73, 1983-1992. [CrossRef]

196. Cucullo, L.; Hossain, M.; Puvenna, V.; Marchi, N.; Janigro, D. The role of shear stress in Blood-Brain Barrier endothelial physiology. BMC Neurosci. 2011, 12, 40. [CrossRef]

197. Walsh, T.G.; Murphy, R.P.; Fitzpatrick, P.; Rochfort, K.D.; Guinan, A.F.; Murphy, A.; Cummins, P.M. Stabilization of brain microvascular endothelial barrier function by shear stress involves VE-cadherin signaling leading to modulation of pTyr-occludin levels. J. Cell. Physiol. 2011, 226, 3053-3063. [CrossRef]

198. Dewey, C.F.; Bussolari, S.R.; Gimbrone, M.A.; Davies, P.F. The Dynamic Response of Vascular Endothelial Cells to Fluid Shear Stress. J. Biomech. Eng. 1981, 103, 177-185. [CrossRef] [PubMed]

199. Colgan, O.C.; Ferguson, G.; Collins, N.T.; Murphy, R.P.; Meade, G.; Cahill, P.A.; Cummins, P.M. Regulation of bovine brain microvascular endothelial tight junction assembly and barrier function by laminar shear stress. Am. J. Physiol. Circ. Physiol. 2007, 292, H3190-H3197. [CrossRef] [PubMed]

200. Stanness, K.A.; Westrum, L.E.; Fornaciari, E.; Mascagni, P.; Nelson, J.A.; Stenglein, S.G.; Myers, T.; Janigro, D. Morphological and functional characterization of an in vitro blood-brain barrier model. Brain Res. 1997, 771, 329-342. [CrossRef]

201. Cucullo, L.; Hossain, M.; Rapp, E.; Manders, T.; Marchi, N.; Janigro, D. Development of a humanized in vitro blood-brain barrier model to screen for brain penetration of antiepileptic drugs. Epilepsia 2007, 48, 505-516. [CrossRef]

202. Cucullo, L.; Couraud, P.-O.; Weksler, B.; Romero, I.-A.; Hossain, M.; Rapp, E.; Janigro, D. Immortalized human brain endothelial cells and flow-based vascular modeling: A marriage of convenience for rational neurovascular studies. J. Cereb. Blood Flow Metab. 2008, 28, 312-328. [CrossRef]

203. Bussolari, S.R.; Dewey, C.F.; Gimbrone, M.A. Apparatus for subjecting living cells to fluid shear stress. Rev. Sci. Instrum. 1982. [CrossRef]

204. Stanness, K.A.; Guatteo, E.; Janigro, D. A dynamic model of the blood-brain barrier "in vitro". Neurotoxicology 1996, 17, 481-496. 
205. Janigro, D.; Leaman, S.M.; Stanness, K.A. Dynamic in vitro modeling of the blood-brain barrier: A novel tool for studies of drug delivery to the brain. Pharm. Sci. Technolo. Today 1999, 2, 7-12. [CrossRef]

206. Jiang, L.; Li, S.; Zheng, J.; Li, Y.; Huang, H. Recent Progress in Microfluidic Models of the Blood-Brain Barrier. Micromachines 2019, 10, 375. [CrossRef]

207. Brown, J.A.; Codreanu, S.G.; Shi, M.; Sherrod, S.D.; Markov, D.A.; Neely, M.D.; Britt, C.M.; Hoilett, O.S.; Reiserer, R.S.; Samson, P.C.; et al. Metabolic consequences of inflammatory disruption of the blood-brain barrier in an organ-on-chip model of the human neurovascular unit. J. Neuroinflammation 2016, 13, 306. [CrossRef]

208. Park, T.-E.; Mustafaoglu, N.; Herland, A.; Hasselkus, R.; Mannix, R.; FitzGerald, E.A.; Prantil-Baun, R.; Watters, A.; Henry, O.; Benz, M.; et al. Hypoxia-enhanced Blood-Brain Barrier Chip recapitulates human barrier function and shuttling of drugs and antibodies. Nat. Commun. 2019, 10, 2621. [CrossRef] [PubMed]

209. Monnot, A.D.; Zheng, W. Culture of Choroid Plexus Epithelial Cells and In Vitro Model of Blood-CSF Barrier. In Methods in Molecular Biology; Randell, S.H., Fulcher, M.L., Eds.; Humana Press: Totowa, NJ, USA, 2012; pp. 13-29, ISBN 9781627031240.

210. Menheniott, T.R.; Charalambous, M.; Ward, A. Derivation of Primary Choroid Plexus Epithelial Cells from the Mouse. In Methods in molecular biology (Clifton, N.J.); Ward, A., Tosh, D., Eds.; Humana Press: Totowa, NJ, USA, 2010; pp. 207-220.

211. Kläs, J.; Wolburg, H.; Terasaki, T.; Fricker, G.; Reichel, V. Characterization of immortalized choroid plexus epithelial cell lines for studies of transport processes across the blood-cerebrospinal fluid barrier. Cerebrospinal Fluid Res. 2010, 7, 11. [CrossRef] [PubMed]

212. ANGELOW, S.; ZENI, P.; GALLA, H. Usefulness and limitation of primary cultured porcine choroid plexus epithelial cells as an in vitro model to study drug transport at the blood?CSF barrier. Adv. Drug Deliv. Rev. 2004, 56, 1859-1873. [CrossRef] [PubMed]

213. Baehr, C.; Reichel, V.; Fricker, G. Choroid plexus epithelial monolayers-A cell culture model from porcine brain. Cerebrospinal Fluid Res. 2006, 3, 1-14. [CrossRef]

214. Delery, E.C.; MacLean, A.G. Culture Model for Non-human Primate Choroid Plexus. Front. Cell. Neurosci. 2019, 13, 1-10. [CrossRef]

215. Zheng, W.; Zhao, Q. Establishment and characterization of an immortalized Z310 choroidal epithelial cell line from murine choroid plexus. Brain Res. 2002, 958, 371-380. [CrossRef]

216. Kitazawa, T.; Hosoya, K.; Watanabe, M.; Takashima, T.; Ohtsuki, S.; Takanaga, H.; Ueda, M.; Yanai, N.; Obinata, M.; Terasaki, T. Characterization of the amino acid transport of new immortalized choroid plexus epithelial cell lines: A novel in vitro system for investigating transport functions at the blood-cerebrospinal fluid barrier. Pharm. Res. 2001, 18, 16-22. [CrossRef]

217. Janson, C.; Romanova, L.; Hansen, E.; Hubel, A.; Lam, C. Immortalization and functional characterization of rat arachnoid cell lines. Neuroscience 2011, 177, 23-34. [CrossRef]

218. Holman, D.W.; Grzybowski, D.M.; Mehta, B.C.; Katz, S.E.; Lubow, M. Characterization of cytoskeletal and junctional proteins expressed by cells cultured from human arachnoid granulation tissue. Cerebrospinal Fluid Res. 2005, 2, 1-12. [CrossRef]

219. Hansen, E.A.; Romanova, L.; Janson, C.; Lam, C.H. The effects of blood and blood products on the arachnoid cell. Exp. Brain Res. 2017, 235, 1749-1758. [CrossRef]

220. Chen, X.; Loryan, I.; Payan, M.; Keep, R.F.; Smith, D.E.; Hammarlund-Udenaes, M. Effect of transporter inhibition on the distribution of cefadroxil in rat brain. Fluids Barriers CNS 2014, 11, 25. [CrossRef] [PubMed]

221. Cho, S.; Wood, A.; Bowlby, M. Brain Slices as Models for Neurodegenerative Disease and Screening Platforms to Identify Novel Therapeutics. Curr. Neuropharmacol. 2007, 5, 19-33. [CrossRef] [PubMed]

222. Uchida, Y.; Ohtsuki, S.; Kamiie, J.; Terasaki, T. Blood-Brain Barrier (BBB) Pharmacoproteomics: Reconstruction of In Vivo Brain Distribution of 11 P-Glycoprotein Substrates Based on the BBB Transporter Protein Concentration, In Vitro Intrinsic Transport Activity, and Unbound Fraction in Plasma and Brain. J. Pharmacol. Exp. Ther. 2011, 339, 579-588. [CrossRef] [PubMed]

223. Chaves, C.; Gómez-Zepeda, D.; Auvity, S.; Menet, M.-C.; Crété, D.; Labat, L.; Remião, F.; Cisternino, S.; Declèves, X. Effect of Subchronic Intravenous Morphine Infusion and Naloxone-Precipitated Morphine Withdrawal on P-gp and Bcrp at the Rat Blood-Brain Barrier. J. Pharm. Sci. 2016, 105, 350-358. [CrossRef] [PubMed] 
224. Jacob, A.; Hartz, A.M.; Potin, S.; Coumoul, X.; Yousif, S.; Scherrmann, J.-M.; Bauer, B.; Declèves, X. Aryl hydrocarbon receptor-dependent upregulation of Cyp1b1 by TCDD and diesel exhaust particles in rat brain microvessels. Fluids Barriers CNS 2011, 8, 23. [CrossRef] [PubMed]

225. Luo, H.; Gauthier, M.; Tan, X.; Landry, C.; Poupon, J.; Dehouck, M.-P.; Gosselet, F.; Perrière, N.; Bellivier, F.; Cisternino, S.; et al. Sodium Transporters Are Involved in Lithium Influx in Brain Endothelial Cells. Mol. Pharm. 2018, 15, 2528-2538. [CrossRef]

226. Luo, H.; Rossi, E.; Saubamea, B.; Chasseigneaux, S.; Cochois, V.; Choublier, N.; Smirnova, M.; Glacial, F.; Perrière, N.; Bourdoulous, S.; et al. Cannabidiol Increases Proliferation, Migration, Tubulogenesis, and Integrity of Human Brain Endothelial Cells through TRPV2 Activation. Mol. Pharm. 2019, 16, 1312-1326. [CrossRef]

227. Dodacki, A.; Wortman, M.; Saubaméa, B.; Chasseigneaux, S.; Nicolic, S.; Prince, N.; Lochus, M.; Raveu, A.-L.; Declèves, X.; Scherrmann, J.-M.; et al. Expression and function of Abcg4 in the mouse blood-brain barrier: Role in restricting the brain entry of amyloid- $\beta$ peptide. Sci. Rep. 2017, 7, 13393. [CrossRef]

228. Dayton, J.R.; Franke, M.C.; Yuan, Y.; Cruz-Orengo, L. Straightforward method for singularized and region-specific CNS microvessels isolation. J. Neurosci. Methods 2019, 318, 17-33. [CrossRef]

229. Rosas-Hernandez, H.; Cuevas, E.; Lantz, S.M.; Paule, M.G.; Ali, S.F. Isolation and Culture of Brain Microvascular Endothelial Cells for In Vitro Blood-Brain Barrier Studies. In Neurotrophic Factors: Methods and Protocols; Skaper, S.D., Ed.; Humana Press: Totowa, NJ, USA, 2018; Volume 1727, pp. 315-331, ISBN 9780128110379.

230. Steffensen, A.B.; Oernbo, E.K.; Stoica, A.; Gerkau, N.J.; Barbuskaite, D.; Tritsaris, K.; Rose, C.R.; MacAulay, N. Cotransporter-mediated water transport underlying cerebrospinal fluid formation. Nat. Commun. 2018, 9, 1-13. [CrossRef]

231. Baird, A.; Eliceiri, B.P.; Gonzalez, A.M.; Johanson, C.E.; Leadbeater, W.; Stopa, E.G. Targeting the Choroid Plexus-CSF-Brain Nexus Using Peptides Identified by Phage Display. In Methods in Molecular Biology (Clifton, N.J.); Humana Press: Totowa, NJ, USA, 2011; Volume 686, pp. 483-498, ISBN 9781607619383.

232. Gonzalez, A.; Leadbeater, W.E.; Burg, M.; Sims, K.; Terasaki, T.; Johanson, C.E.; Stopa, E.G.; Eliceiri, B.P.; Baird, A. Targeting choroid plexus epithelia and ventricular ependyma for drug delivery to the central nervous system. BMC Neurosci. 2011, 12, 4. [CrossRef] [PubMed]

233. Brandhonneur, N.; Dollo, G.; Ratajczak-Enselme, M.; Deniau, A.L.; Chevanne, F.; Estbe, J.P.; Legrand, A.; Le Corre, P. Ex vivo and in vivo diffusion of ropivacaine through spinal meninges: Influence of absorption enhancers. Int. J. Pharm. 2011, 404, 36-41. [CrossRef] [PubMed]

234. Glimcher, S.A.; Holman, D.W.; Lubow, M.; Grzybowski, D.M. Ex Vivo Model of Cerebrospinal Fluid Outflow across Human Arachnoid Granulations. Investig. Opthalmology Vis. Sci. 2008, 49, 4721. [CrossRef] [PubMed]

235. Huse, J.T.; Holland, E.C. Genetically engineered mouse models of brain cancer and the promise of preclinical testing. Brain Pathol. 2009, 19, 132-143. [CrossRef] [PubMed]

236. Sadiq, M.W.; Uchida, Y.; Hoshi, Y.; Tachikawa, M.; Terasaki, T.; Hammarlund-Udenaes, M. Validation of a P-Glycoprotein (P-gp) Humanized Mouse Model by Integrating Selective Absolute Quantification of Human MDR1, Mouse Mdr1a and Mdr1b Protein Expressions with In Vivo Functional Analysis for Blood-Brain Barrier Transport. PLoS ONE 2015, 10, e0118638. [CrossRef]

237. Yamasaki, Y.; Kobayashi, K.; Okuya, F.; Kajitani, N.; Kazuki, K.; Abe, S.; Takehara, S.; Ito, S.; Ogata, S.; Uemura, T.; et al. Characterization of P-glycoprotein humanized mice generated by chromosome engineering technology: Its utility for prediction of drug distribution to the brain in humans. Drug Metab. Dispos. 2018, 46, 1756-1766. [CrossRef]

238. Dallas, S.; Salphati, L.; Gomez-Zepeda, D.; Wanek, T.; Chu, X.; Kunta, J.; Mezler, M.; Menet, M.M.-C.; Declèves, X.; Langer, O.; et al. Generation and Characterization of a Breast Cancer Resistance Protein Humanized Mouse Model. Mol. Pharmacol. 2016, 89, 492-504. [CrossRef]

239. Krohn, M.; Zoufal, V.; Mairinger, S.; Wanek, T.; Paarmann, K.; Brüning, T.; Eiriz, I.; Brackhan, M.; Langer, O.; Pahnke, J. Generation and Characterization of an Abcc1 Humanized Mouse Model (hABCC1 flx/flx) with Knockout Capability. Mol. Pharmacol. 2019, 96, 138-147. [CrossRef]

240. Kusuhara, H.; Sugiyama, Y. Active efflux across the blood-brain barrier: Role of the solute carrier family. NeuroRx 2005, 2, 73-85. [CrossRef]

241. Takasato, Y.; Rapoport, S.I.; Smith, Q.R. An in situ brain perfusion technique to study cerebrovascular transport in the rat. Am. J. Physiol. Circ. Physiol. 1984, 247, H484-H493. [CrossRef] 
242. Cattelotte, J.; André, P.; Ouellet, M.; Bourasset, F.; Scherrmann, J.-M.; Cisternino, S. In situ mouse carotid perfusion model: Glucose and cholesterol transport in the eye and brain. J. Cereb. Blood Flow Metab. 2008, 28, 1449-1459. [CrossRef]

243. Chapy, H.; Saubaméa, B.; Tournier, N.; Bourasset, F.; Behar-Cohen, F.; Declèves, X.; Scherrmann, J.-M.; Cisternino, S. Blood-brain and retinal barriers show dissimilar ABC transporter impacts and concealed effect of P-glycoprotein on a novel verapamil influx carrier. Br. J. Pharmacol. 2016, 173, 497-510. [CrossRef]

244. Taccola, C.; Cartot-Cotton, S.; Valente, D.; Barneoud, P.; Aubert, C.; Boutet, V.; Gallen, F.; Lochus, M.; Nicolic, S.; Dodacki, A.; et al. High brain distribution of a new central nervous system drug candidate despite its P-glycoprotein-mediated efflux at the mouse blood-brain barrier. Eur. J. Pharm. Sci. 2018, 117, 68-79. [CrossRef]

245. Tournier, N.; Stieger, B.; Langer, O. Imaging techniques to study drug transporter function in vivo. Pharmacol. Ther. 2018, 189, 104-122. [CrossRef]

246. Langer, O. Use of PET Imaging to Evaluate Transporter-Mediated Drug-Drug Interactions. J. Clin. Pharmacol. 2016, 56, S143-S156. [CrossRef]

247. Suridjan, I.; Comley, R.A.; Rabiner, E.A. The application of positron emission tomography (PET) imaging in CNS drug development. Brain Imaging Behav. 2019, 13, 354-365. [CrossRef]

248. Syvänen, S.; Eriksson, J. Advances in PET imaging of P-glycoprotein function at the blood-brain barrier. ACS Chem. Neurosci. 2013, 4, 225-237. [CrossRef]

249. Traxl, A.; Wanek, T.; Mairinger, S.; Stanek, J.; Filip, T.; Sauberer, M.; Muller, M.; Kuntner, C.; Langer, O. Breast Cancer Resistance Protein and P-Glycoprotein Influence In Vivo Disposition of ${ }^{11}$ C-Erlotinib. J. Nucl. Med. 2015, 56, 1930-1936. [CrossRef]

250. Tournier, N.; Goutal, S.; Auvity, S.; Traxl, A.; Mairinger, S.; Wanek, T.; Helal, O.; Buvat, I.; Soussan, M.; Caillé, F.; et al. Strategies to Inhibit ABCB1- and ABCG2-Mediated Efflux Transport of Erlotinib at the Blood-Brain Barrier: A PET Study on Nonhuman Primates. J. Nucl. Med. 2017, 58, 117-122. [CrossRef]

251. Bauer, M.; Karch, R.; Wulkersdorfer, B.; Philippe, C.; Nics, L.; Klebermass, E.; Weber, M.; Poschner, S.; Haslacher, H.; Jäger, W.; et al. A Proof-of-Concept Study to Inhibit ABCG2- and ABCB1-Mediated Efflux Transport at the Human Blood-Brain Barrier. J. Nucl. Med. 2019, 60, 486-491. [CrossRef]

252. Kawamura, K.; Konno, F.; Yamasaki, T.; Yui, J.; Hatori, A.; Yanamoto, K.; Irie, T.; Fukumura, T.; Suzuki, K.; Kanno, I.; et al. Synthesis and evaluation of C-11 labeled dual modulator for P-gp and BCRP as a PET probe. J. Label. Compd. Radiopharm. 2009, 52, S370.

253. Wanek, T.; Kuntner, C.; Bankstahl, J.P.; Bankstahl, M.; Stanek, J.; Sauberer, M.; Mairinger, S.; Strommer, S.; Wacheck, V.; Löscher, W.; et al. A comparative small-animal PET evaluation of $\left[{ }^{11} \mathrm{C}\right]$ tariquidar, $\left[{ }^{11} \mathrm{C}\right]$ elacridar and (R)-[ $\left.{ }^{11} \mathrm{C}\right]$ verapamil for detection of P-glycoprotein-expressing murine breast cancer. Eur. J. Nucl. Med. Mol. Imaging 2012, 39, 149-159. [CrossRef]

254. Bauer, M.; Karch, R.; Zeitlinger, M.; Stanek, J.; Philippe, C.; Wadsak, W.; Mitterhauser, M.; Jager, W.; Haslacher, H.; Muller, M.; et al. Interaction of ${ }^{11} \mathrm{C}$-Tariquidar and ${ }^{11} \mathrm{C}$-Elacridar with P-Glycoprotein and Breast Cancer Resistance Protein at the Human Blood-Brain Barrier. J. Nucl. Med. 2013, 54, 1181-1187. [CrossRef]

255. Dörner, B.; Kuntner, C.; Bankstahl, J.P.; Bankstahl, M.; Stanek, J.; Wanek, T.; Stundner, G.; Mairinger, S.; Löscher, W.; Müller, M.; et al. Synthesis and Small-Animal Positron Emission Tomography Evaluation of $\left[{ }^{11} \mathrm{C}\right]$-Elacridar As a Radiotracer to Assess the Distribution of P-Glycoprotein at the Blood-Brain Barrier. J. Med. Chem. 2009, 52, 6073-6082. [CrossRef]

256. Wanek, T.; Kuntner, C.; Bankstahl, J.P.; Mairinger, S.; Bankstahl, M.; Stanek, J.; Sauberer, M.; Filip, T.; Erker, T.; Müller, M.; et al. A Novel PET Protocol for Visualization of Breast Cancer Resistance Protein Function at the Blood-Brain Barrier. J. Cereb. Blood Flow Metab. 2012, 32, 2002-2011. [CrossRef]

257. Bauer, F.; Kuntner, C.; Bankstahl, J.P.; Wanek, T.; Bankstahl, M.; Stanek, J.; Mairinger, S.; Dörner, B.; Löscher, W.; Müller, M.; et al. Synthesis and in vivo evaluation of $\left[{ }^{11} \mathrm{C}\right]$ tariquidar, a positron emission tomography radiotracer based on a third-generation P-glycoprotein inhibitor. Bioorg. Med. Chem. 2010, 18, 5489-5497. [CrossRef]

258. Saleem, A.; Brown, G.D.; Brady, F.; Aboagye, E.O.; Osman, S.; Luthra, S.K.; Ranicar, A.S.O.; Brock, C.S.; Stevens, M.F.G.; Newlands, E.; et al. Metabolic activation of temozolomide measured in vivo using positron emission tomography. Cancer Res. 2003, 63, 2409-2415. 
259. Römermann, K.; Wanek, T.; Bankstahl, M.; Bankstahl, J.P.; Fedrowitz, M.; Müller, M.; Löscher, W.; Kuntner, C.; Langer, O. (R)-[ $\left.{ }^{11} \mathrm{C}\right]$ verapamil is selectively transported by murine and human P-glycoprotein at the blood-brain barrier, and not by MRP1 and BCRP. Nucl. Med. Biol. 2013, 40, 873-878. [CrossRef]

260. Luurtsema, G.; Molthoff, C.F.; Windhorst, A.; Smit, J.; Keizer, H.; Boellaard, R.; Lammertsma, A.; Franssen, E.J. (R)- and (S)-[ $\left.{ }^{11} \mathrm{C}\right]$ verapamil as PET-tracers for measuring P-glycoprotein function: In vitro and in vivo evaluation. Nucl. Med. Biol. 2003, 30,747-751. [CrossRef]

261. Hendrikse, N.H.; De Vries, E.G.E.; Eriks-Fluks, L.; Van Der Graaf, W.T.A.; Hospers, G.A.P.; Willemsen, A.T.M.; Vaalburg, W.; Franssen, E.J.F. A new in vivo method to study P-glycoprotein transport in tumors and the blood-brain barrier. Cancer Res. 1999, 59, 2411-2416.

262. Sasongko, L.; Link, J.; Muzi, M.; Mankoff, D.; Yang, X.; Collier, A.; Shoner, S.; Unadkat, J. Imaging P-glycoprotein transport activity at the human blood-brain barrier with positron emission tomography. Clin. Pharmacol. Ther. 2005, 77, 503-514. [CrossRef] [PubMed]

263. Kannan, P.; Brimacombe, K.R.; Zoghbi, S.S.; Liow, J.-S.; Morse, C.; Taku, A.K.; Pike, V.W.; Halldin, C.; Innis, R.B.; Gottesman, M.M.; et al. N-desmethyl -Loperamide Is Selective for P-Glycoprotein among Three ATP-Binding Cassette Transporters at the Blood-Brain Barrier. Drug Metab. Dispos. 2010, 38, 917-922. [CrossRef] [PubMed]

264. Damont, A.; Goutal, S.; Auvity, S.; Valette, H.; Kuhnast, B.; Saba, W.; Tournier, N. Imaging the impact of cyclosporin A and dipyridamole on P-glycoprotein (ABCB1) function at the blood-brain barrier:

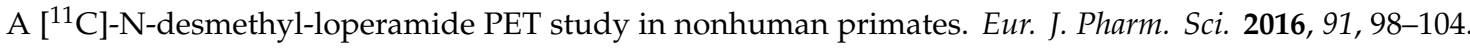
[CrossRef] [PubMed]

265. Zoghbi, S.S.; Liow, J.-S.; Yasuno, F.; Hong, J.; Tuan, E.; Lazarova, N.; Gladding, R.L.; Pike, V.W.; Innis, R.B. ${ }^{11}$ C-Loperamide and Its N-Desmethyl Radiometabolite Are Avid Substrates for Brain Permeability-Glycoprotein Efflux. J. Nucl. Med. 2008, 49, 649-656. [CrossRef] [PubMed]

266. Hosten, B.; Boisgard, R.; Jacob, A.; Goutal, S.; Saubaméa, B.; Dollé, F.; Scherrmann, J.-M.; Cisternino, S.; Tournier, N. $\left[{ }^{11} \mathrm{C}\right]$ befloxatone brain kinetics is not influenced by Bcrp function at the blood-brain barrier: A PET study using Bcrp TGEM knockout rats. Eur. J. Pharm. Sci. 2013, 50, 520-525. [CrossRef]

267. Mairinger, S.; Langer, O.; Kuntner, C.; Wanek, T.; Bankstahl, J.P.; Bankstahl, M.; Stanek, J.; Dörner, B.; Bauer, F.; Baumgartner, C.; et al. Synthesis and in vivo evaluation of the putative breast cancer resistance protein inhibitor $\left[{ }^{11} \mathrm{C}\right]$ methyl 4-((4-(2-(6,7-dimethoxy-1,2,3,4-tetrahydroisoquinolin-2-yl)ethyl) phenyl)amino-carbonyl)-2-(quinoline-2-carbonylamino)benzoate. Nucl. Med. Biol. 2010, 37, 637-644. [CrossRef]

268. Sivapackiam, J.; Harpstrite, S.E.; Prior, J.L.; Mattingly, S.; Sharma, V. 67/68Galmydar: A metalloprobe for monitoring breast cancer resistance protein (BCRP)-mediated functional transport activity. Nucl. Med. Biol. 2016, 43, 191-197. [CrossRef]

269. Okamura, T.; Kikuchi, T.; Okada, M.; Toramatsu, C.; Fukushi, K.; Takei, M.; Irie, T. Noninvasive and Quantitative Assessment of the Function of Multidrug Resistance-Associated Protein 1 in the Living Brain. J. Cereb. Blood Flow Metab. 2009, 29, 504-511. [CrossRef]

270. Krohn, M.; Wanek, T.; Menet, M.-C.; Noack, A.; Declèves, X.; Langer, O.; Löscher, W.; Pahnke, J. Humanization of the blood-brain barrier transporter $\mathrm{ABCB} 1$ in mice disrupts genomic locus - lessons from three unsuccessful approaches. Eur. J. Microbiol. Immunol. 2018, 8, 78-86. [CrossRef]

271. Bart, J.; Willemsen, A.T.M.; Groen, H.J.M.; van der Graaf, W.T.; Wegman, T.D.; Vaalburg, W.; de Vries, E.G.; Hendrikse, N.H. Quantitative assessment of P-glycoprotein function in the rat blood-brain barrier by distribution volume of $\left[{ }^{11} \mathrm{C}\right]$ verapamil measured with PET. Neuroimage 2003, 20, 1775-1782. [CrossRef]

272. Bauer, M.; Tournier, N.; Langer, O. Imaging P-Glycoprotein Function at the Blood-Brain Barrier as a Determinant of the Variability in Response to Central Nervous System Drugs. Clin. Pharmacol. Ther. 2019, 105, 1061-1064. [CrossRef]

273. Goutal, S.; Gerstenmayer, M.; Auvity, S.; Caillé, F.; Mériaux, S.; Buvat, I.; Larrat, B.; Tournier, N. Physical blood-brain barrier disruption induced by focused ultrasound does not overcome the transporter-mediated efflux of erlotinib. J. Control. Release 2018, 292, 210-220. [CrossRef]

274. Prideaux, B.; Stoeckli, M. Mass spectrometry imaging for drug distribution studies. J. Proteomics 2012, 75, 4999-5013. [CrossRef]

275. Nilsson, A.; Goodwin, R.J.A.; Shariatgorji, M.; Vallianatou, T.; Webborn, P.J.H.; Andrén, P.E. Mass Spectrometry Imaging in Drug Development. Anal. Chem. 2015, 87, 1437-1455. [CrossRef] 
276. Fack, F.; Tardito, S.; Hochart, G.; Oudin, A.; Zheng, L.; Fritah, S.; Golebiewska, A.; Nazarov, P.V.; Bernard, A.; Hau, A.; et al. Altered metabolic landscape in IDH-mutant gliomas affects phospholipid, energy, and oxidative stress pathways. EMBO Mol. Med. 2017, 9, 1681-1695. [CrossRef]

277. Dilillo, M.; Ait-Belkacem, R.; Esteve, C.; Pellegrini, D.; Nicolardi, S.; Costa, M.; Vannini, E.; de Graaf, E.L.; Caleo, M.; McDonnell, L.A. Ultra-High Mass Resolution MALDI Imaging Mass Spectrometry of Proteins and Metabolites in a Mouse Model of Glioblastoma. Sci. Rep. 2017, 7, 603. [CrossRef]

278. Jarmusch, A.K.; Alfaro, C.M.; Pirro, V.; Hattab, E.M.; Cohen-Gadol, A.A.; Cooks, R.G. Differential Lipid Profiles of Normal Human Brain Matter and Gliomas by Positive and Negative Mode Desorption Electrospray Ionization-Mass Spectrometry Imaging. PLoS ONE 2016, 11, e0163180. [CrossRef]

279. Liu, X.; Ide, J.L.; Norton, I.; Marchionni, M.A.; Ebling, M.C.; Wang, L.Y.; Davis, E.; Sauvageot, C.M.; Kesari, S.; Kellersberger, K.A.; et al. Molecular imaging of drug transit through the blood-brain barrier with MALDI mass spectrometry imaging. Sci. Rep. 2013, 3, 2859. [CrossRef]

280. Jove, M.; Spencer, J.; Clench, M.; Loadman, P.M.; Twelves, C. Precision pharmacology: Mass spectrometry imaging and pharmacokinetic drug resistance. Crit. Rev. Oncol. Hematol. 2019, 141, 153-162. [CrossRef]

281. Eberlin, L.S.; Norton, I.; Orringer, D.; Dunn, I.F.; Liu, X.; Ide, J.L.; Jarmusch, A.K.; Ligon, K.L.; Jolesz, F.A.; Golby, A.J.; et al. Ambient mass spectrometry for the intraoperative molecular diagnosis of human brain tumors. Proc. Natl. Acad. Sci. USA 2013, 110, 1611-1616. [CrossRef]

282. Eberlin, L.S.; Norton, I.; Dill, A.L.; Golby, A.J.; Ligon, K.L.; Santagata, S.; Cooks, R.G.; Agar, N.Y.R. Classifying Human Brain Tumors by Lipid Imaging with Mass Spectrometry. Cancer Res. 2012, 72, 645-654. [CrossRef]

283. Clark, A.R.; Calligaris, D.; Regan, M.S.; Pomeranz Krummel, D.; Agar, J.N.; Kallay, L.; MacDonald, T.; Schniederjan, M.; Santagata, S.; Pomeroy, S.L.; et al. Rapid discrimination of pediatric brain tumors by mass spectrometry imaging. J. Neurooncol. 2018, 140, 269-279. [CrossRef]

284. Le Rhun, E.; Duhamel, M.; Wisztorski, M.; Gimeno, J.-P.; Zairi, F.; Escande, F.; Reyns, N.; Kobeissy, F.; Maurage, C.-A.; Salzet, M.; et al. Evaluation of non-supervised MALDI mass spectrometry imaging combined with microproteomics for glioma grade III classification. Biochim. Biophys. Acta-Proteins Proteomics 2017, 1865, 875-890. [CrossRef]

285. de Lange, E.C.M.; van den Brink, W.; Yamamoto, Y.; de Witte, W.E.A.; Wong, Y.C. Novel CNS drug discovery and development approach: Model-based integration to predict neuro-pharmacokinetics and pharmacodynamics. Expert Opin. Drug Discov. 2017, 12, 1207-1218. [CrossRef]

286. Bendels, S.; Kansy, M.; Wagner, B.; Huwyler, J. In silico prediction of brain and CSF permeation of small molecules using PLS regression models. Eur. J. Med. Chem. 2008, 43, 1581-1592. [CrossRef]

287. Loryan, I.; Sinha, V.; Mackie, C.; Van Peer, A.; Drinkenburg, W.H.; Vermeulen, A.; Heald, D.; Hammarlund-Udenaes, M.; Wassvik, C.M. Molecular Properties Determining Unbound Intracellular and Extracellular Brain Exposure of CNS Drug Candidates. Mol. Pharm. 2015, 12, 520-532. [CrossRef]

288. Fleming, N. How artificial intelligence is changing drug discovery. Nature 2018, 557, S55-S57. [CrossRef]

289. Chen, H.; Winiwarter, S.; Fridén, M.; Antonsson, M.; Engkvist, O. In silico prediction of unbound brain-to-plasma concentration ratio using machine learning algorithms. J. Mol. Graph. Model. 2011, 29, 985-995. [CrossRef]

290. Plisson, F.; Piggott, A. Predicting Blood-Brain Barrier Permeability of Marine-Derived Kinase Inhibitors Using Ensemble Classifiers Reveals Potential Hits for Neurodegenerative Disorders. Mar. Drugs 2019, $17,81$. [CrossRef]

291. de Lange, E.C.M. PBPK Modeling Approach for Predictions of Human CNS Drug Brain Distribution. In Blood-Brain Barrier in Drug Discovery; John Wiley \& Sons, Inc.: Hoboken, NJ, USA, 2015; pp. $296-323$.

292. Bouzom, F.; Ball, K.; Perdaems, N.; Walther, B. Physiologically based pharmacokinetic (PBPK) modelling tools: How to fit with our needs? Biopharm. Drug Dispos. 2012, 33, 55-71. [CrossRef]

293. Ball, K.; Bouzom, F.; Scherrmann, J.-M.; Walther, B.; Declèves, X. Development of a Physiologically Based Pharmacokinetic Model for the Rat Central Nervous System and Determination of an In Vitro-In Vivo Scaling Methodology for the Blood-Brain Barrier Permeability of Two Transporter Substrates, Morphine and Oxycodone. J. Pharm. Sci. 2012, 101, 4277-4292. [CrossRef]

294. Yamamoto, Y.; Välitalo, P.A.; Wong, Y.C.; Huntjens, D.R.; Proost, J.H.; Vermeulen, A.; Krauwinkel, W.; Beukers, M.W.; Kokki, H.; Kokki, M.; et al. Prediction of human CNS pharmacokinetics using a physiologically-based pharmacokinetic modeling approach. Eur. J. Pharm. Sci. 2018, 112, 168-179. [CrossRef] 
295. Uchida, Y.; Wakayama, K.; Ohtsuki, S.; Chiba, M.; Ohe, T.; Ishii, Y.; Terasaki, T. Blood-Brain Barrier Pharmacoproteomics-Based Reconstruction of the In Vivo Brain Distribution of P-Glycoprotein Substrates in Cynomolgus Monkeys. J. Pharmacol. Exp. Ther. 2014, 350, 578-588. [CrossRef]

296. Trapa, P.E.; Troutman, M.D.; Lau, T.Y.; Wager, T.T.; Maurer, T.S.; Patel, N.C.; West, M.A.; Umland, J.P.; Carlo, A.A.; Feng, B.; et al. In Vitro-In Vivo Extrapolation of Key Transporter Activity at the Blood-Brain Barrier. Drug Metab. Dispos. 2019, 47, 405-411. [CrossRef]

297. Al Feteisi, H.; Al-Majdoub, Z.M.; Achour, B.; Couto, N.; Rostami-Hodjegan, A.; Barber, J. Identification and quantification of blood-brain barrier transporters in isolated rat brain microvessels. J. Neurochem. 2018, 146, 670-685. [CrossRef]

298. Chun, H.B.; Scott, M.; Niessen, S.; Hoover, H.; Baird, A.; Yates, J.; Torbett, B.E.; Eliceiri, B.P. The proteome of mouse brain microvessel membranes and basal lamina. J. Cereb. Blood Flow Metab. 2011, 31, 2267-2281. [CrossRef]

299. Chasseigneaux, S.; Moraca, Y.; Cochois-Guégan, V.; Boulay, A.-C.; Gilbert, A.; Le Crom, S.; Blugeon, C.; Firmo, C.; Cisternino, S.; Laplanche, J.-L.; et al. Isolation and differential transcriptome of vascular smooth muscle cells and mid-capillary pericytes from the rat brain. Sci. Rep. 2018, 8, 12272. [CrossRef]

300. Porte, B.; Chatelain, C.; Hardouin, J.; Derambure, C.; Zerdoumi, Y.; Hauchecorne, M.; Dupré, N.; Bekri, S.; Gonzalez, B.; Marret, S.; et al. Proteomic and transcriptomic study of brain microvessels in neonatal and adult mice. PLoS ONE 2017, 12, e0171048. [CrossRef]

301. Karamanos, Y.; Gosselet, F.; Dehouck, M.-P.; Cecchelli, R. Blood-Brain Barrier Proteomics: Towards the Understanding of Neurodegenerative Diseases. Arch. Med. Res. 2014, 45, 730-737. [CrossRef]

302. Uchida, Y.; Tachikawa, M.; Obuchi, W.; Hoshi, Y.; Tomioka, Y.; Ohtsuki, S.; Terasaki, T. A study protocol for quantitative targeted absolute proteomics (QTAP) by LC-MS/MS: Application for inter-strain differences in protein expression levels of transporters, receptors, claudin-5, and marker proteins at the blood-brain barrier in ddY, FVB, an. Fluids Barriers CNS 2013, 10, 21. [CrossRef]

303. Gomez-Zepeda, D.; Taghi, M.; Smirnova, M.; Sergent, P.; Liu, W.; Chhuon, C.; Vidal, M.; Picard, M.; Thioulouse, E.; Broutin, I.; et al. LC-MS/MS-based quantification of efflux transporter proteins at the BBB. J. Pharm. Biomed. Anal. 2019, 164, 496-508. [CrossRef]

304. Gerber, S.A.; Rush, J.; Stemman, O.; Kirschner, M.W.; Gygi, S.P. Absolute quantification of proteins and phosphoproteins from cell lysates by tandem MS. Proc. Natl. Acad. Sci. USA 2003, 100, 6940-6945. [CrossRef]

305. Billington, S.; Salphati, L.; Hop, C.E.C.A.; Chu, X.; Evers, R.; Burdette, D.; Rowbottom, C.; Lai, Y.; Xiao, G.; Humphreys, W.G.; et al. Interindividual and Regional Variability in Drug Transporter Abundance at the Human Blood-Brain Barrier Measured by Quantitative Targeted Proteomics. Clin. Pharmacol. Ther. 2019, 106, 228-237. [CrossRef]

306. Prasad, B.; Achour, B.; Artursson, P.; Hop, C.E.C.A.; Lai, Y.; Smith, P.C.; Barber, J.; Wisniewski, J.R.; Spellman, D.; Uchida, Y.; et al. Toward a Consensus on Applying Quantitative Liquid Chromatography-Tandem Mass Spectrometry Proteomics in Translational Pharmacology Research: A White Paper. Clin. Pharmacol. Ther. 2019, 106, 525-543. [CrossRef]

307. Plate, K.H.; Scholz, A.; Dumont, D.J. Tumor angiogenesis and anti-angiogenic therapy in malignant gliomas revisited. Acta Neuropathol. 2012, 124, 763-775. [CrossRef]

308. Ohgaki, H. Genetic Pathways to Glioblastoma: A Population-Based Study. Cancer Res. 2004, 64, 6892-6899. [CrossRef]

309. Thompson, C.B. Metabolic Enzymes as Oncogenes or Tumor Suppressors. N. Engl. J. Med. 2009, 360, $813-815$. [CrossRef]

310. Yan, H.; Parsons, D.W.; Jin, G.; McLendon, R.; Rasheed, B.A.; Yuan, W.; Kos, I.; Batinic-Haberle, I.; Jones, S.; Riggins, G.J.; et al. IDH1 and IDH2 Mutations in Gliomas. N. Engl. J. Med. 2009, 360, 765-773. [CrossRef]

311. Chen, R.; Smith-Cohn, M.; Cohen, A.L.; Colman, H. Glioma Subclassifications and Their Clinical Significance. Neurotherapeutics 2017, 14, 284-297. [CrossRef]

312. Sun, H.; Yin, L.; Li, S.; Han, S.; Song, G.; Liu, N.; Yan, C. Prognostic significance of IDH mutation in adult low-grade gliomas: A meta-analysis. J. Neurooncol. 2013, 113, 277-284. [CrossRef]

313. Choi, C.; Ganji, S.K.; DeBerardinis, R.J.; Hatanpaa, K.J.; Rakheja, D.; Kovacs, Z.; Yang, X.-L.; Mashimo, T.; Raisanen, J.M.; Marin-Valencia, I.; et al. 2-hydroxyglutarate detection by magnetic resonance spectroscopy in IDH-mutated patients with gliomas. Nat. Med. 2012, 18, 624-629. [CrossRef] 
314. Schumacher, T.; Bunse, L.; Pusch, S.; Sahm, F.; Wiestler, B.; Quandt, J.; Menn, O.; Osswald, M.; Oezen, I.; Ott, M.; et al. A vaccine targeting mutant IDH1 induces antitumour immunity. Nature 2014, 512, 324-327. [CrossRef]

315. Forman, D.; Bray, F.; Brewster, D.H.; Gombe Mbalawa, C.; Kohler, B.; Piñeros, M.; Steliarova-Foucher, E.; Swaminathan, R.; Ferlay, J. (Eds.) Cancer Incidence in Five Continents Volume X; IARC Scientific Publication: Lyon, France, 2014; Volume 164, ISBN 978-92-832-2165-4.

316. Ostrom, Q.T.; Bauchet, L.; Davis, F.G.; Deltour, I.; Fisher, J.L.; Langer, C.E.; Pekmezci, M.; Schwartzbaum, J.A.; Turner, M.C.; Walsh, K.M.; et al. The epidemiology of glioma in adults: A state of the science review. Neuro. Oncol. 2014, 16, 896-913. [CrossRef]

317. Bauchet, L.; Mathieu-Daude, H.; Fabbro-Peray, P.; Rigau, V.; Fabbro, M.; Chinot, O.; Pallusseau, L.; Carnin, C.; Laine, K.; Schlama, A.; et al. Oncological patterns of care and outcome for 952 patients with newly diagnosed glioblastoma in 2004. Neuro. Oncol. 2010, 12, 725-735. [CrossRef]

318. Dropcho, E.J.; Soong, S.J. The prognostic impact of prior low grade histology in patients with anaplastic gliomas: A case-control study. Neurology 1996, 47, 684-690. [CrossRef]

319. Walsh, K.M.; Ohgaki, H.; Wrensch, M.R. Epidemiology. In Handbook of Clinical Neurology; Berger, M., Weller, M., Eds.; Elsevier: Amsterdam, The Netherlands, 2016; Volume 134, pp. 3-18, ISBN 9780128029978.

320. Bredel, M.; Zentner, J. Brain-tumour drug resistance: The bare essentials. Lancet Oncol. 2002, 3, $397-406$. [CrossRef]

321. Shen, D.W.; Goldenberg, S.; Pastan, I.; Gottesman, M.M. Decreased accumulation of $\left[{ }^{14}\right.$ C $]$ carboplatin in human cisplatin-resistant cells results from reduced energy-dependent uptake. J. Cell. Physiol. 2000, 183, 108-116. [CrossRef]

322. Korashy, H.M.; Abuohashish, H.M.; Maayah, Z.H. The role of aryl hydrocarbon receptor-regulated cytochrome P450 enzymes in glioma. Curr. Pharm. Des. 2013, 19, 7155-7166. [CrossRef]

323. Lowe, S.W.; Ruley, H.E.; Jacks, T.; Housman, D.E. p53-dependent apoptosis modulates the cytotoxicity of anticancer agents. Cell 1993, 74, 957-967. [CrossRef]

324. Liu, Y.Y.; Han, T.Y.; Giuliano, A.E.; Cabot, M.C. Ceramide glycosylation potentiates cellular multidrug resistance. FASEB J. 2001, 15, 719-730. [CrossRef]

325. Ramirez, Y.; Weatherbee, J.; Wheelhouse, R.; Ross, A. Glioblastoma Multiforme Therapy and Mechanisms of Resistance. Pharmaceuticals 2013, 6, 1475-1506. [CrossRef]

326. Kathawala, R.J.; Gupta, P.; Ashby, C.R.; Chen, Z.-S.; Ashby, C.R., Jr.; Chen, Z.-S. The modulation of ABC transporter-mediated multidrug resistance in cancer: A review of the past decade. Drug Resist. Updat. 2015, 18, 1-17. [CrossRef]

327. Machein, M.R.; Kullmer, J.; Fiebich, B.L.; Plate, K.H.; Warnke, P.C. Vascular endothelial growth factor expression, vascular volume, and, capillary permeability in human brain tumors. Neurosurgery 1999, 44, 732-740. [CrossRef]

328. Hardee, M.E.; Zagzag, D. Mechanisms of glioma-associated neovascularization. Am. J. Pathol. 2012, 181, 1126-1141. [CrossRef]

329. Dhermain, F.G.; Hau, P.; Lanfermann, H.; Jacobs, A.H.; van den Bent, M.J.; van den Bent, M.; Vogelbaum, M.; Wen, P.; Macdonald, D.; Chang, S.; et al. Advanced MRI and PET imaging for assessment of treatment response in patients with gliomas. Lancet. Neurol. 2010, 9, 906-920. [CrossRef]

330. Sarkaria, J.N.; Hu, L.S.; Parney, I.F.; Pafundi, D.H.; Brinkmann, D.H.; Laack, N.N.; Giannini, C.; Burns, T.C.; Kizilbash, S.H.; Laramy, J.K.; et al. Is the blood-brain barrier really disrupted in all glioblastomas? A critical assessment of existing clinical data. Neuro. Oncol. 2018, 20, 184-191. [CrossRef]

331. Agarwal, S.; Manchanda, P.; Vogelbaum, M.A.; Ohlfest, J.R.; Elmquist, W.F. Function of the Blood-Brain Barrier and Restriction of Drug Delivery to Invasive Glioma Cells: Findings in an Orthotopic Rat Xenograft Model of Glioma. Drug Metab. Dispos. 2013, 41, 33-39. [CrossRef]

332. Parrish, K.E.; Cen, L.; Murray, J.; Calligaris, D.; Kizilbash, S.; Mittapalli, R.K.; Carlson, B.L.; Schroeder, M.A.; Sludden, J.; Boddy, A.V.; et al. Efficacy of PARP Inhibitor Rucaparib in Orthotopic Glioblastoma Xenografts Is Limited by Ineffective Drug Penetration into the Central Nervous System. Mol. Cancer Ther. 2015, 14, 2735-2743. [CrossRef]

333. Parrish, K.E.; Pokorny, J.; Mittapalli, R.K.; Bakken, K.; Sarkaria, J.N.; Elmquist, W.F. Efflux Transporters at the Blood-Brain Barrier Limit Delivery and Efficacy of Cyclin-Dependent Kinase 4/6 Inhibitor Palbociclib (PD-0332991) in an Orthotopic Brain Tumor Model. J. Pharmacol. Exp. Ther. 2015, 355, 264-271. [CrossRef] 
334. Mittapalli, R.K.; Chung, A.H.; Parrish, K.E.; Crabtree, D.; Halvorson, K.G.; Hu, G.; Elmquist, W.F.; Becher, O.J. ABCG2 and ABCB1 Limit the Efficacy of Dasatinib in a PDGF-B-Driven Brainstem Glioma Model. Mol. Cancer Ther. 2016, 15, 819-829. [CrossRef]

335. Randall, E.C.; Emdal, K.B.; Laramy, J.K.; Kim, M.; Roos, A.; Calligaris, D.; Regan, M.S.; Gupta, S.K.; Mladek, A.C.; Carlson, B.L.; et al. Integrated mapping of pharmacokinetics and pharmacodynamics in a patient-derived xenograft model of glioblastoma. Nat. Commun. 2018, 9, 4904. [CrossRef]

336. Declèves, X.; Bihorel, S.; Debray, M.; Yousif, S.; Camenisch, G.; Scherrmann, J.M. ABC transporters and the accumulation of imatinib and its active metabolite CGP74588 in rat C6 glioma cells. Pharmacol. Res. 2008, 57, 214-222. [CrossRef]

337. Declèves, X.; Fajac, A.; Lehmann-Che, J.; Tardy, M.; Mercier, C.; Hurbain, I.; Laplanche, J.-L.; Bernaudin, J.-F.; Scherrmann, J.-M. Molecular and functional MDR1-Pgp and MRPs expression in human glioblastoma multiforme cell lines. Int. J. Cancer 2002, 98, 173-180. [CrossRef]

338. Breedveld, P. The Effect of Bcrp1 (Abcg2) on the In vivo Pharmacokinetics and Brain Penetration of Imatinib Mesylate (Gleevec): Implications for the Use of Breast Cancer Resistance Protein and P-Glycoprotein Inhibitors to Enable the Brain Penetration of Imatinib in Pat. Cancer Res. 2005, 65, 2577-2582. [CrossRef]

339. Oberoi, R.K.; Mittapalli, R.K.; Elmquist, W.F. Pharmacokinetic Assessment of Efflux Transport in Sunitinib Distribution to the Brain. J. Pharmacol. Exp. Ther. 2013, 347, 755-764. [CrossRef]

340. Balaji, S.A.; Udupa, N.; Chamallamudi, M.R.; Gupta, V.; Rangarajan, A. Role of the drug transporter ABCC3 in breast cancer chemoresistance. PLoS ONE 2016, 11, 1-22. [CrossRef]

341. Calcagno, A.M.; Fostel, J.M.; To, K.K.W.; Salcido, C.D.; Martin, S.E.; Chewning, K.J.; Wu, C.-P.; Varticovski, L.; Bates, S.E.; Caplen, N.J.; et al. Single-step doxorubicin-selected cancer cells overexpress the ABCG2 drug transporter through epigenetic changes. Br. J. Cancer 2008, 98, 1515-1524. [CrossRef]

342. Loging, W.T.; Lal, A.; Siu, I.M.; Loney, T.L.; Wikstrand, C.J.; Marra, M.A.; Prange, C.; Bigner, D.D.; Strausberg, R.L.; Riggins, G.J. Identifying potential tumor markers and antigens by database mining and rapid expression screening. Genome Res. 2000, 10, 1393-1402. [CrossRef]

343. Haga, S.; Hinoshita, E.; Ikezaki, K.; Fukui, M.; Scheffer, G.L.; Uchiumi, T.; Kuwano, M. Involvement of the multidrug resistance protein 3 in drug sensitivity and its expression in human glioma. Jpn. J. Cancer Res. 2001, 92, 211-219. [CrossRef]

344. Kuan, C.-T.; Wakiya, K.; Herndon, J.E.; Lipp, E.S.; Pegram, C.N.; Riggins, G.J.; Rasheed, A.; Szafranski, S.E.; McLendon, R.E.; Wikstrand, C.J.; et al. MRP3: A molecular target for human glioblastoma multiforme immunotherapy. BMC Cancer 2010, 10, 468. [CrossRef]

345. Wang, F. Identification of CD44 and ABCC3 as chemotherapy resistant markers for Glioblastoma. Neuro. Oncol. 2016, 18, 54-55. [CrossRef]

346. Demeule, M.; Shedid, D.; Beaulieu, E.; Del Maestro, R.F.; Moghrabi, A.; Ghosn, P.B.; Moumdjian, R.; Berthelet, F.; Béliveau, R. Expression of multidrug-resistance P-glycoprotein (MDR1) in human brain tumors. Int. J. cancer 2001, 93, 62-66. [CrossRef]

347. Benyahia, B.; Huguet, S.; Declèves, X.; Mokhtari, K.; Crinière, E.; Bernaudin, J.F.; Scherrmann, J.M.; Delattre, J.Y. Multidrug resistance-associated protein MRP1 expression in human gliomas: Chemosensitization to vincristine and etoposide by indomethacin in human glioma cell lines overexpressing MRP1. J. Neurooncol. 2004, 66, 65-70. [CrossRef]

348. Kirches, E.; Oda, Y.; Von Bossanyi, P.; Diete, S.; Schneider, T.; Warich-Kirches, M.; Dietzmann, K. Mdr1 mRNA expression differs between grade III astrocytomas and glioblastomas. Clin. Neuropathol. 1997, 16, $34-36$.

349. Liebner, S.; Fischmann, A.; Rascher, G.; Duffner, F.; Grote, E.-H.; Kalbacher, H.; Wolburg, H. Claudin-1 and claudin-5 expression and tight junction morphology are altered in blood vessels of human glioblastoma multiforme. Acta Neuropathol. 2000, 100, 323-331. [CrossRef]

350. Anfuso, C.D.; Motta, C.; Giurdanella, G.; Arena, V.; Alberghina, M.; Lupo, G. Endothelial PKC $\alpha$-MAPK/ERK-phospholipase A2 pathway activation as a response of glioma in a triple culture model. A new role for pericytes? Biochimie 2014, 99, 77-87. [CrossRef]

351. Walter, F.R.; Veszelka, S.; Pásztói, M.; Péterfi, Z.A.; Tóth, A.; Rákhely, G.; Cervenak, L.; Ábrahám, C.S.; Deli, M.A. Tesmilifene modifies brain endothelial functions and opens the blood-brain/blood-glioma barrier. J. Neurochem. 2015, 134, 1040-1054. [CrossRef]

352. Raub, T.J.; Kuentzel, S.L.; Sawada, G.A. Permeability of bovine brain microvessel endothelial cells in vitro: Barrier tightening by a factor released from astroglioma cells. Exp. Cell Res. 1992, 199, 330-340. [CrossRef] 
353. DeBault, L.E.; Cancilla, P.A. $\gamma$-glutamyl transpeptidase in isolated brain endothelial cells: Induction by glial cells in vitro. Science 1980, 207, 653-655. [CrossRef]

354. Terrell-Hall, T.B.; Ammer, A.G.; Griffith, J.I.G.; Lockman, P.R. Permeability across a novel microfluidic blood-tumor barrier model. Fluids Barriers CNS 2017, 14, 1-10. [CrossRef]

355. Chen, L.; Zhang, Y.; Yang, J.; Hagan, J.P.; Li, M. Vertebrate animal models of glioma: Understanding the mechanisms and developing new therapies. Biochim. Biophys. Acta-Rev. Cancer 2013, 1836, 158-165. [CrossRef]

356. Becher, O.J.; Holland, E.C. Genetically engineered models have advantages over xenografts for preclinical studies. Cancer Res. 2006, 66, 3355-3358. [CrossRef]

357. Reilly, K.M.; Loisel, D.A.; Bronson, R.T.; McLaughlin, M.E.; Jacks, T. Nf1;Trp53 mutant mice develop glioblastoma with evidence of strain-specific effects. Nat. Genet. 2000, 26, 109-113. [CrossRef]

358. Hu, X.; Pandolfi, P.P.; Li, Y.; Koutcher, J.A.; Rosenblum, M.; Holland, E.C. mTOR Promotes Survival and Astrocytic Characteristics Induced by Pten/Akt Signaling in Glioblastoma. Neoplasia 2005, 7, 356-368. [CrossRef]

359. Dai, C.; Celestino, J.C.; Okada, Y.; Louis, D.N.; Fuller, G.N.; Holland, E.C. PDGF autocrine stimulation dedifferentiates cultured astrocytes and induces oligodendrogliomas and oligoastrocytomas from neural progenitors and astrocytes in vivo. Genes Dev. 2001, 15, 1913-1925. [CrossRef]

360. Xiao, A.; Wu, H.; Pandolfi, P.P.; Louis, D.N.; Van Dyke, T. Astrocyte inactivation of the pRb pathway predisposes mice to malignant astrocytoma development that is accelerated by PTEN mutation. Cancer Cell 2002, 1, 157-168. [CrossRef]

361. Chen, P.-Y.; Ozawa, T.; Drummond, D.C.; Kalra, A.; Fitzgerald, J.B.; Kirpotin, D.B.; Wei, K.-C.; Butowski, N.; Prados, M.D.; Berger, M.S.; et al. Comparing routes of delivery for nanoliposomal irinotecan shows superior anti-tumor activity of local administration in treating intracranial glioblastoma xenografts. Neuro. Oncol. 2013, 15, 189-197. [CrossRef]

362. Yamashita, Y.; Krauze, M.T.; Kawaguchi, T.; Noble, C.O.; Drummond, D.C.; Park, J.W.; Bankiewicz, K.S. Convection-enhanced delivery of a topoisomerase I inhibitor (nanoliposomal topotecan) and a topoisomerase II inhibitor (pegylated liposomal doxorubicin) in intracranial brain tumor xenografts1. Neuro. Oncol. 2007, 9, 20-28. [CrossRef]

363. Takamiya, Y.; Abe, Y.; Tanaka, Y.; Tsugu, A.; Kazuno, M.; Oshika, Y.; Maruo, K.; Ohnishi, Y.; Sato, O.; Yamazaki, H.; et al. Murine P-glycoprotein on stromal vessels mediates multidrug resistance in intracerebral human glioma xenografts. Br. J. Cancer 1997, 76, 445-450. [CrossRef]

364. Schlageter, K.E.; Molnar, P.; Lapin, G.D.; Groothuis, D.R. Microvessel Organization and Structure in Experimental Brain Tumors: Microvessel Populations with Distinctive Structural and Functional Properties. Microvasc. Res. 1999, 58, 312-328. [CrossRef]

365. Tanaka, Y.; Abe, Y.; Tsugu, A.; Takamiya, Y.; Akatsuka, A.; Tsuruo, T.; Yamazaki, H.; Ueyama, Y.; Sato, O.; Tamaoki, N. Ultrastructural localization of P-glycoprotein on capillary endothelial cells in human gliomas. Virchows Arch. 1994, 425, 133-138. [CrossRef]

366. Pardridge, W.M. CSF, blood-brain barrier, and brain drug delivery. Expert Opin. Drug Deliv. 2016, 13, 963-975. [CrossRef]

367. Parrish, K.; Sarkaria, J.; Elmquist, W. Improving drug delivery to primary and metastatic brain tumors: Strategies to overcome the blood-brain barrier. Clin. Pharmacol. Ther. 2015, 97, 336-346. [CrossRef]

368. Bush, N.A.O.; Chang, S.M.; Berger, M.S. Current and future strategies for treatment of glioma. Neurosurg. Rev. 2017, 40, 1-14. [CrossRef]

369. Oberoi, R.K.; Parrish, K.E.; Sio, T.T.; Mittapalli, R.K.; Elmquist, W.F.; Sarkaria, J.N. Strategies to improve delivery of anticancer drugs across the blood-brain barrier to treat glioblastoma. Neuro. Oncol. 2016, 18, 27-36. [CrossRef]

370. Pennock, G.D.; Dalton, W.S.; Roeske, W.R.; Appleton, C.P.; Mosley, K.; Plezia, P.; Miller, T.P.; Salmon, S.E. Systemic Toxic Effects Associated With High-Dose Verapamil Infusion and Chemotherapy Administration. JNCI J. Natl. Cancer Inst. 1991, 83, 105-110. [CrossRef]

371. Ferry, D.R.; Traunecker, H.; Kerr, D.J. Clinical trials of p-glycoprotein reversal in solid tumours. Eur. J. Cancer 1996, 32, 1070-1081. [CrossRef]

372. de Bruin, M.; Miyake, K.; Litman, T.; Robey, R.; Bates, S.E. Reversal of resistance by GF120918 in cell lines expressing the ABC half-transporter, MXR. Cancer Lett. 1999, 146, 117-126. [CrossRef] 
373. Tsvankin, V.; Hashizume, R.; Katagi, H.; Herndon, J.E.; Lascola, C.; Venkatraman, T.N.; Picard, D.; Burrus, B.; Becher, O.J.; Thompson, E.M. ABC Transporter Inhibition Plus Dexamethasone Enhances the Efficacy of Convection Enhanced Delivery in H3.3K27M Mutant Diffuse Intrinsic Pontine Glioma. Neurosurgery 2019, 92, nyz212. [CrossRef]

374. Da Silva, C.G.; Peters, G.J.; Ossendorp, F.; Cruz, L.J. The potential of multi-compound nanoparticles to bypass drug resistance in cancer. Cancer Chemother. Pharmacol. 2017, 80, 881-894. [CrossRef]

375. Choo, E.F.; Kurnik, D.; Muszkat, M.; Ohkubo, T.; Shay, S.D.; Higginbotham, J.N.; Glaeser, H.; Kim, R.B.; Wood, A.J.J.; Wilkinson, G.R. Differential in vivo sensitivity to inhibition of P-glycoprotein located in lymphocytes, testes, and the blood-brain barrier. J. Pharmacol. Exp. Ther. 2006, 317, 1012-1018. [CrossRef] [PubMed]

376. Rabindran, S.K.; Ross, D.D.; Doyle, L.A.; Yang, W.; Greenberger, L.M. Fumitremorgin C reverses multidrug resistance in cells transfected with the breast cancer resistance protein. Cancer Res. 2000, 60, 47-50. [PubMed]

377. Allen, J.D.; van Loevezijn, A.; Lakhai, J.M.; van der Valk, M.; van Tellingen, O.; Reid, G.; Schellens, J.H.M.; Koomen, G.-J.; Schinkel, A.H. Potent and specific inhibition of the breast cancer resistance protein multidrug transporter in vitro and in mouse intestine by a novel analogue of fumitremorgin C. Mol. Cancer Ther. 2002, 1, 417-425.

378. Shukla, S.; Sauna, Z.E.; Ambudkar, S. V Evidence for the interaction of imatinib at the transport-substrate site(s) of the multidrug-resistance-linked ABC drug transporters ABCB1 (P-glycoprotein) and ABCG2. Leukemia 2008, 22, 445-447. [CrossRef] [PubMed]

379. Weiss, J. Short Communication Nucleoside, Nucleotide, and Non-Nucleoside Reverse ABSTRACT. Drug Metab. Dispos. 2007, 35, 340-344. [CrossRef]

380. Giacomini, K.M.; Huang, S.-M.; Tweedie, D.J.; Benet, L.Z.; Brouwer, K.L.R.; Chu, X.; Dahlin, A.; Evers, R.; Fischer, V.; Hillgren, K.M.; et al. Membrane transporters in drug development. Nat. Rev. Drug Discov. 2010, 9, 215-236.

381. Li, K.; Lai, H. TanshinoneIIA enhances the chemosensitivity of breast cancer cells to doxorubicin through down-regulating the expression of MDR-related ABC transporters. Biomed. Pharmacother. 2017, 96, 371-377. [CrossRef]

382. Zhang, X.; Liu, X.; Zhou, W.; Yang, M.; Ding, Y.; Wang, Q.; Hu, R. Fasudil increases temozolomide sensitivity and suppresses temozolomide-resistant glioma growth via inhibiting ROCK2/ABCG2. Cell Death Dis. 2018, 9, 190. [CrossRef]

383. Chowdhury, E.H. Strategies for tumor-directed delivery of siRNA. Expert Opin. Drug Deliv. 2011, 8, 389-401. [CrossRef]

384. Wu, H.; Hait, W.N.; Yang, J.-M. Small interfering RNA-induced suppression of MDR1 (P-glycoprotein) restores sensitivity to multidrug-resistant cancer cells. Cancer Res. 2003, 63, 1515-1519.

385. Ee, P.L.R.; He, X.; Ross, D.D.; Beck, W.T. Modulation of breast cancer resistance protein (BCRP/ABCG2) gene expression using RNA interference. Mol. Cancer Ther. 2004, 3, 1577-1583.

386. Li, Y.T.; Chua, M.J.; Kunnath, A.P.; Chowdhury, E.H. Reversing multidrug resistance in breast cancer cells by silencing $\mathrm{ABC}$ transporter genes with nanoparticle-facilitated delivery of target siRNAs. Int. J. Nanomed. 2012, 7, 2473-2481. [CrossRef]

387. Michalak, K.; Wesolowska, O. Polyphenols Counteract Tumor Cell Chemoresistance Conferred by Multidrug Resistance Proteins. Anticancer. Agents Med. Chem. 2012, 12, 880-890. [CrossRef]

388. Huang, X.-C.; Xiao, X.; Zhang, Y.-K.; Talele, T.; Salim, A.; Chen, Z.-S.; Capon, R. Lamellarin O, a Pyrrole Alkaloid from an Australian Marine Sponge, Ianthella sp., Reverses BCRP Mediated Drug Resistance in Cancer Cells. Mar. Drugs 2014, 12, 3818-3837. [CrossRef] [PubMed]

389. Lopez, D.; Martinez-Luis, S. Marine Natural Products with P-Glycoprotein Inhibitor Properties. Mar. Drugs 2014, 12, 525-546. [CrossRef]

390. Pan, M.; Cui, J.; Jiao, L.; Ghaleb, H.; Liao, C.; Zhou, J.; Kairuki, M.; Lin, H.; Huang, W.; Qian, H. Synthesis and biological evaluation of JL-A7 derivatives as potent ABCB1 inhibitors. Bioorganic Med. Chem. 2017. [CrossRef]

391. Gampa, G.; Vaidhyanathan, S.; Sarkaria, J.N.; Elmquist, W.F. Drug delivery to melanoma brain metastases: Can current challenges lead to new opportunities? Pharmacol. Res. 2017, 123, 10-25. [CrossRef] [PubMed] 
392. Salphati, L.; Heffron, T.P.; Alicke, B.; Nishimura, M.; Barck, K.; Carano, R.A.; Cheong, J.; Edgar, K.A.; Greve, J.; Kharbanda, S.; et al. Targeting the PI3K Pathway in the Brain-Efficacy of a PI3K Inhibitor Optimized to Cross the Blood-Brain Barrier. Clin. Cancer Res. 2012, 18, 6239-6248. [CrossRef] [PubMed]

393. Salphati, L.; Alicke, B.; Heffron, T.P.; Shahidi-Latham, S.; Nishimura, M.; Cao, T.; Carano, R.A.; Cheong, J.; Greve, J.; Koeppen, H.; et al. Brain distribution and efficacy of the brain penetrant PI3K inhibitor GDC-0084 in orthotopic mouse models of human glioblastoma. Drug Metab. Dispos. 2016, 44, 1881-1889. [CrossRef]

394. Salphati, L.; Shahidi-Latham, S.; Quiason, C.; Barck, K.; Nishimura, M.; Alicke, B.; Pang, J.; Carano, R.A.; Olivero, A.G.; Phillips, H.S. Distribution of the phosphatidylinositol 3-kinase inhibitors pictilisib (GDC-0941) and GNE-317 in U87 and GS2 intracranial glioblastoma models - Assessment by matrix-assisted laser desorption ionization imaging. Drug Metab. Dispos. 2014, 42, 1110-1116. [CrossRef] [PubMed]

395. Becker, C.M.; Oberoi, R.K.; McFarren, S.J.; Muldoon, D.M.; Pafundi, D.H.; Pokorny, J.L.; Brinkmann, D.H.; Ohlfest, J.R.; Sarkaria, J.N.; Largaespada, D.A.; et al. Decreased affinity for efflux transporters increases brain penetrance and molecular targeting of a PI3K/mTOR inhibitor in a mouse model of glioblastoma. Neuro. Oncol. 2015, 17, 1210-1219. [CrossRef] [PubMed]

396. NIHClinicalTrials.gov. Safety, Pharmacokinetics and Efficacy of GDC-0084 in Newly-Diagnosed Glioblastoma Multiforme. Available online: https://clinicaltrials.gov/ct2/show/NCT03522298 (accessed on 12 November 2019).

397. Wait, S.D.; Prabhu, R.S.; Burri, S.H.; Atkins, T.G.; Asher, A.L. Polymeric drug delivery for the treatment of glioblastoma. Neuro. Oncol. 2015, 17, ii9-ii23. [CrossRef] [PubMed]

398. Westphal, M.; Hilt, D.C.; Bortey, E.; Delavault, P.; Olivares, R.; Warnke, P.C.; Whittle, I.R.; Jääskeläinen, J.; Ram, Z. A phase 3 trial of local chemotherapy with biodegradable carmustine (BCNU) wafers (Gliadel wafers) in patients with primary malignant glioma. Neuro. Oncol. 2003, 5, 79-88. [CrossRef] [PubMed]

399. Brem, H.; Piantadosi, S.; Burger, P.; Walker, M.; Selker, R.; Vick, N.; Black, K.; Sisti, M.; Brem, S.; Mohr, G.; et al. Placebo-controlled trial of safety and efficacy of intraoperative controlled delivery by biodegradable polymers of chemotherapy for recurrent gliomas. Lancet 1995, 345, 1008-1012. [CrossRef]

400. Valtonen, S.; la Timonen, U.; Toivanen, P.; Kalimo, H.; Kivipelto, L.; Heiskanen, O.; Unsgaard, G.; Kuurne, T. Interstitial Chemotherapy with Carmustine-loaded Polymers for High-grade Gliomas: A Randomized Double-blind Study. Neurosurgery 1997, 41, 44-49. [CrossRef]

401. Bregy, A.; Shah, A.H.; Diaz, M.V.; Pierce, H.E.; Ames, P.L.; Diaz, D.; Komotar, R.J. The role of Gliadel wafers in the treatment of high-grade gliomas. Expert Rev. Anticancer Ther. 2013, 13, 1453-1461. [CrossRef]

402. Morrison, P.F.; Laske, D.W.; Bobo, H.; Oldfield, E.H.; Dedrick, R.L. High-flow microinfusion: Tissue penetration and pharmacodynamics. Am. J. Physiol. Integr. Comp. Physiol. 1994, 266, R292-R305. [CrossRef]

403. Bobo, R.H.; Laske, D.W.; Akbasak, A.; Morrison, P.F.; Dedrick, R.L.; Oldfield, E.H. Convection-enhanced delivery of macromolecules in the brain. Proc. Natl. Acad. Sci. USA 1994, 91, 2076-2080. [CrossRef]

404. Lonser, R.R.; Sarntinoranont, M.; Morrison, P.F.; Oldfield, E.H. Convection-enhanced delivery to the central nervous system. J. Neurosurg. 2015, 122, 697-706. [CrossRef]

405. Shi, M.; Sanche, L. Convection-Enhanced Delivery in Malignant Gliomas: A Review of Toxicity and Efficacy. J. Oncol. 2019, 2019, 1-13. [CrossRef]

406. Sampson, J.H.; Archer, G.; Pedain, C.; Wembacher-Schröder, E.; Westphal, M.; Kunwar, S.; Vogelbaum, M.A.; Coan, A.; Herndon, J.E.; Raghavan, R.; et al. Poor drug distribution as a possible explanation for the results of the PRECISE trial. J. Neurosurg. 2010, 113, 301-309. [CrossRef] [PubMed]

407. Asthagiri, A.R.; Walbridge, S.; Heiss, J.D.; Lonser, R.R. Effect of concentration on the accuracy of convective imaging distribution of a gadolinium-based surrogate tracer. J. Neurosurg. 2011, 115, 467-473. [CrossRef] [PubMed]

408. Chittiboina, P.; Heiss, J.D.; Warren, K.E.; Lonser, R.R. Magnetic resonance imaging properties of convective delivery in diffuse intrinsic pontine gliomas. J. Neurosurg. Pediatr. 2014, 13, 276-282. [CrossRef] [PubMed]

409. Kunwar, S.; Chang, S.; Westphal, M.; Vogelbaum, M.; Sampson, J.; Barnett, G.; Shaffrey, M.; Ram, Z.; Piepmeier, J.; Prados, M.; et al. Phase III randomized trial of CED of IL13-PE38QQR vs Gliadel wafers for recurrent glioblastoma. Neuro. Oncol. 2010, 12, 871-881. [CrossRef] [PubMed]

410. Wang, W.; Sivakumar, W.; Torres, S.; Jhaveri, N.; Vaikari, V.P.; Gong, A.; Howard, A.; Golden, E.B.; Louie, S.G.; Schönthal, A.H.; et al. Effects of convection-enhanced delivery of bevacizumab on survival of glioma-bearing animals. Neurosurg. Focus 2015, 38, E8. [CrossRef] [PubMed] 
411. D'Amico, R.S.; Neira, J.A.; Yun, J.; Alexiades, N.G.; Banu, M.; Englander, Z.K.; Kennedy, B.C.; Ung, T.H.; Rothrock, R.J.; Romanov, A.; et al. Validation of an effective implantable pump-infusion system for chronic convection-enhanced delivery of intracerebral topotecan in a large animal model. J. Neurosurg. 2019, 2, 1-10. [CrossRef]

412. Neuwelt, E.A.; Maravilla, K.R.; Frenkel, E.P.; Rapaport, S.I.; Hill, S.A.; Barnett, P.A. Osmotic blood-brain barrier disruption. Computerized tomographic monitoring of chemotherapeutic agent delivery. J. Clin. Invest. 1979, 64, 684-688. [CrossRef]

413. Angelov, L.; Doolittle, N.D.; Kraemer, D.F.; Siegal, T.; Barnett, G.H.; Peereboom, D.M.; Stevens, G.; McGregor, J.; Jahnke, K.; Lacy, C.A.; et al. Blood-Brain Barrier Disruption and Intra-Arterial Methotrexate-Based Therapy for Newly Diagnosed Primary CNS Lymphoma: A Multi-Institutional Experience. J. Clin. Oncol. 2009, 27, 3503-3509. [CrossRef]

414. Chakraborty, S.; Filippi, C.G.; Wong, T.; Ray, A.; Fralin, S.; Tsiouris, A.J.; Praminick, B.; Demopoulos, A.; McCrea, H.J.; Bodhinayake, I.; et al. Superselective intraarterial cerebral infusion of cetuximab after osmotic blood/brain barrier disruption for recurrent malignant glioma: Phase I study. J. Neurooncol. 2016, 128, 405-415. [CrossRef]

415. Burkhardt, J.-K.; Riina, H.; Shin, B.J.; Christos, P.; Kesavabhotla, K.; Hofstetter, C.P.; Tsiouris, A.J.; Boockvar, J.A. Intra-Arterial Delivery of Bevacizumab after Blood-Brain Barrier Disruption for the Treatment of Recurrent Glioblastoma: Progression-Free Survival and Overall Survival. World Neurosurg. 2012, 77, 130-134. [CrossRef]

416. NIH ClinicalTrials.gov. Super-Selective Intraarterial Cerebral Infusion of Cetuximab (Erbitux) for Treatment of Relapsed/Refractory GBM and AA. Available online: https://linicaltrials.gov/ct2/show/NCT01238237 (accessed on 12 November 2019).

417. Rodriguez, A.; Tatter, S.; Debinski, W. Neurosurgical Techniques for Disruption of the Blood-Brain Barrier for Glioblastoma Treatment. Pharmaceutics 2015, 7, 175-187. [CrossRef] [PubMed]

418. Hynynen, K.; McDannold, N.; Vykhodtseva, N.; Raymond, S.; Weissleder, R.; Jolesz, F.A.; Sheikov, N. Focal disruption of the blood-brain barrier due to $260-\mathrm{kHz}$ ultrasound bursts: A method for molecular imaging and targeted drug delivery. J. Neurosurg. 2006, 105, 445-454. [CrossRef] [PubMed]

419. Etame, A.B.; Diaz, R.J.; Smith, C.A.; Mainprize, T.G.; Hynynen, K.; Rutka, J.T. Focused ultrasound disruption of the blood-brain barrier: A new frontier for therapeutic delivery in molecular neurooncology. Neurosurg. Focus 2012, 32, E3. [CrossRef] [PubMed]

420. Fan, C.-H.; Liu, H.-L.; Huang, C.-Y.; Ma, Y.-J.; Yen, T.-C.; Yeh, C.-K. Detection of Intracerebral Hemorrhage and Transient Blood-Supply Shortage in Focused-Ultrasound-Induced Blood-Brain Barrier Disruption by Ultrasound Imaging. Ultrasound Med. Biol. 2012, 38, 1372-1382. [CrossRef] [PubMed]

421. Ting, C.-Y.; Fan, C.-H.; Liu, H.-L.; Huang, C.-Y.; Hsieh, H.-Y.; Yen, T.-C.; Wei, K.-C.; Yeh, C.-K. Concurrent blood-brain barrier opening and local drug delivery using drug-carrying microbubbles and focused ultrasound for brain glioma treatment. Biomaterials 2012, 33, 704-712. [CrossRef] [PubMed]

422. Wu, S.-K.; Santos, M.A.; Marcus, S.L.; Hynynen, K. MR-guided Focused Ultrasound Facilitates Sonodynamic Therapy with 5-Aminolevulinic Acid in a Rat Glioma Model. Sci. Rep. 2019, 9, 10465. [CrossRef]

423. Horodyckid, C.; Canney, M.; Vignot, A.; Boisgard, R.; Drier, A.; Huberfeld, G.; François, C.; Prigent, A.; Santin, M.D.; Adam, C.; et al. Safe long-term repeated disruption of the blood-brain barrier using an implantable ultrasound device: A multiparametric study in a primate model. J. Neurosurg. 2017, 126, 1351-1361. [CrossRef]

424. Beccaria, K.; Canney, M.; Goldwirt, L.; Fernandez, C.; Piquet, J.; Perier, M.; Lafon, C.; Chapelon, J.; Carpentier, A. Ultrasound-induced opening of the blood-brain barrier to enhance temozolomide and irinotecan delivery: An experimental study in rabbits. J. Neurosurg. 2016, 124, 1602-1610. [CrossRef]

425. NIH ClinicalTrials.gov. Safety of BBB Opening With the SonoCloud (SONOCLOUD). Available online: https://clinicaltrials.gov/ct2/show/NCT02253212 (accessed on 12 November 2019).

426. Idbaih, A.; Canney, M.; Belin, L.; Desseaux, C.; Vignot, A.; Bouchoux, G.; Asquier, N.; Law-Ye, B.; Leclercq, D.; Bissery, A.; et al. Safety and Feasibility of Repeated and Transient Blood-Brain Barrier Disruption by Pulsed Ultrasound in Patients with Recurrent Glioblastoma. Clin. Cancer Res. 2019, 25, 3793-3801. [CrossRef]

427. Teleanu, D.M.; Chircov, C.; Grumezescu, A.M.; Teleanu, R.I. Neuronanomedicine: An up-to-date overview. Pharmaceutics 2019, 11, 101. [CrossRef] 
428. Jiang, Y.; Lv, L.; Shi, H.; Hua, Y.; Lv, W.; Wang, X.; Xin, H.; Xu, Q. PEGylated Polyamidoamine dendrimer conjugated with tumor homing peptide as a potential targeted delivery system for glioma. Colloids Surfaces $B$ Biointerfaces 2016, 147, 242-249. [CrossRef] [PubMed]

429. Patel, H.K.; Gajbhiye, V.; Kesharwani, P.; Jain, N.K. Ligand anchored poly(propyleneimine) dendrimers for brain targeting: Comparative in vitro and in vivo assessment. J. Colloid Interface Sci. 2016, 482, 142-150. [CrossRef] [PubMed]

430. Anders, C.K.; Adamo, B.; Karginova, O.; Deal, A.M.; Rawal, S.; Darr, D.; Schorzman, A.; Santos, C.; Bash, R.; Kafri, T.; et al. Pharmacokinetics and Efficacy of PEGylated Liposomal Doxorubicin in an Intracranial Model of Breast Cancer. PLoS ONE 2013, 8, e61359. [CrossRef] [PubMed]

431. Brandsma, D.; Kerklaan, B.M.; Diéras, V.; Altintas, S.; Anders, C.K.; Ballester, M.A.; Gelderblom, H.; Soetekouw, P.M.M.B.; Gladdines, W.; Lonnqvist, F.; et al. 472 Phase 1/2 a Study of Glutathione Pegylated Liposomal Doxorubicin (2B3-101) in Patients with Brain Metastases (BM) from Solid Tumors or Recurrent High Grade Gliomas (HGG). Ann. Oncol. 2014, 25, iv157-iv158. [CrossRef]

432. Tian, C.; Asghar, S.; Xu, Y.; Chen, Z.; Zhang, J.; Ping, Q.; Xiao, Y. Tween 80-modified hyaluronic acid-ss-curcumin micelles for targeting glioma: Synthesis, characterization and their in vitro evaluation. Int. J. Biol. Macromol. 2018, 120, 2579-2588. [CrossRef]

433. Kafa, H.; Wang, J.T.-W.; Rubio, N.; Klippstein, R.; Costa, P.M.; Hassan, H.A.F.M.; Sosabowski, J.K.; Bansal, S.S.; Preston, J.E.; Abbott, N.J.; et al. Translocation of LRP1 targeted carbon nanotubes of different diameters across the blood-brain barrier in vitro and in vivo. J. Control. Release 2016, 225, 217-229. [CrossRef]

434. Duan, J.; Mansour, H.M.; Zhang, Y.; Deng, X.; Chen, Y.; Wang, J.; Pan, Y.; Zhao, J. Reversion of multidrug resistance by co-encapsulation of doxorubicin and curcumin in chitosan/poly(butyl cyanoacrylate) nanoparticles. Int. J. Pharm. 2012, 426, 193-201. [CrossRef]

435. Pramanik, D.; Campbell, N.R.; Das, S.; Gupta, S.; Chenna, V.; Bisht, S.; Sysa-shah, P.; Bedja, D.; Karikari, C.; Steenbergen, C.; et al. A composite polymer nanoparticle overcomes multidrug resistance and ameliorates doxorubicin-associated cardiomyopathy. Oncotarget 2012, 3, 640-650. [CrossRef]

436. Liu, Y.; Li, L.-L.; Qi, G.-B.; Chen, X.-G.; Wang, H. Dynamic disordering of liposomal cocktails and the spatio-temporal favorable release of cargoes to circumvent drug resistance. Biomaterials 2014, 35, 3406-3415. [CrossRef]

(C) 2019 by the authors. Licensee MDPI, Basel, Switzerland. This article is an open access article distributed under the terms and conditions of the Creative Commons Attribution (CC BY) license (http://creativecommons.org/licenses/by/4.0/). 